\title{
The 2015 National Nursing Workforce Survey
}

\section{Executive Summary}

The National Council of State Boards of Nursing has partnered for the second time with The National Forum of State Nursing Workforce Centers to conduct the only national-level survey specifically focused on the U.S. nursing workforce.

The National Nursing Workforce Survey, first conducted in 2013, generates information on the supply of nurses in the United States, information that is critical to planning for well-prepared and well-educated nurses in sufficient numbers to meet the health care needs of the nation, ensuring a safe, diverse, accessible, and effective health care system.

In addition to providing a portrait of the current state of the nursing workforce, the data from this study facilitate the following: - Examination of national workforce trends. The current survey data can be compared with data from previous Nursing Workforce surveys, including the 2013 study mentioned above, and the Health Resources and Services Administration (HRSA) nursing surveys (conducted from 1990 to 2008). Also, trends can be ascertained by a look at this year's data only; for example, this year's data concerning age and year licensed provide an idea of how the workforce will change as nurses retire.

- State-level analysis. Each board of nursing and state nursing workforce center will be provided their state's data for further analyses that can help employers, educators, and others in developing policies and initiatives impacting the supply of nurses in their state.

- Further research. The national survey generates a broad data set from which important substudies or analyses can be conducted.

As of June 2015, the total number of active registered nurse (RN) licenses held was 4,378,273 and active licensed practical/ vocational nurse (LPN/VN) licenses held was 1,030,080. These numbers include approximately $12 \%$ who hold multiple licenses; these individuals were removed prior to sampling. Over 260,000 individual RNs and LPN/VNs were randomly selected from the study sample to participate in the survey (140,154 RNs and 120,793 LPN/VNs). Nurses throughout the United States with active licenses were asked to report on their age, gender, race, education, employment, and other characteristics.

Participants received an announcement postcard in late June of 2015 and received their first survey in early July. Participants could submit their responses via mail or online until the survey closed on September 15th. In total, 78,739 nurses (46,476 RNs and 32,263 LPN/VNs) responded to the survey. A formal nonresponse analysis was conducted and weighting was used in the analysis process to adjust the distribution across states, age, and gender.

\section{Selected Results From the Survey Size of the Nurse Workforce}

As of June 2015, an estimated 3,852,881 individuals held an active RN license (up from 3,530,174 in 2013) in the United States and its territories, representing an increase of 322,707 RN licensees from 2013; an estimated 906,471 individuals held an LPN/ VN license in the United States and its territories. Respondents had been licensed for an average of 20.9 years $(M, 19, S D 14.8)$; $81.1 \%$ of RNs and $77 \%$ of LPN/VNs were employed in nursing. Only $5.4 \%$ of RNs were initially licensed as an RN or LPN/ VN outside of the United States (2.6\% in the Philippines; $0.5 \%$ in Canada, and $2.0 \%$ in other countries). An examination of the type of license currently held by RNs revealed that $8.6 \%$ held an advanced practice registered nurse (APRN) license and, of those, $70.4 \%$ were licensed as a nurse practitioner.

\section{Education of RNs and LPN/VNs}

Evidence on the academic progression of RNs has been steadily accumulating over the past few years. When asked to indicate highest level of education, $65 \%$ of respondents in the current study indicated that they had obtained a baccalaureate or higher degree, up from $61 \%$ in 2013 . The current study also found an increase in the percentage of respondents with a BSN as their initial nursing education. Specifically, in 2013,36\% indicated a BSN as their initial nursing education, while in 2015, 39.0\% indicated this. Additionally, in the current study, almost $42 \%$ of RNs held either a BSN (39.0\%) or graduate degree (3.0\%) as their initial credential. Newly licensed RNs, those licensed from 2013 to 2015, were more likely to have obtained a BSN as their initial education (48.6\%) versus RNs licensed prior to 2000 (34.8\%). 
More than two-thirds of LPN/VNs indicated their highest level of education was a vocational/practical certificate in nursing; about $6 \%$ have gone on to obtain further education beyond this certificate. The vast majority (95.1\%) were educated in the United States. The $4.9 \%$ of LPN/VNs who were educated outside the United States tended to have achieved a higher level of education-17.6\% of foreign-educated LPN/VNs held BSN degrees, compared to $0.3 \%$ for U.S.-educated LPN/VNs.

\section{Employment Status}

The study revealed $81.1 \%$ of RN licensees were actively employed in nursing and of those, $62.9 \%$ worked full time. In $2013,85 \%$ of RNs were actively employed, with $60 \%$ employed full time. The current study shows that the percentage of those younger than age 30 who are working in nursing is consistent with 2013 data. However, in the 50-and-older age cohort, the current study shows a drop-off in percentage employed in nursing when compared to 2013 data. For instance, in 2013, 47\% of those age 65 and older were employed in nursing; in 2015, $40.1 \%$ were employed in nursing.

Hospitals remain the most common employment setting for RNs, at 54\% (down from 56\% in 2013 and down from HRSA's $62 \%$ in 2008). Therefore, although numbers of RNs are increasing, fewer are working in hospitals.

Overall, $77 \%$ of LPN/VNs were employed in nursing. However, data indicate that LPN/VNs older than age 60 were less likely to be employed in nursing, as compared to the younger-than-30 age cohort. The most common primary care setting of LPN/ VN respondents was nursing home/extended care (30\%), followed by home health (15\%) and hospitals (approximately 11\%).

The "work setting" for both RNs and LPN/VNs is changing, as patient care is no longer confined within the walls of the health care facility owing in part to the growing use and acceptance of technology (American Well, 2015; HIMSS Analytics, 2015). The current survey found that nearly half of RNs and LPN/VNs have provided nurse services using telehealth technologies. Of those, $39.4 \%$ of RNs provided these services across a state border and $7.7 \%$ across a national border; $17 \%$ of LPN/VNs did so across a state border, and $4 \%$ engaged in telehealth across a national border.

\section{Demographics}

Promoting diversity, including gender, race, and ethnic diversity, in the profession to better represent the patient population it serves has been a specific recommendation to the nursing profession for many years (IOM, 2010).

The current study indicates that male RNs (8.0\%) were better represented in the nursing workforce compared to 2013 results (7\%). While this percentage is lower than the $9.2 \%$ reported by HRSA (2015), our data indicate a substantially higher proportion of male nurses in the more recently licensed cohorts (12.7\%) as opposed to those licensed prior to 2000 (4.7\%). A substantially larger proportion of foreign-educated LPN/VNs were male (22.7\%) compared to U.S.-educated LPN/VNs (6.7\%).

The aging of the RN workforce has slowed. The average age of the RN respondents was 48.8 (down from age 50 in 2013); $50 \%$ of respondents were age 50 or older and $12.4 \%$ were age 65 or older. The average age of LPN/VNs was 47.8 .

The current study did not indicate an impending shortage of RNs as a result of large numbers of older nurses retiring. In fact, there was not a disproportionate number of older RNs; further, RNs in the older age cohorts were less likely to be employed in nursing full time. However, among APRNs, an increasing age was detected with certified nurse midwives and clinical nurse specialists, more so than with nurse practitioners and certified registered nurses anesthetists. However, data do suggest an aging nurse faculty. Approximately $50 \%$ of full-time faculty were age 50 and older.

In terms of racial and ethnic diversity, minority groups accounted for approximately $19.5 \%$ of the RN respondents in both the 2015 and 2013 surveys and for 32\% of LPN/VN respondents. HRSA's brief on gender and racial/ethnic diversity of U.S. health occupations for 2010-2012 found a rate of ethnic minorities of 21.4\% (HRSA, 2015). These estimates are below the almost $40 \%$ of ethnic minorities in the U.S. population (U.S. Census Bureau, 2015). When compared with White/Caucasian nurses, the current study's data indicate ethnic minorities are better represented in younger age-groups and in more recently licensed RNs than in older RNs and RNs licensed prior to 2000. Newly licensed LPN/VNs were more likely to have a more diverse racial/ethnic composition; specifically, of LPN/VNs licensed prior to 2000, $78.8 \%$ were White/Caucasian versus $55.6 \%$ of LPN/VNs licensed from 2013 to 2015, a fact suggesting that as older RNs retire, the RN workforce may become more racially/ethnically diverse.

The median salary for female RNs was $\$ 64,000$, while the median salary for male RNs was $\$ 72,000$. The current study found that salary does increase with higher levels of education. The median earnings for male LPN/VNs was $\$ 43,200$, while the median earnings for female LPN/VNs was $\$ 38,000$.

\section{Conclusion}

This National Nursing Workforce Survey represents just one point in time. Ongoing monitoring and evaluation will be very important as the nursing workforce continues to evolve. Overall, the nursing workforce is expected to change as older nurses retire and new nurses step in to fill their shoes; however, the data do not suggest an impending shortage of RNs or LPN/VNs due to large 
numbers of older nurses retiring. The nursing workforce today is younger, has a higher initial nursing education, and is more diverse, demonstrated by changes in the ratios of racial/ethnic minorities and the ratio of men to women - a trend that is likely to continue.

Data gleaned from the current survey suggest that advances in technology will contribute to higher percentages of nurses providing services across state borders using telehealth.

Changes in the health care environment are especially relevant for LPN/VNs, as the demand may be changing as the health care environment calls for higher levels of nursing education.

Without question, a new generation of nurses will play a large role in transforming how, where, and why nurses learn and practice. The nursing workforce will certainly undergo significant changes over the next 5 years due in no small part to the fact that the millennial generation (those born between 1980 and 1999) is the largest generation ever-numbering more than 90 million. If millennials enter the nursing profession at the same numbers as the current nursing population, they will likely replace the nurses retiring, resolving any shortage issues. With millennials being the most-educated group, our entry-to-practice debates may also be resolved by this generation. 


\section{Introduction}

Having an adequate supply of registered nurses (RNs) and licensed practical/vocational nurses (LPN/VNs) in the U.S. workforce is critical to ensuring a safe and effective health care system. Data on the supply of the nursing workforce can be used to predict possible shortages and assist in the allocation of resources, program development, and recruitment efforts in both the health care system and education sectors. A recent report on the future of nursing noted that the nursing workforce is constantly evolving, and supply and demand of RNs will be affected by many uncertain factors, including population growth, aging of the population, economic conditions, and changes in the health care environment (Health Resources and Services Administration [HRSA], 2014). This national survey of RNs and LPN/VNs represents one point in time and needs ongoing monitoring and evaluation.

For 3 decades, the HRSA reported on the supply of RNs through the National Sample Survey of Registered Nurses (NSSRN). The final NSSRN was completed in 2008 (HRSA, 2010). In 2013, the National Council of State Boards of Nursing (NCSBN) and the National Forum of State Nursing Workforce Centers, through a collaborative effort, stepped in to fill the void of national RN workforce supply data (Budden, Zhong, Moulton, \& Cimiotti, 2013). This study is an ongoing joint venture to collect current nursing workforce supply data. In addition to collecting $\mathrm{RN}$ workforce data, the current study collected data on the LPN/VN workforce for the first time. To help illustrate trends in workforce supply data, in some instances the current study's 2015 data were compared to 2013 data (Budden et al., 2013), 2008 data (HRSA, 2010), and 2008-2010 American Community Survey data (HRSA, 2013).

\section{Method}

\section{Sample}

All RNs and LPN/VNs in the United States and its territories were eligible candidates for survey participation. A portion of the sample was drawn from Nursys ${ }^{\circledR}$, NCSBN's licensure database. This database contains basic demographic and licensure information for RN and LPN/VN licensees, with the exception of Alabama, Hawaii, Louisiana (PN), and Oklahoma because, at the time of the study, these states did not participate in Nursys. Additionally, Kansas, Massachusetts, and Washington restricted addresses in Nursys, and Pennsylvania did not include addresses. These states were contacted to obtain licensee lists and addresses directly. Boards of nursing (BONs) that participate in Nursys were contacted and asked permission to use their licensee list in Nursys for this study. Medical Marketing Service list was used to obtain the sample for New York.

As of June 2015, the total number of active RN licenses held was 4,378,273 and active LPN/VN licenses held was 1,030,080. These numbers include an estimated $12 \%$ of individuals with multiple licenses. Individuals with multiple licenses were removed prior to sampling. Sampling was stratified random sampling and stratified by state. The sample included approximately 140,000 RNs and 121,000 LPN/VNs (see Tables 1 and 2).

Tables 1 and Table 2 present the sampling by jurisdiction/state. Each jurisdiction is listed with the actual number of active licenses at the time of sampling. The number of surveys needed to be received from each jurisdiction in order to receive $95 \%$ confidence and 3\% error is presented. Regardless of jurisdiction size, this calculated out to be approximately 1,000/jurisdiction. To calculate the number of surveys needed to be mailed out to reach the target survey response, response rates via online and paper from the previous 2013 survey administration were used as estimates. For example, for Alaska, in 2013, there was a 36\% response rate. Given the estimated 36\% response rate in Alaska, 2,753 participants were selected to be sent a survey in order to receive the target of 991 surveys. Actual response from Alaska RNs to the current survey (i.e., the number received) was 971, very close to the target of 991 surveys (see Table 1).

\section{Materials}

Data were collected between July and September 2015. The study instrument was a two-page (front and back) Scantron fillable document with 31 questions (see Appendix D). Questions for the 2015 survey repeated most of the questions from the 2013 NCSBN survey, which was based on The National Forum of State Nursing Workforce Center's minimum dataset (MDS) for the nursing workforce. Additional questions were added to the 2015 survey on the topics of salary, specialty settings, and telehealth. In general, the following items were added: specialty setting, salary, and telehealth. Additionally, some MDS questions were modified; for instance, additional specialties and position titles were added. No pretesting was done with these modifications. Items were added because, for example, workforce data were lacking in a specific specialty or specialty setting area. The salary item was worded in a manner similar to HRSA (2010), and the telehealth items were added in an effort to collect much needed data in this growing area of nursing practice.

The nursing MDS instrument was created through a process of consensus-building. The National Forum's workgroups (participating states included Alabama, Colorado, Florida, Hawaii, Illinois, Indiana, Iowa, Massachusetts, New Jersey, North Dakota, Oklahoma, Tennessee, Vermont, and West Virginia) drafted the dataset. Following a public comment period, which allowed input 
from national organizations, The National Forum voted and approved the datasets in September 2009. NCSBN and The National Forum currently use the MDS questionnaire to collect data on the nursing workforce at the state level and believe that the dataset enhances the ability to plan for the future. More information about the development and current status can be found in Moulton et al. (2013) and Nooney et al. (2010).

\section{Procedure}

Institutional review board approval was obtained by Western Institutional Review Board (WIRB). A unique identification number was generated and assigned to each sampled participant. The identification was only to be used to record that the survey had been returned. This helped prevent unnecessary and expensive duplicate mailings to those selected to participate in the study. Also, a unique access code identified was used for the online survey option.

Electronic versions of the data will be kept on department-secured servers. NCSBN's research department, three key members of The National Forum of State Nursing Workforce Centers, and key personnel at Scantron had initial access to the identifiable data. Scantron no longer has access to the identifiable data. A de-identified data file was created for use with additional analyses and for distribution to state BONs and state nursing workforce centers.

The Dillman approach was used to plan and distribute the materials and includes a series of steps where the potential participant is repeatedly contacted in an effort to get a survey response (Dillman, Smyth, \& Christian, 2009). Dillman specified a specific set of procedures, including creating a booklet survey with a precise schedule of contacts. For example, in the first week, a survey is sent. In the second week, a thank you or reminder postcard is sent. In the fourth week, a replacement/duplicate survey is sent to nonresponders, and in the seventh week, a replacement/duplicate survey is sent to nonrespondents by first-class mail.

Postcards, letters, paper surveys, and Web surveys were designed, and a participant sampling file was compiled according to the sampling protocol. Once materials were developed and the sampling file was complete, surveys were distributed over a 14-week period that included the following steps:

1. Week 1: An announcement postcard was sent to all nurses selected to participate.

2. Week 2: A letter inviting nurses to complete the survey was mailed. The hardcopy survey was included, along with an online option. Instructions were to return the survey within 1 week of receipt. Two versions were mailed in the same week, one sent first class and the second sent using a nonprofit rate.

3. Week 8: For nurses who had not responded, a letter inviting nurses to complete the survey was mailed. The hardcopy survey was included, along with an online option. Instructions were to return the survey within 1 week of receipt. Again, two versions were mailed in the same week, one sent first class and the second sent using a nonprofit rate.

4. Week 14: Deadline for receipt of surveys for data analysis was set internally, along with the closure of the online option.

Once the survey was closed, the final datafile was compiled separately for RNs and LPN/VNs. A nonresponse bias analysis for both the RN and LPN/VN datasets was performed and a variable weighting procedure was used for study analyses to correct for response bias.

\section{Analysis}

At the close of the survey, 46,476 of the 140,154 RNs had responded, after removing 4,448 undeliverables the response rate was $34.2 \%$; 32,263 of the 120,793 LPN/VNs had responded, after removing the 5,493 undeliverables for a response rate of $28.0 \%$. A formal nonresponse bias analysis was conducted immediately following the close of the survey. An analysis of basic demographic data (i.e., gender, age, race/ethnicity, number of years since graduation and first licensed ) for all RN licensees sampled from the Nursys database was used to compare the survey respondents and nonrespondents, to determine the representation of the survey participants. Results revealed that the following groups of nurses may have been slightly overrepresented: White/Caucasian, female, age 60 or older. Because of missing or incomplete data on race/ethnicity, only gender and age were used to make nonresponse weighting adjustments. Additionally, since the sampling was stratified by state, to prevent smaller states from being overrepresented in the overall analysis, a weighting variable was constructed to adjust for differing nursing population sizes across states.

Descriptive statistics, including means, frequencies, and cross-tabulations were used to analyze survey data. Unavoidably, missing data in certain variables caused inconsistent statistics in certain categories. To help the readers get an accurate and comprehensive view of the statistics drawn from the sample, the number of actual valid answers to each question is reported in every table. Missing data were not imputed; hence, the presented statistics represent the actual responses from participants who responded to each respective survey item. If a participant did not respond to a certain item, they were not part of the analysis for that item.

Additionally, some tables display data for all responding nurse licensees while other tables display data for employed nurses. If a table is specific to nurses employed in nursing, it will be explicitly stated. For example, "Initial Nursing Education of RNs Employed in Nursing, by Gender" displays data from only respondents employed in nursing. However, if the table was titled, "Initial Nursing Education of RNs, by Gender," this table would present data from all respondents, regardless of their employment 
status. Conversely, employment status may be implicit, given the data in a table; for instance, a table displaying the percentage of nurses with a specific job title implies that the data being presented is specific to nurses employed in nursing.

Finally, when analyzing table data, know that some tables are organized horizontally while others are organized vertically. The "n's" in the table help guide the reader in the direction to read the data. For example, for tables analyzed by age, data is read horizontally. The large number of age categories serves as a means to provide an age distribution for each variable in the table (e.g., the age distribution of men followed by the age distribution of women or the age distribution of Asian in comparison to the age distribution of White/Caucasian). In general, reading tables row by row, or column by column is suggested over attempting to consume all of the statistics presented in a table at once.

TABLE 1

RN Sampling: Number of Active RN Licenses

\begin{tabular}{|c|c|c|c|c|c|c|c|c|c|}
\hline Jurisdiction & $\begin{array}{c}\text { Number of } \\
\text { Active RN } \\
\text { Licenses }\end{array}$ & $\begin{array}{c}\text { Sample: } 95 \% \\
\text { Confidence, } \\
3 \% \text { Error }\end{array}$ & $\begin{array}{c}\text { Estimated } \\
\text { Total } \\
\text { Response } \\
\text { Rate } \\
\end{array}$ & $\begin{array}{c}\text { Number } \\
\text { of } \\
\text { Surveys } \\
\text { Mailed }\end{array}$ & $\begin{array}{l}\text { Undeliver- } \\
\text { able }\end{array}$ & $\begin{array}{l}\text { Number } \\
\text { Received }\end{array}$ & $\begin{array}{c}\text { Online } \\
\text { Response }\end{array}$ & $\begin{array}{c}\text { Paper } \\
\text { Response }\end{array}$ & $\begin{array}{c}\text { Total } \\
\text { Response } \\
\text { Rate }\end{array}$ \\
\hline $\mathrm{AK}$ & 13,843 & 991 & $36 \%$ & 2,753 & 83 & 971 & $130(13.4 \%)$ & $841(86.6 \%)$ & $36.4 \%$ \\
\hline$A L$ & 68,398 & 1,051 & $31 \%$ & 3,390 & 22 & 945 & 131 (13.9\%) & 814 (86.1\%) & $28.1 \%$ \\
\hline AR & 38,520 & 1,038 & $34 \%$ & 3,053 & 42 & 906 & $131(14.5 \%)$ & $775(85.5 \%)$ & $30.1 \%$ \\
\hline$A Z$ & 80,286 & 1,053 & $33 \%$ & 3,191 & 218 & 975 & $137(14.1 \%)$ & $838(86.0 \%)$ & $32.8 \%$ \\
\hline $\mathrm{CA}$ & 409,971 & 1,064 & $35 \%$ & 3,040 & 90 & 946 & $123(13.0 \%)$ & $823(87.0 \%)$ & $32.1 \%$ \\
\hline $\mathrm{CO}$ & 69,722 & 1,051 & $38 \%$ & 2,766 & 191 & 885 & $101(11.4 \%)$ & $784(88.6 \%)$ & $34.4 \%$ \\
\hline $\mathrm{CT}$ & 61,832 & 1,049 & $40 \%$ & 2,623 & 49 & 924 & $88(9.5 \%)$ & $836(90.5 \%)$ & $35.9 \%$ \\
\hline $\mathrm{DC}$ & 22,700 & 1,019 & $31 \%$ & 3,287 & 208 & 894 & $131(14.7 \%)$ & $763(85.4 \%)$ & $29.0 \%$ \\
\hline $\mathrm{DE}$ & 18,051 & 1,008 & $43 \%$ & 2,344 & 73 & 856 & $108(13 \%)$ & $748(87.4 \%)$ & $37.7 \%$ \\
\hline $\mathrm{FL}$ & 285,317 & 1,063 & $32 \%$ & 3,322 & 161 & 864 & $102(11.8 \%)$ & $762(88.2 \%)$ & $27.3 \%$ \\
\hline $\mathrm{GA}$ & 120,581 & 1,058 & $33 \%$ & 3,206 & 124 & 926 & $135(14.6 \%)$ & $791(85.4 \%)$ & $30.0 \%$ \\
\hline $\mathrm{HI}$ & 25,246 & 1,024 & $40 \%$ & 2,560 & 72 & 911 & 105 (11.5\%) & $806(88.5 \%)$ & $36.6 \%$ \\
\hline $\mathrm{IA}$ & 51,071 & 1,045 & $46 \%$ & 2,272 & 72 & 866 & $86(9.9 \%)$ & $780(90.1 \%)$ & $39.4 \%$ \\
\hline ID & 24,124 & 1,022 & $44 \%$ & 2,323 & 146 & 901 & $136(15.1 \%)$ & 765 (85\%) & $41.4 \%$ \\
\hline IL & 179,026 & 1,061 & $37 \%$ & 2,868 & 49 & 879 & $106(12 \%)$ & $773(87.9 \%)$ & $31.2 \%$ \\
\hline $\mathrm{IN}$ & 110,294 & 1,057 & $39 \%$ & 2,710 & 71 & 995 & $102(10.3 \%)$ & $893(89.8 \%)$ & $37.7 \%$ \\
\hline KS & 57,738 & 1,048 & $44 \%$ & 2,382 & 26 & 847 & $92(10.9 \%)$ & $755(89.1 \%)$ & $36.0 \%$ \\
\hline $\mathrm{KY}$ & 66,049 & 1,050 & $36 \%$ & 2,917 & 30 & 889 & $118(13.3 \%)$ & $771(86.7 \%)$ & $30.8 \%$ \\
\hline LA & 60,898 & 1,049 & $32 \%$ & 3,278 & 19 & 927 & $119(12.8 \%)$ & $808(87.2 \%)$ & $28.4 \%$ \\
\hline MA & 123,507 & 1,058 & $35 \%$ & 3,023 & 25 & 1020 & $90(8.8 \%)$ & $930(91.2 \%)$ & $34.0 \%$ \\
\hline $\mathrm{MD}$ & 77,007 & 1,053 & $38 \%$ & 2,771 & 93 & 842 & $103(12.2 \%)$ & $739(87.8 \%)$ & $31.4 \%$ \\
\hline $\mathrm{ME}$ & 23,510 & 1,021 & $42 \%$ & 2,431 & 46 & 863 & $70(8.1 \%)$ & $793(91.9 \%)$ & $36.2 \%$ \\
\hline $\mathrm{Ml}$ & 140,746 & 1,059 & $45 \%$ & 2,353 & 43 & 912 & $96(10.5 \%)$ & $816(89.5 \%)$ & $39.5 \%$ \\
\hline $\mathrm{MN}$ & 96,086 & 1,055 & $46 \%$ & 2,293 & 28 & 959 & $101(10.5 \%)$ & $858(89.5 \%)$ & $42.3 \%$ \\
\hline $\mathrm{MO}$ & 98,277 & 1,056 & $42 \%$ & 2,514 & 42 & 929 & $131(14.1 \%)$ & $798(85.9 \%)$ & $37.6 \%$ \\
\hline MS & 44,742 & 1,042 & $29 \%$ & 3,593 & 60 & 891 & $137(15.4 \%)$ & $754(84.6 \%)$ & $25.2 \%$ \\
\hline MT & 16,361 & 1,002 & $51 \%$ & 1,965 & 85 & 832 & $73(8.8 \%)$ & $759(91.2 \%)$ & $44.3 \%$ \\
\hline $\mathrm{NC}$ & 125,721 & 1,058 & $43 \%$ & 2,460 & 61 & 872 & $130(14.9 \%)$ & $742(85.1 \%)$ & $36.3 \%$ \\
\hline ND & 13,701 & 990 & $50 \%$ & 1,980 & 38 & 812 & $110(13.6 \%)$ & $702(86.5 \%)$ & $41.8 \%$ \\
\hline $\mathrm{NE}$ & 26,765 & 1,026 & $45 \%$ & 2,280 & 65 & 942 & 111 (11.8\%) & $831(88.2 \%)$ & $42.5 \%$ \\
\hline $\mathrm{NH}$ & 21,459 & 1,017 & $44 \%$ & 2,311 & 36 & 853 & $88(10.3 \%)$ & $765(89.7 \%)$ & $37.5 \%$ \\
\hline $\mathrm{NJ}$ & 121,452 & 1,058 & $39 \%$ & 2,713 & 63 & 809 & $91(11.3 \%)$ & $718(88.8 \%)$ & $30.5 \%$ \\
\hline NM & 25,609 & 1,024 & $38 \%$ & 2,695 & 120 & 853 & $101(11.8 \%)$ & $752(88.2 \%)$ & $33.1 \%$ \\
\hline NV & 31,993 & 1,033 & $34 \%$ & 3,038 & 178 & 883 & $137(15.5 \%)$ & $746(84.5 \%)$ & $30.9 \%$ \\
\hline
\end{tabular}




\begin{tabular}{|c|c|c|c|c|c|c|c|c|c|}
\hline Jurisdiction & $\begin{array}{c}\text { Number of } \\
\text { Active RN } \\
\text { Licenses }\end{array}$ & $\begin{array}{c}\text { Sample: 95\% } \\
\text { Confidence, } \\
\text { 3\% Error }\end{array}$ & $\begin{array}{c}\text { Estimated } \\
\text { Total } \\
\text { Response } \\
\text { Rate }\end{array}$ & $\begin{array}{l}\text { Number } \\
\text { of } \\
\text { Surveys } \\
\text { Mailed }\end{array}$ & $\begin{array}{c}\text { Undeliver- } \\
\text { able }\end{array}$ & $\begin{array}{l}\text { Number } \\
\text { Received }\end{array}$ & $\begin{array}{c}\text { Online } \\
\text { Response }\end{array}$ & $\begin{array}{c}\text { Paper } \\
\text { Response }\end{array}$ & $\begin{array}{c}\text { Total } \\
\text { Response } \\
\text { Rate }\end{array}$ \\
\hline NY & 311,395 & 1,063 & $37 \%$ & 2,873 & 168 & 958 & $61(6.4 \%)$ & $897(93.6 \%)$ & $35.4 \%$ \\
\hline $\mathrm{OH}$ & 199,755 & 1,061 & $41 \%$ & 2,588 & 86 & 929 & $98(10.6 \%)$ & $831(89.5 \%)$ & $37.1 \%$ \\
\hline OK & 48,461 & 1,044 & $33 \%$ & 3,164 & 53 & 948 & 137 (14.5\%) & 811 (85.6\%) & $30.5 \%$ \\
\hline PA & 193,503 & 1,061 & $44 \%$ & 2,411 & 12 & 955 & 107 (11.2\%) & $848(88.8 \%)$ & $39.8 \%$ \\
\hline $\mathrm{RI}$ & 18,367 & 1,009 & $37 \%$ & 2,727 & 217 & 852 & 72 (8.5\%) & 780 (91.6\%) & $33.9 \%$ \\
\hline $\mathrm{SC}$ & 62,328 & 1,049 & $35 \%$ & 2,997 & 91 & 935 & 127 (13.6\%) & 808 (86.4\%) & $32.2 \%$ \\
\hline SD & 16,317 & 1,002 & $46 \%$ & 2,178 & 52 & 901 & 77 (8.6\%) & $824(91.5 \%)$ & $42.4 \%$ \\
\hline VA & 99,778 & 1,056 & $38 \%$ & 2,779 & 79 & 852 & $131(15.4 \%)$ & $721(84.6 \%)$ & $31.6 \%$ \\
\hline VT & 11,604 & 977 & $44 \%$ & 2,220 & 35 & 830 & $88(10.6 \%)$ & 742 (89.4\%) & $38.0 \%$ \\
\hline WA & 69,319 & 1,051 & $41 \%$ & 2,563 & 46 & 970 & $121(14.5 \%)$ & $849(87.5 \%)$ & $38.5 \%$ \\
\hline WI & 94,331 & 1,055 & $53 \%$ & 1,991 & 39 & 914 & $98(10.7 \%)$ & $816(89.3 \%)$ & $46.8 \%$ \\
\hline WV & 31,763 & 1,032 & $34 \%$ & 3,035 & 51 & 909 & $104(11.4 \%)$ & 805 (88.6\%) & $30.5 \%$ \\
\hline WY & 10,161 & 966 & $46 \%$ & 2,100 & 33 & 844 & $103(12.2 \%)$ & 741 (87.8\%) & $40.8 \%$ \\
\hline $\begin{array}{l}\text { Virgin } \\
\text { Islands }\end{array}$ & 1,144 & 552 & $29 \%$ & 844 & 112 & 188 & $51(27.1 \%)$ & 137 (72.9\%) & $25.7 \%$ \\
\hline Guam & 1,878 & 680 & $29 \%$ & 871 & 186 & 164 & $41(25.0 \%)$ & $123(75.0 \%)$ & $23.9 \%$ \\
\hline
\end{tabular}

\section{TABLE 2}

\section{LPN/VN Sampling: Number of Active LPN/VN Licenses}

\begin{tabular}{|c|c|c|c|c|c|c|c|c|c|}
\hline Jurisdiction & $\begin{array}{l}\text { Number of } \\
\text { Active } \\
\text { LPN/VN } \\
\text { Licenses }\end{array}$ & $\begin{array}{c}\text { Sample: } 95 \% \\
\text { Confidence, } \\
3 \% \text { Error }\end{array}$ & $\begin{array}{c}\text { Estimated } \\
\text { Total } \\
\text { Response } \\
\text { Rate }\end{array}$ & $\begin{array}{c}\begin{array}{c}\text { Number } \\
\text { of } \\
\text { Surveys } \\
\text { Mailed }\end{array}\end{array}$ & $\begin{array}{c}\text { Undeliver- } \\
\text { able }\end{array}$ & $\begin{array}{l}\text { Number } \\
\text { Received }\end{array}$ & $\begin{array}{c}\text { Online } \\
\text { Response }\end{array}$ & $\begin{array}{c}\text { Paper } \\
\text { Response }\end{array}$ & $\begin{array}{c}\text { Total } \\
\text { Response } \\
\text { Rate }\end{array}$ \\
\hline AK & 1,051 & 529 & $36 \%$ & 600 & 34 & 174 & $15(8.6 \%)$ & 159 (91.4\%) & $30.7 \%$ \\
\hline $\mathrm{AL}$ & 17,888 & 1,007 & $31 \%$ & 3,248 & 77 & 907 & $108(11.9 \%)$ & $799(88.1 \%)$ & $28.6 \%$ \\
\hline$A R$ & 15,448 & 998 & $34 \%$ & 2,935 & 84 & 797 & 77 (9.7\%) & $720(90.3 \%)$ & $28.0 \%$ \\
\hline $\mathrm{CA}$ & 95,682 & 1055 & $35 \%$ & 3,014 & 98 & 655 & 76 (11.6\%) & $579(88.4 \%)$ & $22.5 \%$ \\
\hline $\mathrm{CO}$ & 8,325 & 946 & $38 \%$ & 2,489 & 228 & 575 & $36(6.3 \%)$ & $539(93.7 \%)$ & $25.4 \%$ \\
\hline CT & 13,318 & 988 & $40 \%$ & 2,470 & 68 & 552 & $29(5.3 \%)$ & $523(94.8 \%)$ & $23.0 \%$ \\
\hline
\end{tabular}

S10 Journal of Nursing Regulation 


\begin{tabular}{|c|c|c|c|c|c|c|c|c|c|}
\hline Jurisdiction & $\begin{array}{c}\text { Number of } \\
\text { Active } \\
\text { LPN/VN } \\
\text { Licenses } \\
\end{array}$ & $\begin{array}{c}\text { Sample: } 95 \% \\
\text { Confidence, } \\
3 \% \text { Error }\end{array}$ & $\begin{array}{c}\text { Estimated } \\
\text { Total } \\
\text { Response } \\
\text { Rate } \\
\end{array}$ & $\begin{array}{c}\begin{array}{c}\text { Number } \\
\text { of } \\
\text { Surveys } \\
\text { Mailed }\end{array} \\
\end{array}$ & $\begin{array}{l}\text { Undeliver- } \\
\text { able }\end{array}$ & $\begin{array}{l}\text { Number } \\
\text { Received }\end{array}$ & $\begin{array}{c}\text { Online } \\
\text { Response }\end{array}$ & $\begin{array}{c}\text { Paper } \\
\text { Response }\end{array}$ & $\begin{array}{c}\text { Total } \\
\text { Response } \\
\text { Rate }\end{array}$ \\
\hline $\mathrm{DC}$ & 3,062 & 791 & $31 \%$ & 796 & 78 & 164 & $10(6.1 \%)$ & $154(93.9 \%)$ & $22.8 \%$ \\
\hline $\mathrm{DE}$ & 3,011 & 788 & $43 \%$ & 1,833 & 68 & 488 & $52(10.7 \%)$ & $436(89.3 \%)$ & $27.6 \%$ \\
\hline $\mathrm{FL}$ & 73,845 & 1,052 & $32 \%$ & 3,288 & 270 & 721 & $74(10.3 \%)$ & $647(89.7 \%)$ & $23.9 \%$ \\
\hline $\mathrm{GA}$ & 35,866 & 1,036 & $33 \%$ & 3,139 & 166 & 716 & 80 (11.2\%) & $636(88.8 \%)$ & $24.1 \%$ \\
\hline $\mathrm{HI}$ & 2,937 & 783 & $40 \%$ & 1,958 & 62 & 583 & $54(9.3 \%)$ & $529(90.7 \%)$ & $30.7 \%$ \\
\hline IA & 11,338 & 975 & $46 \%$ & 2,120 & 75 & 654 & $37(5.7 \%)$ & $617(94.3 \%)$ & $32.0 \%$ \\
\hline ID & 4,886 & 876 & $44 \%$ & 1,991 & 108 & 616 & 54 (8.8\%) & $562(91.2 \%)$ & $32.7 \%$ \\
\hline $\mathrm{IL}$ & 26,597 & 1026 & $37 \%$ & 2,773 & 44 & 683 & $50(7.3 \%)$ & $633(92.7 \%)$ & $25.0 \%$ \\
\hline IN & 25,830 & 1025 & $39 \%$ & 2,628 & 59 & 707 & $53(7.5 \%)$ & $654(92.5 \%)$ & $27.5 \%$ \\
\hline $\mathrm{KS}$ & 10,534 & 969 & $44 \%$ & 2,202 & 47 & 696 & $58(8.3 \%)$ & $638(91.7 \%)$ & $32.3 \%$ \\
\hline KY & 15,082 & 997 & $36 \%$ & 2,769 & 57 & 690 & 65 (9.4\%) & $625(90.6 \%)$ & $25.4 \%$ \\
\hline LA & 23,850 & 1,021 & $32 \%$ & 3,191 & 35 & 716 & $79(11.0 \%)$ & $637(89.0 \%)$ & $22.7 \%$ \\
\hline $\mathrm{MA}$ & 21,471 & 1,017 & $35 \%$ & 2,906 & 55 & 737 & $53(7.2 \%)$ & $684(92.8 \%)$ & $25.9 \%$ \\
\hline $\mathrm{MD}$ & 13,144 & 987 & $38 \%$ & 2,597 & 218 & 551 & $60(10.9 \%)$ & $491(89.1 \%)$ & $23.2 \%$ \\
\hline $\mathrm{ME}$ & 2,432 & 742 & $42 \%$ & 1,767 & 45 & 575 & $12(2.1 \%)$ & $563(97.9 \%)$ & $33.4 \%$ \\
\hline $\mathrm{MI}$ & 24,886 & 1,023 & $45 \%$ & 2,273 & 68 & 748 & $42(5.6 \%)$ & 706 (94.4\%) & $33.9 \%$ \\
\hline $\mathrm{MN}$ & 23,128 & 1,020 & $46 \%$ & 2,217 & 57 & 827 & $51(6.2 \%)$ & 776 (93.8\%) & $38.3 \%$ \\
\hline $\mathrm{MO}$ & 24,377 & 1,022 & $42 \%$ & 2,433 & 135 & 713 & 59 (8.3\%) & $654(91.7 \%)$ & $31.0 \%$ \\
\hline MS & 14,699 & 995 & $29 \%$ & 3,431 & 208 & 673 & $67(10.0 \%)$ & $606(90.0 \%)$ & $20.9 \%$ \\
\hline MT & 2,808 & 773 & $51 \%$ & 1,516 & 101 & 594 & $34(5.7 \%)$ & $560(94.3 \%)$ & $42.0 \%$ \\
\hline $\mathrm{NC}$ & 21,925 & 1,018 & $43 \%$ & 2,367 & 91 & 679 & $71(10.5 \%)$ & $608(89.5 \%)$ & $29.8 \%$ \\
\hline ND & 3,705 & 828 & $50 \%$ & 1,656 & 58 & 626 & $43(6.9 \%)$ & $583(93.1 \%)$ & $39.2 \%$ \\
\hline $\mathrm{NE}$ & 7,052 & 927 & $45 \%$ & 2,060 & 113 & 694 & $58(8.4 \%)$ & $636(91.6 \%)$ & $35.6 \%$ \\
\hline $\mathrm{NH}$ & 3,271 & 805 & $44 \%$ & 1,830 & 44 & 533 & $33(6.2 \%)$ & $500(93.8 \%)$ & $29.8 \%$ \\
\hline $\mathrm{NJ}$ & 24,091 & 1,022 & $39 \%$ & 2,621 & 105 & 641 & $58(9.1 \%)$ & $583(91.0 \%)$ & $25.5 \%$ \\
\hline NM & 2,752 & 769 & $38 \%$ & 2,024 & 103 & 558 & $61(10.9 \%)$ & 497 (89.1\%) & $29.0 \%$ \\
\hline NV & 3,546 & 820 & $34 \%$ & 2,412 & 259 & 592 & 68 (11.5\%) & $524(88.5 \%)$ & $27.5 \%$ \\
\hline NY & 81,156 & 1,053 & $37 \%$ & 2,846 & 277 & 613 & 39 (6.4\%) & $574(93.6 \%)$ & $23.9 \%$ \\
\hline $\mathrm{OH}$ & 54,882 & 1,047 & $41 \%$ & 2,554 & 77 & 714 & $45(6.3 \%)$ & 669 (93.7\%) & $28.8 \%$ \\
\hline $\mathrm{OK}$ & 18,212 & 1,008 & $33 \%$ & 3,055 & 93 & 772 & $77(10.0 \%)$ & $695(90.0 \%)$ & $26.1 \%$ \\
\hline $\mathrm{OR}$ & 4,893 & 876 & $41 \%$ & 2,137 & 89 & 594 & 55 (9.3\%) & $539(90.7 \%)$ & $29.0 \%$ \\
\hline PA & 56,179 & 1,047 & $44 \%$ & 2,380 & 27 & 821 & $54(6.6 \%)$ & $767(93.4 \%)$ & $34.9 \%$ \\
\hline $\mathrm{RI}$ & 1,881 & 681 & $37 \%$ & 1,758 & 186 & 431 & $24(5.6 \%)$ & $407(94.4 \%)$ & $27.4 \%$ \\
\hline $\mathrm{SC}$ & 12,139 & 981 & $35 \%$ & 2,803 & 104 & 734 & 65 (8.9\%) & $669(91.1 \%)$ & $27.2 \%$ \\
\hline SD & 2,460 & 744 & $46 \%$ & 1,617 & 43 & 564 & $25(4.4 \%)$ & $539(95.6 \%)$ & $35.8 \%$ \\
\hline $\mathrm{TN}$ & 30,126 & 1,031 & $33 \%$ & 3,124 & 109 & 763 & 85 (11.1\%) & $678(88.9 \%)$ & $25.3 \%$ \\
\hline$T X$ & 100,545 & 1,056 & $32 \%$ & 3,300 & 194 & 735 & $105(14.3 \%)$ & $630(85.7 \%)$ & $23.7 \%$ \\
\hline UT & 2,770 & 770 & $40 \%$ & 1,925 & 101 & 534 & $61(11.4 \%)$ & $473(88.6 \%)$ & $29.3 \%$ \\
\hline VA & 28,361 & 1,028 & $38 \%$ & 2,705 & 113 & 586 & $58(9.9 \%)$ & $528(90.1 \%)$ & $22.6 \%$ \\
\hline $\mathrm{VT}$ & 2,087 & 706 & $44 \%$ & 1,605 & 48 & 486 & $23(4.7 \%)$ & $463(95.3 \%)$ & $31.2 \%$ \\
\hline WA & 11,954 & 980 & $41 \%$ & 2,390 & 64 & 716 & $58(8.1 \%)$ & $658(91.9 \%)$ & $30.8 \%$ \\
\hline $\mathrm{WI}$ & 13,619 & 990 & $53 \%$ & 1,868 & 15 & 791 & 63 (8.0\%) & $728(92.0 \%)$ & $42.7 \%$ \\
\hline WV & 12,886 & 986 & $34 \%$ & 2,900 & 240 & 559 & $41(7.3 \%)$ & $518(92.7 \%)$ & $21.0 \%$ \\
\hline
\end{tabular}




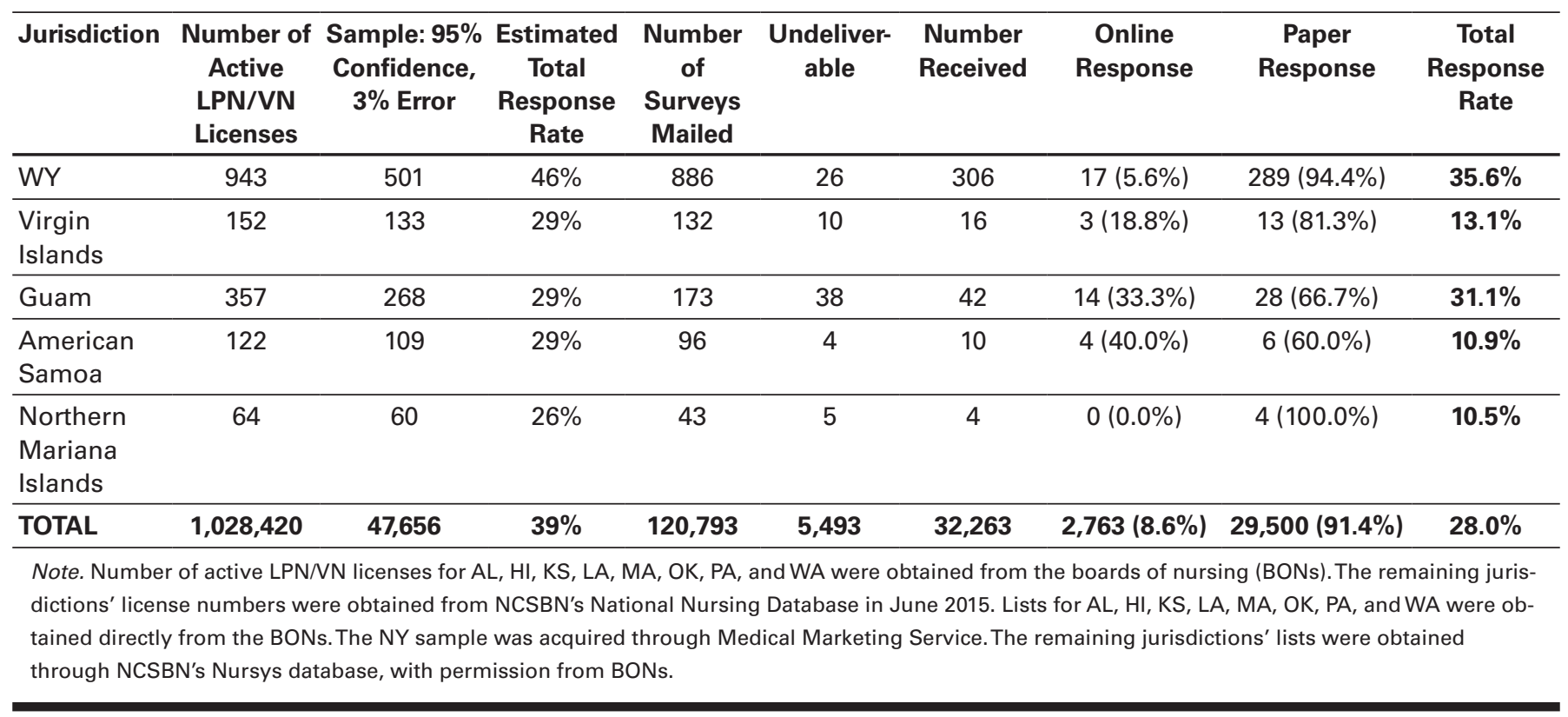

\section{Registered Nurse Results}

\section{Age}

The average age of all the respondents surveyed was 48.8 (see Table 3), higher than HRSA's (2013) most recently reported average age of 44.6 years but lower than the average age of 50 reported in the 2013 National Workforce Survey of Registered Nurses.

As shown in Table 3, $50 \%$ of respondents were age 50 or older, with $12.4 \%$ age 65 and older.

TABLE 3

\section{Age Distribution and Gender, by Age}

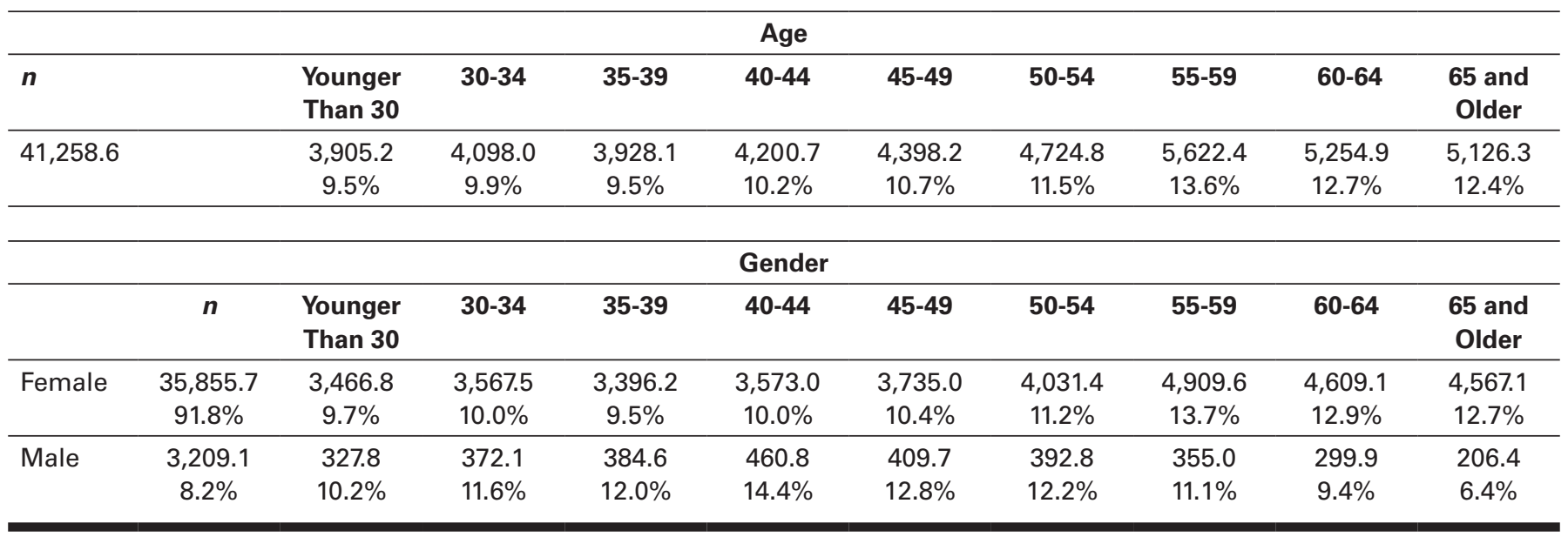

\section{Race/Ethnicity by Age}

In terms of race/ethnicity by age-group, larger percentages of minorities were younger as compared to nearing retirement (Table 4). For instance, $29.8 \%$ of Hispanic/Latino RNs reported being younger than age 35 and only $10 \%$ reported being age 60 or older; $18.9 \%$ of White/Caucasian RNs reported being younger than age 35 and $27.1 \%$ reported being age 60 or older 
TABLE 4

\section{Race/Ethnicity, by Age}

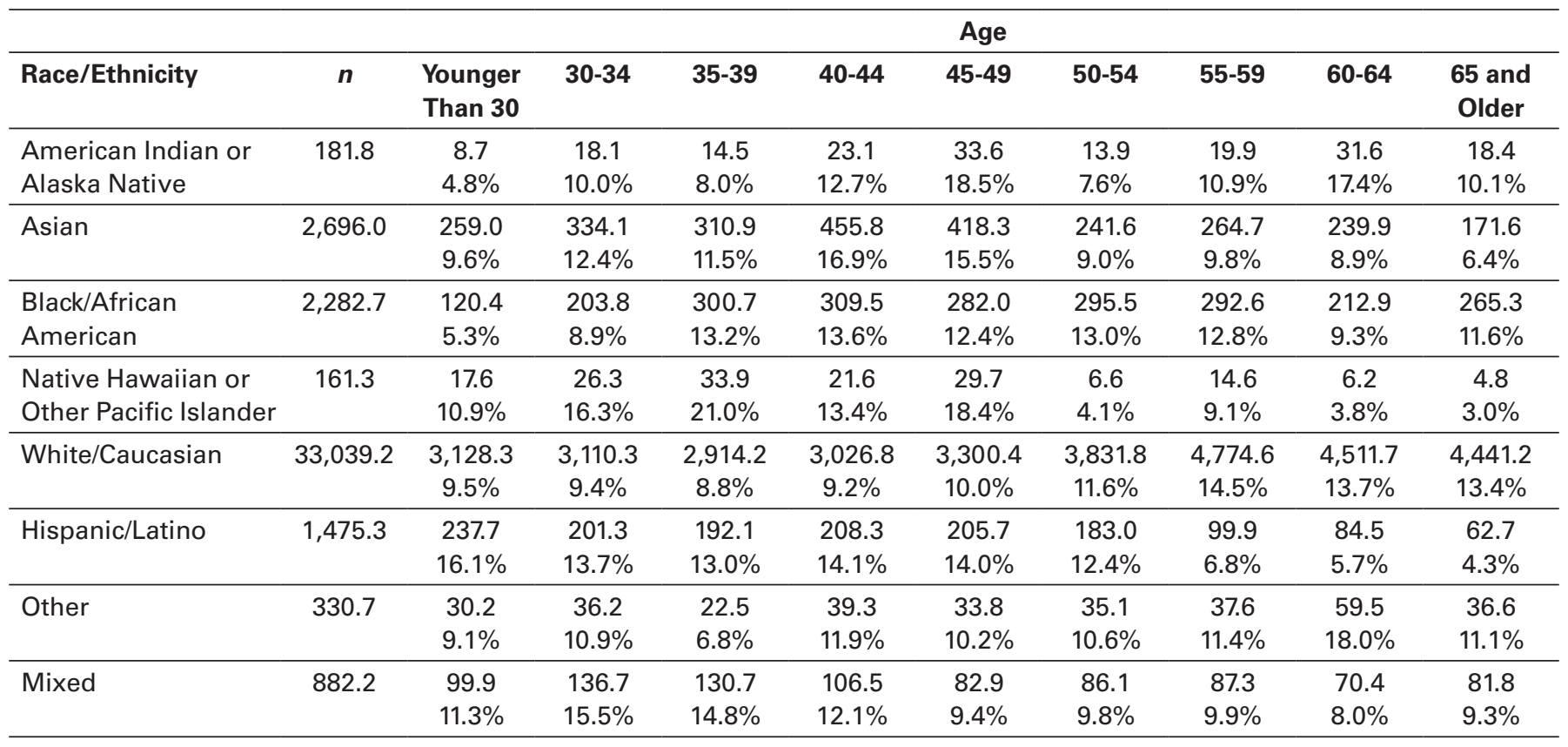

Note. Respondents were asked to mark all that applied for Race/Ethnicity. However, responses were coded to be mutually exclusive. If respondents selected multiple options, they were coded as Mixed Race/Ethnicity.

\section{Initial Nursing Education by Age}

An examination of initial nursing education by age-group revealed that most younger nurses have completed studies at the baccalaureate level (Table 5). In the older-than-age 45 groups, more nurses have completed their degree at the associate level. DNP graduates are most prevalent in the 40-44 age-group, and $\mathrm{PhD}$ nursing degrees are most prevalent in the 45-49 age-group (nurses younger than age 35 were least likely to pursue doctoral education).

\section{TABLE 5}

\section{Initial Nursing Education, by Age}

\begin{tabular}{|c|c|c|c|c|c|c|c|c|c|c|}
\hline \multirow[b]{2}{*}{$\begin{array}{l}\text { Initial Nursing } \\
\text { Education }\end{array}$} & \multirow[b]{2}{*}{$n$} & \multicolumn{9}{|c|}{ Age } \\
\hline & & $\begin{array}{l}\text { Younger } \\
\text { Than } 30\end{array}$ & $30-34$ & $35-39$ & $40-44$ & $45-49$ & $50-54$ & $55-59$ & $60-64$ & $\begin{array}{c}65 \text { and } \\
\text { Older }\end{array}$ \\
\hline $\begin{array}{l}\text { Vocational/practical } \\
\text { certificate-nursing }\end{array}$ & & $3.9 \%$ & $7.7 \%$ & $9.9 \%$ & $9.6 \%$ & $13.9 \%$ & 10.76 & $15.6 \%$ & $15.2 \%$ & $13.4 \%$ \\
\hline \multirow[t]{2}{*}{ Diploma } & 5703.54 & 75.0 & 100.8 & 161.1 & 216.3 & 278.0 & 580.7 & 969.3 & 1157.6 & 2164.9 \\
\hline & & $1.3 \%$ & $1.8 \%$ & $2.8 \%$ & $3.8 \%$ & $4.9 \%$ & $10.2 \%$ & $17.0 \%$ & $20.3 \%$ & $38.0 \%$ \\
\hline ADN & & $7.6 \%$ & $9.3 \%$ & $10.8 \%$ & $11.4 \%$ & $12.4 \%$ & $12.7 \%$ & $14.1 \%$ & $12.7 \%$ & $9.3 \%$ \\
\hline \multirow[t]{2}{*}{ BSN } & 16101.6 & $2,463.2$ & $2,151.9$ & $1,654.7$ & $1,788.8$ & $1,714.4$ & $1,748.1$ & $1,925.1$ & $1,600.8$ & $1,054.6$ \\
\hline & & $15.3 \%$ & $13.4 \%$ & $10.3 \%$ & $11.1 \%$ & $10.7 \%$ & $10.9 \%$ & $12.0 \%$ & $9.9 \%$ & $6.6 \%$ \\
\hline \multirow[t]{2}{*}{ MSN } & 1079.17 & 72.5 & 188.9 & 161.1 & 134.1 & 103.9 & 124.7 & 113.3 & 106.4 & 74.3 \\
\hline & & $6.7 \%$ & $17.5 \%$ & $14.9 \%$ & $12.4 \%$ & $9.6 \%$ & $11.6 \%$ & $10.5 \%$ & $9.9 \%$ & $6.9 \%$ \\
\hline PhD-nursing & & $0.0 \%$ & $0.0 \%$ & $16.6 \%$ & $6.5 \%$ & $30.7 \%$ & $12.0 \%$ & $16.0 \%$ & $6.1 \%$ & $12.2 \%$ \\
\hline
\end{tabular}




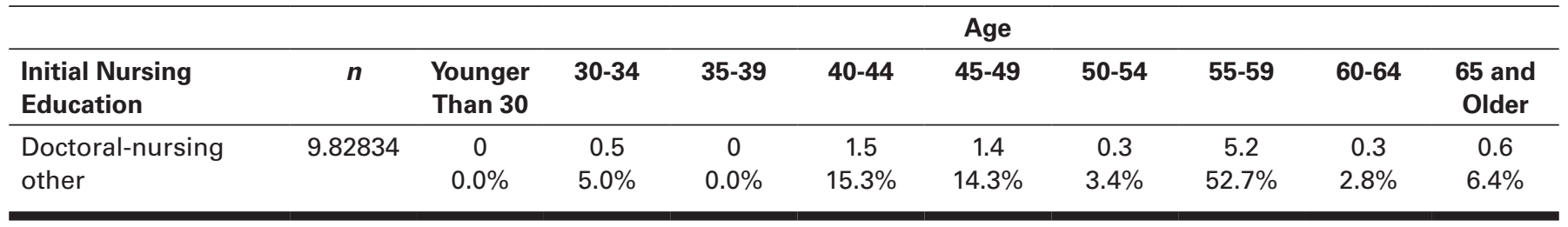

\section{Employment Status by Age}

An analysis of age-group by employment status revealed a gradual decline in employment as nurses age. While there is some fluctuation, over $91 \%$ of nurses younger than age 50 remain employed. After age 50 , more significant drop-offs in employment occur as nurses age (Table 6). The rates of unemployed nurses and those seeking work as a nurse were relatively similar across age-groups.

When comparing results to 2013, from younger than 30 to 49 age cohorts, the percentage employed in nursing is consistent with 2013 data. From 50+, the current study's percentages show a drop-off in percentage employed in nursing when compared to 2013 data. For instance, in 2013, $47 \%$ of those age 65 and older were employed in nursing, while in $201540.1 \%$ were employed in nursing.

\section{TABLE 6}

\section{Age, by Employment Status}

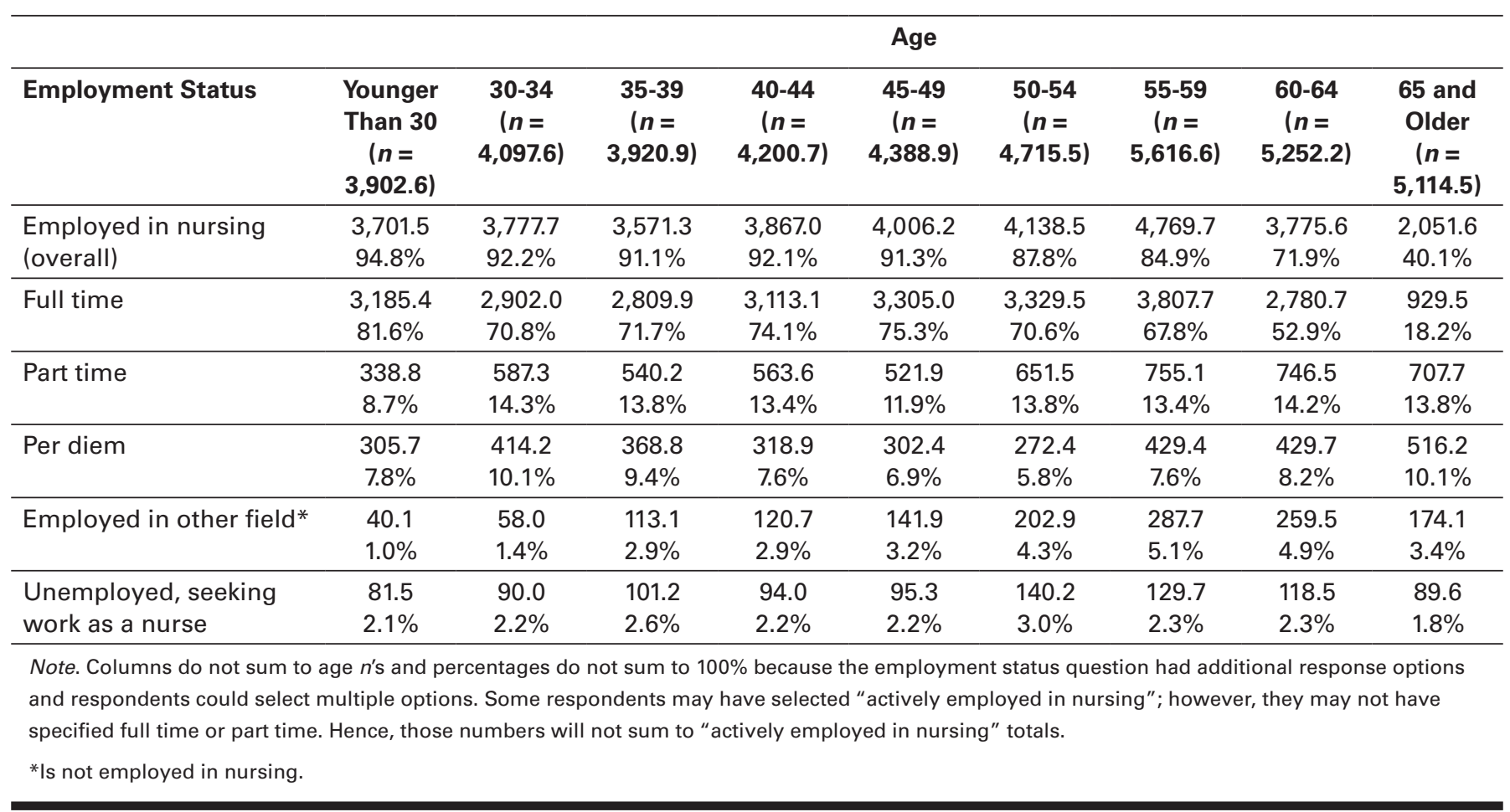

\section{Employment Setting by Age and Hours Worked}

An analysis of average hours worked in nursing per week by employment status and age-group revealed that, on average, full-time and part-time RNs worked 41.6 and 25.1 hours per week, respectively. Other than part-time nurses age 65 and older, the current study showed that the number of weekly hours worked by full-time and part-time RNs was consistent across all age-groups.

An analysis of primary employment setting by age-group revealed that RNs had a steady though gradual decline in the percent employed in hospitals as age increased (Table 7). The older nurse tended to be employed in academic, community, occupational health, and non-direct care settings, such as policy, planning, and regulatory. The current study found that $79 \%$ of RNs younger than age 30 worked in hospitals; this percentage declined with age, where $46 \%$ of RNs age 55 and older worked in hospitals. 
TABLE 7

\section{Primary Employment Setting, by Age}

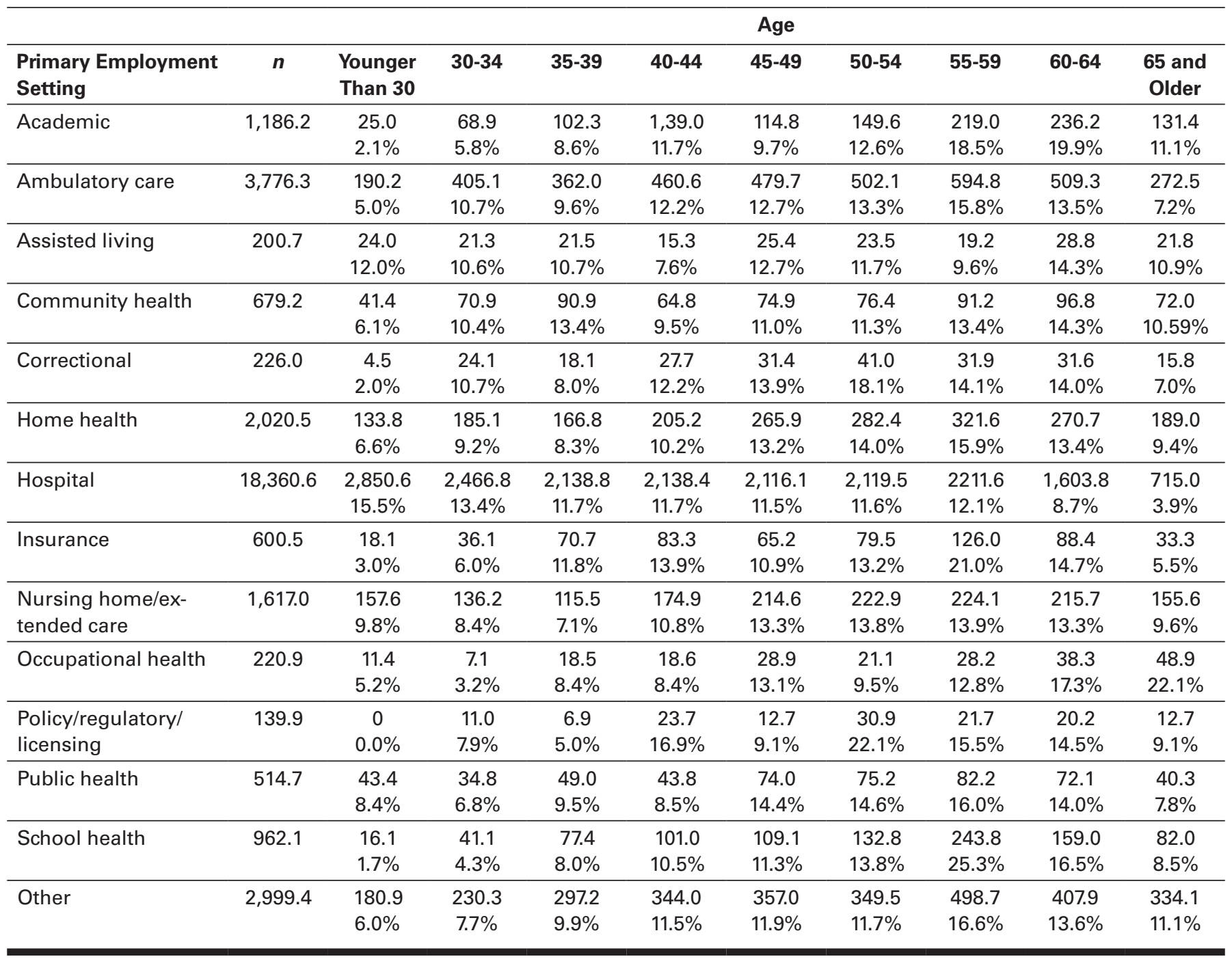

\section{Position Title by Age}

A comparison of position titles by age-group suggested that the largest percentage of RNs with a principal position title of "nurse executive" (22.2\%) was in the 60-64 age-group (Table 8). "Advanced practice nurse" was most common for the 30-34 and 35-39 age-groups. "Nurse faculty" was primarily represented by the 55-59 and 60-64 age-groups (14.8\% each).

\section{TABLE 8}

\section{Primary Position Title, by Age}

\begin{tabular}{lcccccccccc}
\hline \multicolumn{1}{c}{} & \multicolumn{7}{c}{ Age } \\
\hline Primary Position Title & $\boldsymbol{n}$ & $\begin{array}{c}\text { Younger } \\
\text { Than } \mathbf{3 0}\end{array}$ & $\mathbf{3 0 - 3 4}$ & $\mathbf{3 5 - 3 9}$ & $\mathbf{4 0 - 4 4}$ & $\mathbf{4 5 - 4 9}$ & $\mathbf{5 0 - 5 4}$ & $\mathbf{5 5 - 5 9}$ & $\begin{array}{c}\mathbf{6 0 - 6 4} \\
\mathbf{6 5} \text { and } \\
\text { Older }\end{array}$ \\
\hline Advanced practice & $2,694.8$ & 138.5 & 354.0 & 360.4 & 376.5 & 304.6 & 303.6 & 350.6 & 315.4 & 191.2 \\
nurse & & $5.1 \%$ & $13.1 \%$ & $13.4 \%$ & $14.0 \%$ & $11.3 \%$ & $11.3 \%$ & $13.0 \%$ & $11.7 \%$ & $7.1 \%$ \\
\hline Case manager & $2,222.1$ & 99.1 & 163.9 & 163.2 & 235.3 & 316.2 & 307.1 & 426.4 & 336.2 & 174.8 \\
& & $4.5 \%$ & $7.4 \%$ & $7.4 \%$ & $10.6 \%$ & $14.2 \%$ & $13.8 \%$ & $19.2 \%$ & $15.1 \%$ & $7.9 \%$ \\
\hline Clinical nurse leader & $1,374.2$ & 76.2 & 104.2 & 138.9 & 163.9 & 170.0 & 224.7 & 233.3 & 187.0 & 76.1 \\
& & $5.6 \%$ & $7.6 \%$ & $10.1 \%$ & $11.9 \%$ & $12.4 \%$ & $16.4 \%$ & $17.0 \%$ & $13.6 \%$ & $5.5 \%$ \\
\hline
\end{tabular}




\begin{tabular}{|c|c|c|c|c|c|c|c|c|c|c|}
\hline Primary Position Title & $n$ & \multicolumn{9}{|c|}{ Age } \\
\hline Consultant & & $1.9 \%$ & $5.6 \%$ & $7.4 \%$ & $9.6 \%$ & $11.1 \%$ & $13.3 \%$ & $17.4 \%$ & $17.0 \%$ & $16.8 \%$ \\
\hline Nurse executive & 789.0 & 0.9 & 20.1 & 53.1 & 72.3747 & 115.4 & 132.1 & 145.1 & 174.8 & 75.2 \\
\hline Nurse faculty & & $9.4 \%$ & $10.8 \%$ & $9.1 \%$ & $10.0 \%$ & $10.5 \%$ & $10.6 \%$ & $14.8 \%$ & $14.8 \%$ & $10.1 \%$ \\
\hline \multirow[t]{2}{*}{ Nurse manager } & $2,727.0$ & 112.2 & 214.1 & 261.3 & 367.1 & 338.0 & 414.0 & 452.7 & 373.3 & 194.4 \\
\hline & & $4.1 \%$ & $7.9 \%$ & $9.6 \%$ & $13.5 \%$ & $12.4 \%$ & $15.2 \%$ & $16.6 \%$ & $13.7 \%$ & $7.1 \%$ \\
\hline \multirow[t]{2}{*}{ Nurse researcher } & 215.3 & 5.8 & 10.7 & 15.2 & 34.4 & 27.2 & 35.5 & 37.3 & 21.3 & 27.8 \\
\hline & & $2.7 \%$ & $5.0 \%$ & $7.1 \%$ & $16.0 \%$ & $12.6 \%$ & $16.5 \%$ & $17.3 \%$ & $9.9 \%$ & $12.9 \%$ \\
\hline $\begin{array}{l}\text { Other-not health } \\
\text { related }\end{array}$ & & $1.8 \%$ & $14.2 \%$ & $8.9 \%$ & $9.7 \%$ & $8.7 \%$ & $16.9 \%$ & $14.5 \%$ & $15.2 \%$ & $10.1 \%$ \\
\hline \multirow[t]{2}{*}{ Staff nurse } & $19,755.6$ & $3,073.0$ & $2,572.1$ & $2,210.0$ & $2,202.5$ & $2,284.9$ & $2,212.4$ & $2,432.5$ & $1,805.8$ & 962.4 \\
\hline & & $15.6 \%$ & $13.0 \%$ & $11.2 \%$ & $11.2 \%$ & $11.6 \%$ & $11.2 \%$ & $12.3 \%$ & $9.1 \%$ & $4.9 \%$ \\
\hline
\end{tabular}

\section{Employment Specialty by Age}

Primary employment specialty was also compared across age-groups (Table 9). The youngest nurses tended to work in acute care/ critical care and specialty settings, while older nurses were more common in community settings, such as school health, community health, and public health. Anesthesiology, emergency/trauma, neonatal, neurology/neurosurgery, and women's health were more commonly the choice of nurses age 30 to 44 .

\section{TABLE 9}

\section{Primary Employment Specialty, by Age}

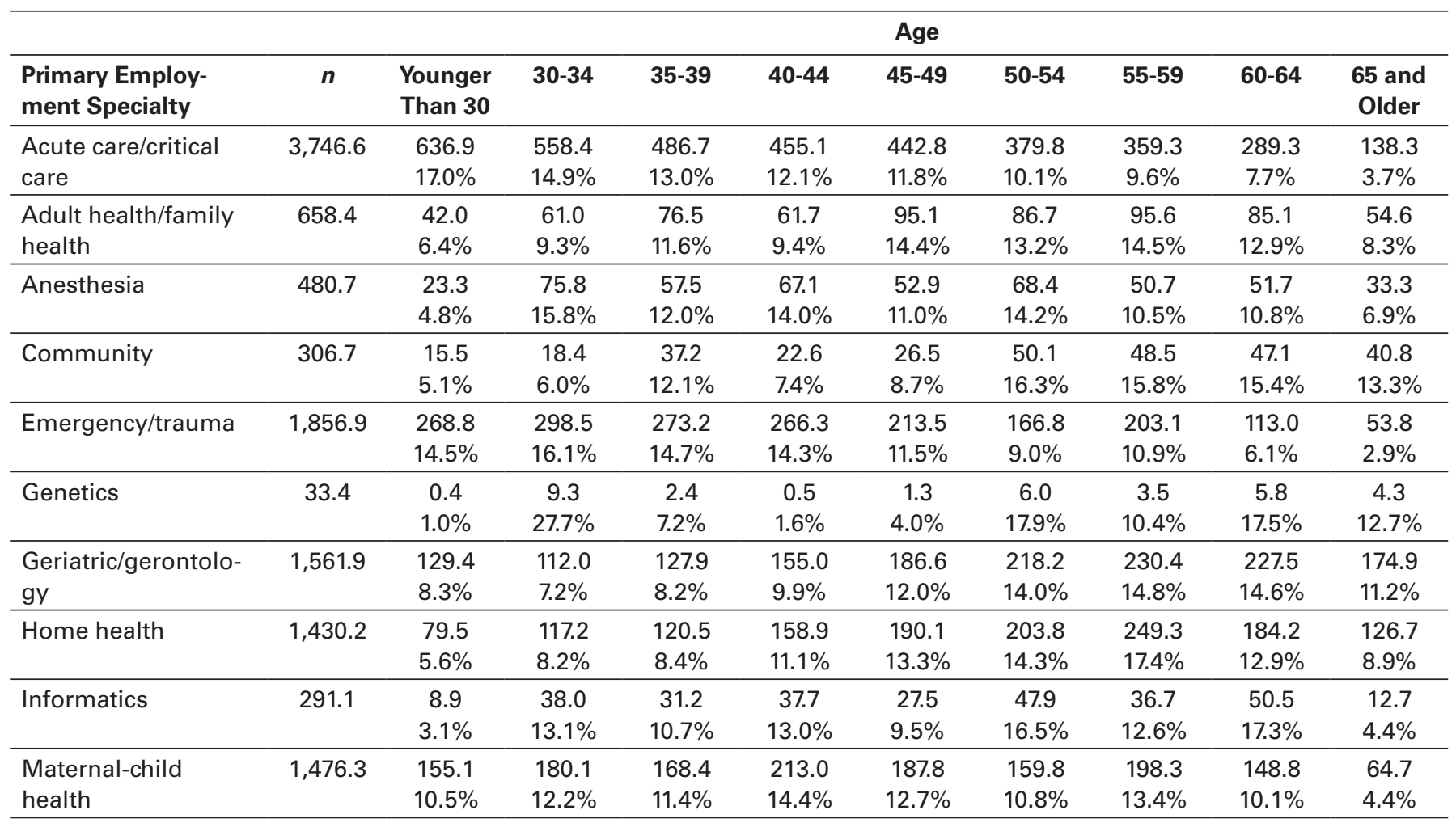




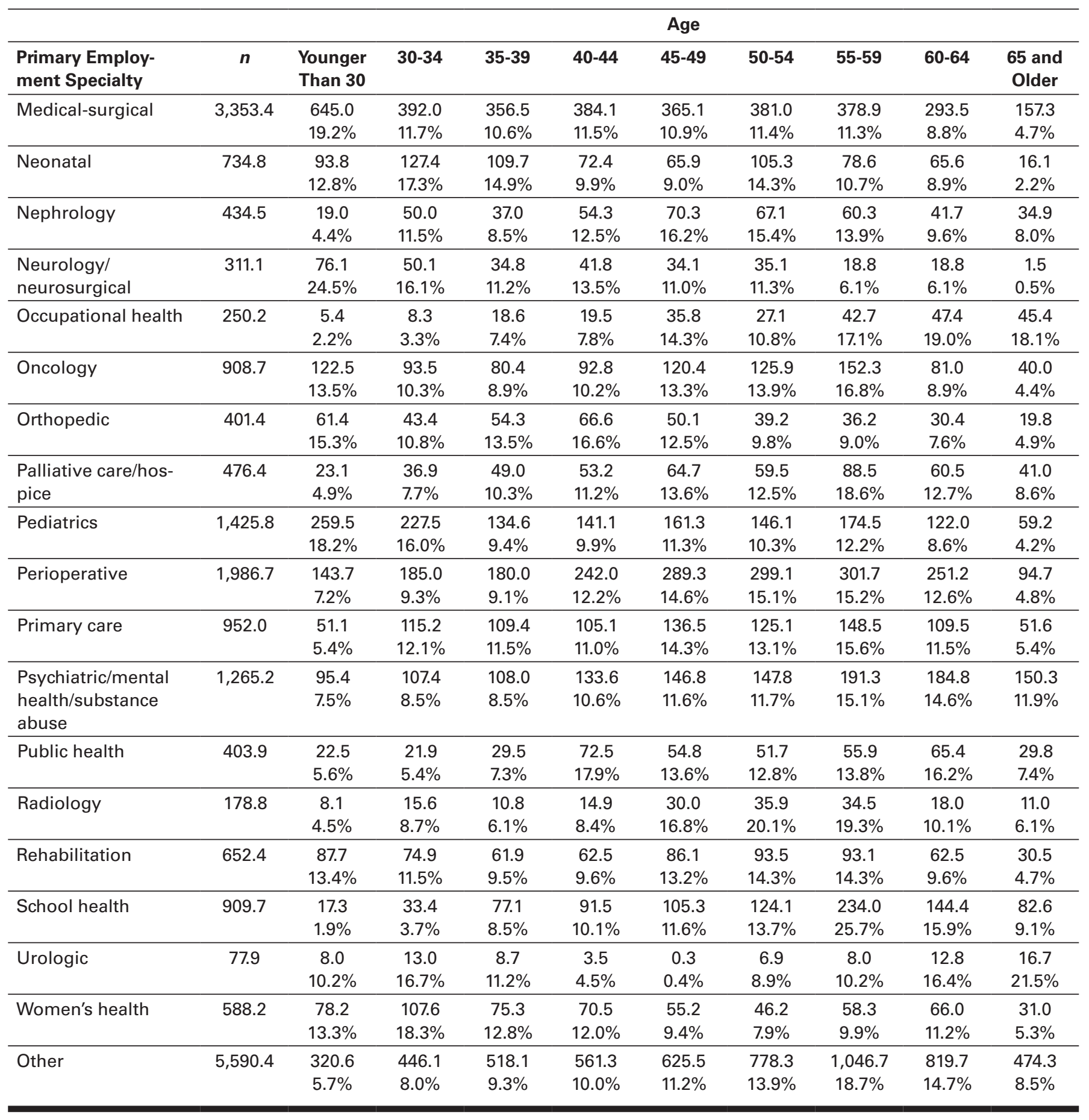

\section{Additional Nursing Positions by Age}

Over $15.2 \%$ of RNs reported working in more than one nursing position, which was approximately the same percentage as in 2013. The 55-59 age-group had the most RNs working in secondary nursing positions (13.6\%) and the 35-39 age-group had the least $(9.5 \%)$.

\section{Gender}

Study respondents $(n=43,331)$ were predominantly female $(92 \%) ; 8 \%$ were male.

\section{Initial Education and Highest Level of Education by Gender}

Results of initial nursing education by gender indicated that men were least prevalent in the diploma group (4.8\%) and DNP group $(1.5 \%)$ (Table 10$)$. 


\section{TABLE 10}

\section{Initial Nursing Education of RNs Employed in Nursing, by Gender}

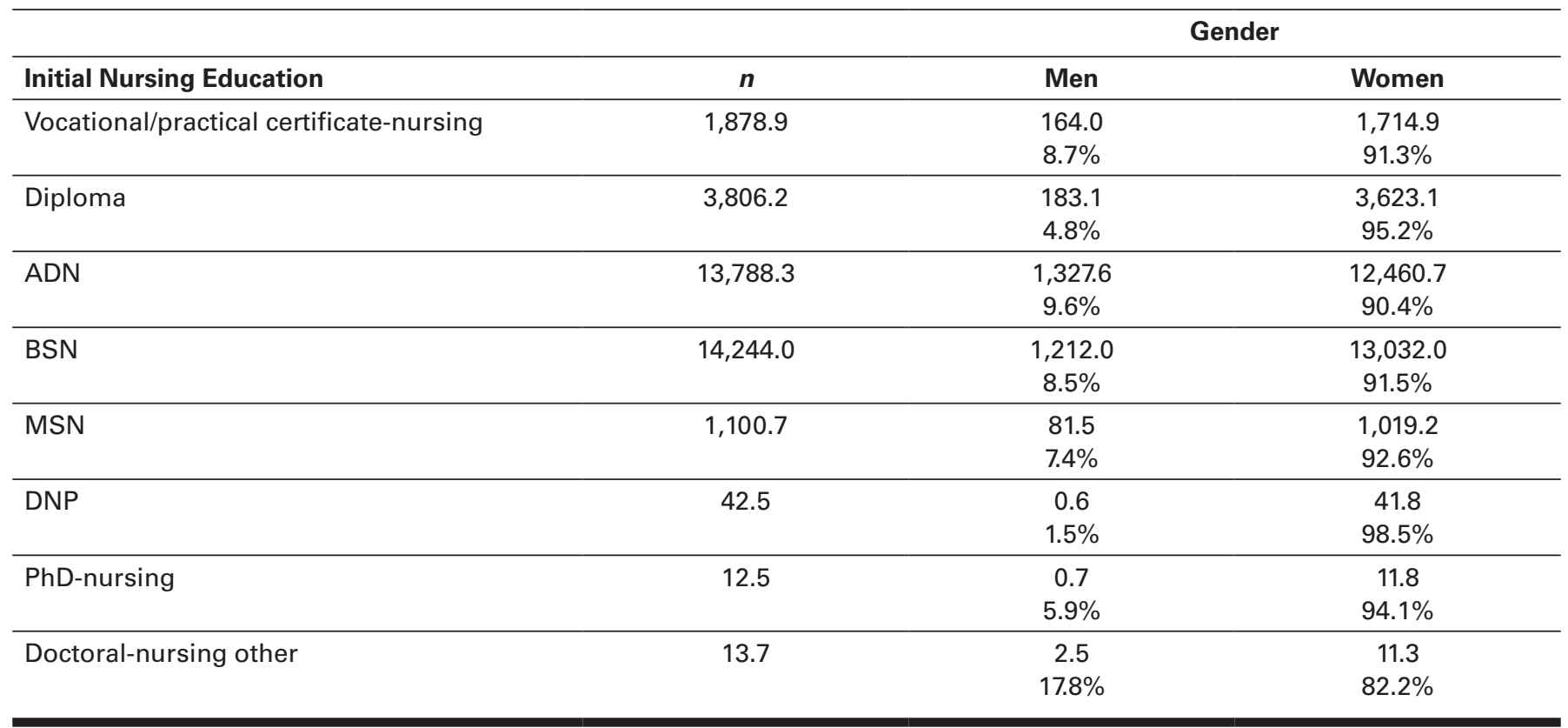

In terms of highest level of education, the degrees with the highest proportion of men were as follows: Doctoral-nursing other (27.8\%), Doctoral-other field (22.0\%), Associate's-other field (14.9\%), Baccalaureate-other field (14.8\%), and Master s-other field (14.6\%) (Table 11).

\section{TABLE 11}

\section{Highest Level of Education of RNs Employed in Nursing, by Gender}

\begin{tabular}{|c|c|c|c|}
\hline \multirow[b]{2}{*}{ Highest Level of Education } & \multirow[b]{2}{*}{$n$} & \multicolumn{2}{|c|}{ Gender } \\
\hline & & Men & Women \\
\hline Vocational/practical certificate-nursing & -- & -- & -- \\
\hline Diploma & & $3.7 \%$ & $96.3 \%$ \\
\hline ADN & $8,966.6$ & 724.3 & $8,242.2$ \\
\hline Associate's-other field & & $14.9 \%$ & $85.1 \%$ \\
\hline \multirow[t]{2}{*}{ BSN } & $13,443.3$ & 988.3 & $12,454.9$ \\
\hline & & $7.4 \%$ & $92.7 \%$ \\
\hline \multirow[t]{2}{*}{ Baccalaureate-other field } & $2,277.5$ & 337.5 & $1,940.1$ \\
\hline & & $14.8 \%$ & $85.2 \%$ \\
\hline Master's-other field & & $14.6 \%$ & $85.4 \%$ \\
\hline \multirow[t]{2}{*}{ DNP } & 311.7 & 25.3 & 286.3 \\
\hline & & $8.1 \%$ & $91.9 \%$ \\
\hline \multirow[t]{2}{*}{ PhD-nursing } & 192.4 & 10.8 & 181.7 \\
\hline & & $5.6 \%$ & $94.4 \%$ \\
\hline
\end{tabular}




\begin{tabular}{|c|c|c|c|}
\hline & \multirow[b]{2}{*}{$n$} & \multicolumn{2}{|c|}{ Gender } \\
\hline Highest Level of Education & & Men & Women \\
\hline Doctoral-nursing other & 19.2 & 5.3 & 13.9 \\
\hline \multirow[t]{2}{*}{ Doctoral-other field } & 203.7 & 44.8 & 158.9 \\
\hline & & $22.0 \%$ & $78.0 \%$ \\
\hline
\end{tabular}

\section{Year Licensed by Gender}

An examination of year licensed cohort by gender revealed a trend toward an increase in the proportion of males in the workforce (Table 12). Specifically, for respondents licensed prior to 2000, 5.8\% were male, while of those licensed between 2013 and 2015 , $14.1 \%$ were male.

\section{TABLE 12}

\section{Year Licensed, by Gender}

\begin{tabular}{|c|c|c|c|c|}
\hline Gender & \multicolumn{4}{|c|}{ Year Licensed } \\
\hline Female & $\begin{array}{c}19,966.7 \\
94.2 \%\end{array}$ & $\begin{array}{l}7,440.4 \\
90.2 \%\end{array}$ & $\begin{array}{c}3,370.5 \\
87.2 \%\end{array}$ & $\begin{array}{c}2,688.1 \\
86.0 \%\end{array}$ \\
\hline
\end{tabular}

Employment Setting, Title, and Specialty by Gender

An analysis of primary employment setting by gender indicated that the proportion of men, relative to women, were highest in the following employment settings: assisted living facility (12.0\%), correctional facility (15.1\%), and hospital (10.5\%) (Table 13).

\section{TABLE 13}

\section{Primary Employment Setting, by Gender}

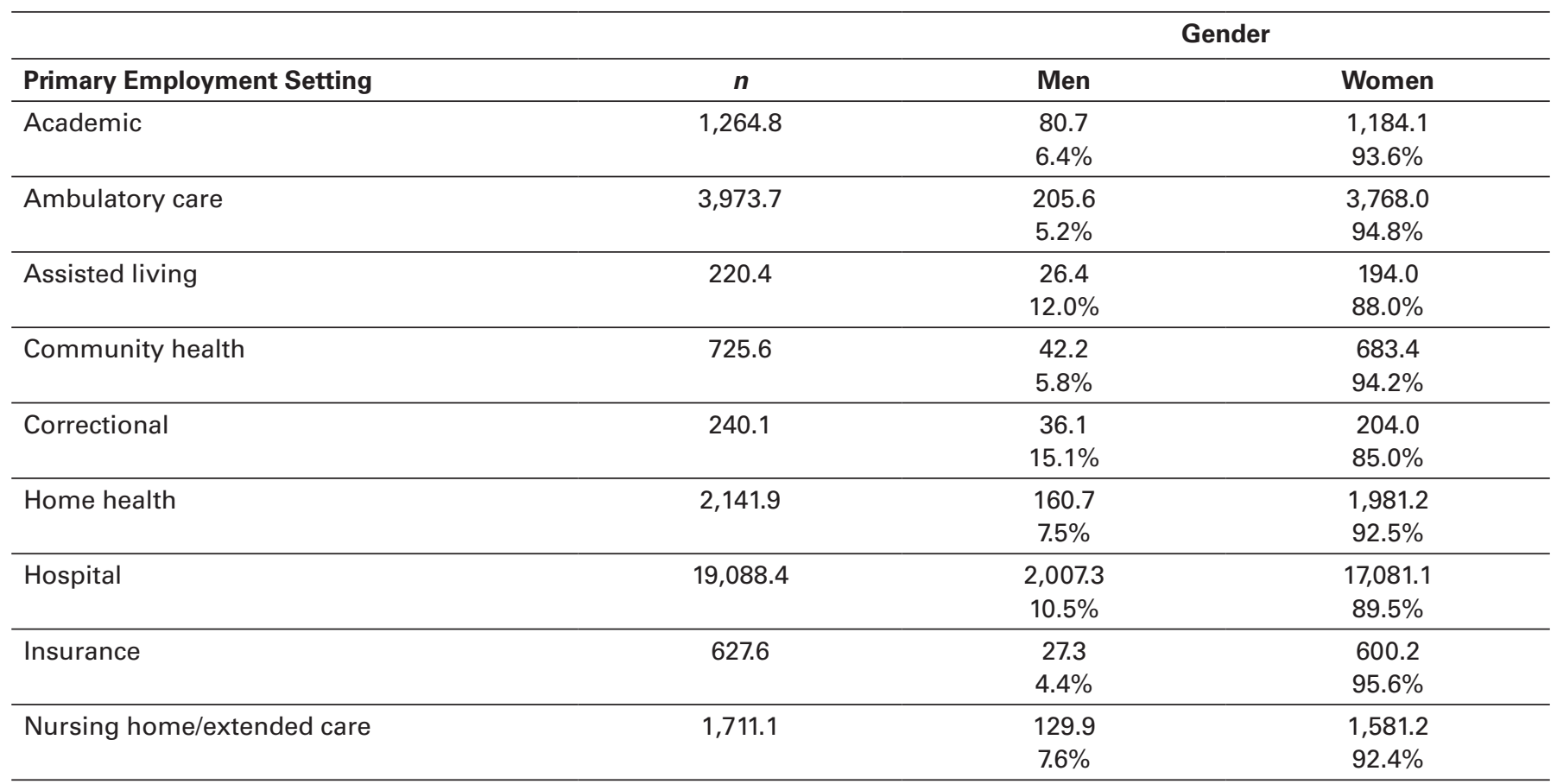




\begin{tabular}{|c|c|c|c|}
\hline \multirow[b]{2}{*}{ Primary Employment Setting } & \multirow[b]{2}{*}{$n$} & \multicolumn{2}{|c|}{ Gender } \\
\hline & & Men & Women \\
\hline Occupational health & 228.7 & 15.9 & 212.8 \\
\hline \multirow[t]{2}{*}{ Policy/regulatory/licensing } & 138.0 & 11.8 & 126.2 \\
\hline & & $8.6 \%$ & $91.5 \%$ \\
\hline \multirow[t]{2}{*}{ School health } & $1,031.7$ & 11.5 & $1,020.2$ \\
\hline & & $1.1 \%$ & $98.9 \%$ \\
\hline \multirow[t]{2}{*}{ Other } & $3,101.9$ & 234.9 & $2,867.0$ \\
\hline & & $7.6 \%$ & $92.4 \%$ \\
\hline
\end{tabular}

An analysis of primary position title by gender indicated that the position titles with the highest proportion of men, relative to women were: "advanced practice nurse" (11.9\%), followed by "staff nurse" (9.3\%), and "clinical nurse leader" (8.9\%) (Table 14). The job titles with the highest proportion of women, relative to men, were "case manager" (95.1\%) and "nurse researcher" (94.4\%).

\section{TABLE 14}

\section{Primary Position Title, by Gender}

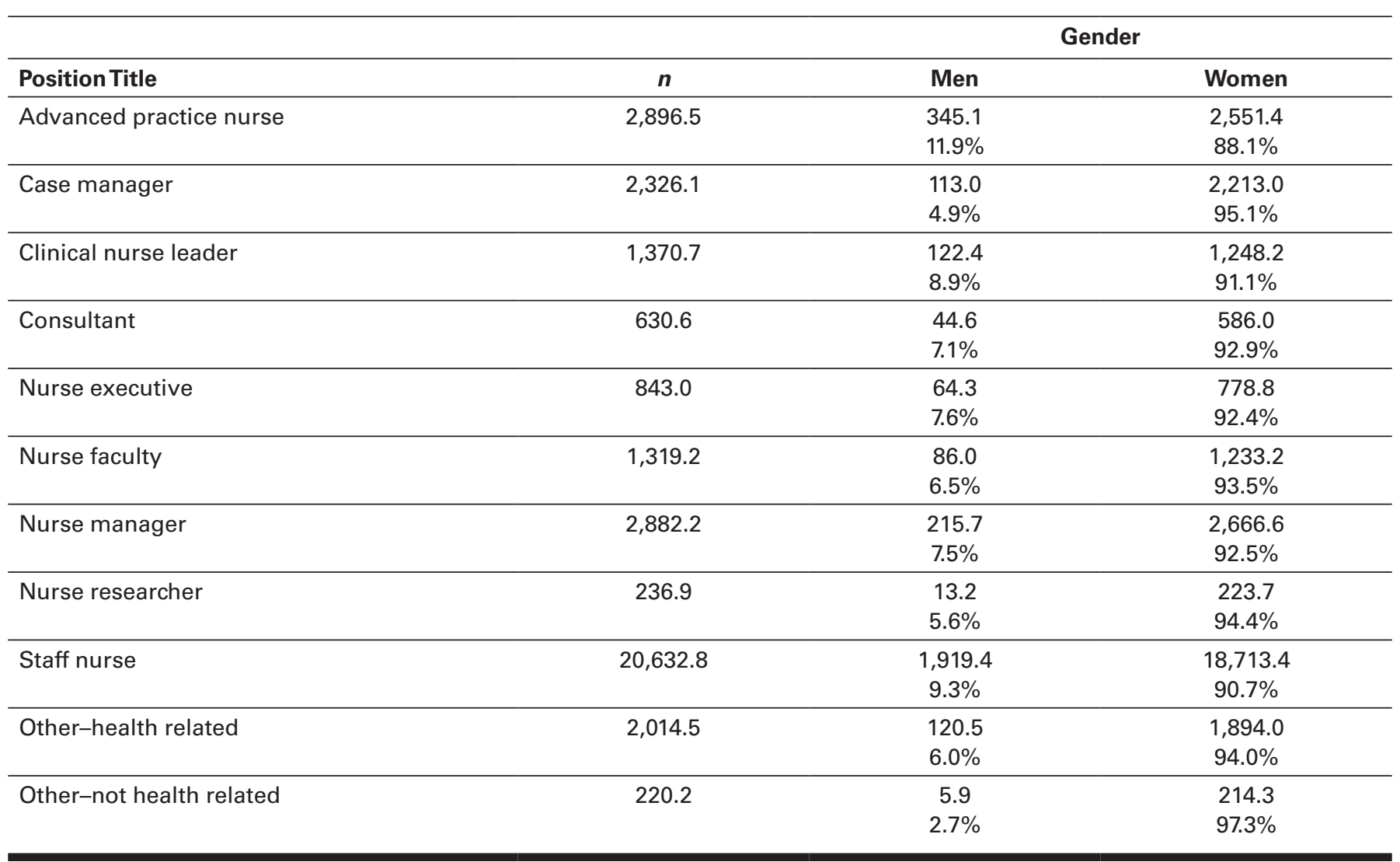

An analysis of primary employment specialty by gender indicated that the proportion of men, relative to women, was highest in the following employment specialties: anesthesia, emergency/trauma, acute care/critical care, psychiatric/mental health/substance abuse, nephrology, rehabilitation, and informatics (Table 15). The proportion of men, relative to women, was lowest in the following employment specialties: maternal-child health, neonatal, school health, and women's health. 


\section{TABLE 15}

\section{Primary Employment Specialty, by Gender}

\begin{tabular}{|c|c|c|c|}
\hline \multirow[b]{2}{*}{ Primary Employment Specialty } & \multicolumn{3}{|c|}{ Gender } \\
\hline & $n$ & Men & Women \\
\hline Acute care/critical care & $3,885.7$ & 591.1 & $3,294.7$ \\
\hline \multirow[t]{2}{*}{ Adult health/family health } & 708.4 & 50.2 & 658.2 \\
\hline & & $7.1 \%$ & $92.9 \%$ \\
\hline \multirow[t]{2}{*}{ Community } & 337.9 & 19.5 & 318.4 \\
\hline & & $5.8 \%$ & $94.2 \%$ \\
\hline \multirow[t]{2}{*}{ Emergency/trauma } & $1,867.4$ & 332.7 & $1,534.7$ \\
\hline & & $17.8 \%$ & $82.2 \%$ \\
\hline Genetics & 35.3 & 1.7 & 33.6 \\
\hline \multirow[t]{2}{*}{ Home health } & $1,493.3$ & 125.2 & $1,368.1$ \\
\hline & & $8.4 \%$ & $91.6 \%$ \\
\hline \multirow[t]{2}{*}{ Informatics } & 298.3 & 31.9 & 266.5 \\
\hline & & $10.7 \%$ & $89.3 \%$ \\
\hline \multirow[t]{2}{*}{ Maternal-child health } & $1,537.6$ & 3.1 & $1,534.4$ \\
\hline & & $0.2 \%$ & $99.8 \%$ \\
\hline \multirow[t]{2}{*}{ Medical-surgical } & $3,486.5$ & 327.6 & $3,158.9$ \\
\hline & & $9.4 \%$ & $90.6 \%$ \\
\hline \multirow[t]{2}{*}{ Neonatal } & 769.1 & 14.4 & 754.8 \\
\hline & & $1.9 \%$ & $98.1 \%$ \\
\hline \multirow[t]{2}{*}{ Oncology } & 989.8 & 47.8 & 942.0 \\
\hline & & $4.8 \%$ & $95.2 \%$ \\
\hline \multirow[t]{2}{*}{ Orthopedic } & 407.8 & 26.1 & 381.7 \\
\hline & & $6.4 \%$ & $93.6 \%$ \\
\hline \multirow[t]{2}{*}{ Palliative care/hospice } & 491.0 & 13.3 & 477.7 \\
\hline & & $2.7 \%$ & $97.3 \%$ \\
\hline \multirow[t]{2}{*}{ Pediatrics } & $1,469.8$ & 33.8 & $1,436.0$ \\
\hline & & $2.3 \%$ & $97.7 \%$ \\
\hline \multirow[t]{2}{*}{ Perioperative } & $2,051.8$ & 159.1 & $1,892.7$ \\
\hline & & $7.8 \%$ & $92.3 \%$ \\
\hline Primary care & $1,005.3$ & 74.6 & 930.7 \\
\hline & & $7.4 \%$ & $92.6 \%$ \\
\hline Psychiatric/mental health/substance abuse & $1,337.3$ & 189.4 & $1,148.0$ \\
\hline & & $14.2 \%$ & $85.8 \%$ \\
\hline Public health & 445.4 & 30.9 & 414.6 \\
\hline & & $6.9 \%$ & $93.1 \%$ \\
\hline Radiology & 185.6 & 15.7 & 170.0 \\
\hline & & $8.5 \%$ & $91.5 \%$ \\
\hline
\end{tabular}




\begin{tabular}{|c|c|c|c|}
\hline \multirow[b]{2}{*}{ Primary Employment Specialty } & \multicolumn{3}{|c|}{ Gender } \\
\hline & $n$ & Men & Women \\
\hline Rehabilitation & 687.5 & 80.7 & 606.8 \\
\hline \multirow[t]{2}{*}{ School health } & 965.9 & 11.3 & 954.7 \\
\hline & & $1.2 \%$ & $98.8 \%$ \\
\hline \multirow[t]{2}{*}{ Women's health } & 621.3 & 3.0 & 618.3 \\
\hline & & $0.5 \%$ & $99.5 \%$ \\
\hline \multirow[t]{2}{*}{ Other } & $5,820.9$ & 411.7 & $5,409.2$ \\
\hline & & $7.1 \%$ & $92.9 \%$ \\
\hline
\end{tabular}

Race/Ethnicity

The current study found that $19.5 \%$ of responding RNs identified themselves with a minority population (Table 16).

\section{TABLE 16}

\section{Race/Ethnicity}

\begin{tabular}{lcc}
\hline & $(\boldsymbol{n}=\mathbf{4 5 , 9 8 9 . 3 )}$ & Percentage \\
\hline American Indian or Alaska Native & 198.5 & $0.4 \%$ \\
\hline Asian & $3,053.0$ & $6.6 \%$ \\
\hline Black/African American & $2,549.9$ & $5.5 \%$ \\
\hline Native Hawaiian or Other Pacific Islander & 171.8 & $0.4 \%$ \\
\hline White/Caucasian & $37,003.0$ & $80.5 \%$ \\
\hline Hispanic/Latino & $1,654.0$ & $3.6 \%$ \\
\hline Other & 390.8 & $0.8 \%$ \\
\hline Mixed & 968.4 & $2.1 \%$ \\
\hline
\end{tabular}

Note. Respondents were asked to mark all that applied for Race/Ethnicity. However, responses were coded to be mutually exclusive. If respondents selected multiple options, they were coded as Mixed Race/Ethnicity.

\section{Advanced Practice Registered Nurses by Race/Ethnicity}

An examination of advanced practice preparation by race/ethnicity revealed that the specialty with the highest level of diversity was certified nurse midwife (79.3\% White/Caucasian), while the specialty with the lowest level of diversity was certified registered nurse anesthetist (97.9\% White/Caucasian) (Table 17).

\section{TABLE 17}

\section{Advanced Practice Preparation of RNs, by Race/Ethnicity}

\begin{tabular}{lccccccccc}
\hline & \multicolumn{1}{c}{ Race/Ethnicity } \\
\hline $\begin{array}{l}\text { Advanced Practice } \\
\text { Preparation }\end{array}$ & $\boldsymbol{n}$ & $\begin{array}{c}\text { American } \\
\text { Indian or } \\
\text { Alaska } \\
\text { Native }\end{array}$ & Asian & $\begin{array}{c}\text { Black/ } \\
\text { African } \\
\text { American }\end{array}$ & $\begin{array}{c}\text { Native } \\
\text { Hawailan } \\
\text { or Other } \\
\text { Pacific } \\
\text { Islander }\end{array}$ & $\begin{array}{c}\text { White/ } \\
\text { Caucasian }\end{array}$ & $\begin{array}{c}\text { Hispanic/ } \\
\text { Latino }\end{array}$ & Other & Mixed \\
Nurse practitioner & $2,862.1$ & 5.5 & 170.7 & 185.4 & 11.5 & $2,280.1$ & 112.2 & 15.1 & 81.7 \\
\hline Clinical nurse spe- & 463.1 & $0.2 \%$ & $6.0 \%$ & $6.5 \%$ & $0.4 \%$ & $79.7 \%$ & $3.9 \%$ & $0.5 \%$ & $2.9 \%$ \\
cialist & 0.8 & 32.8 & 22.1 & 0.1 & 389.6 & 14.5 & 1.9 & 1.2 \\
\hline
\end{tabular}




\begin{tabular}{lcccccccccc}
\hline & \multicolumn{1}{c}{ Race/Ethnicity } \\
\hline $\begin{array}{l}\text { Advanced Practice } \\
\text { Preparation }\end{array}$ & $\boldsymbol{n}$ & $\begin{array}{c}\text { American } \\
\text { Indian or } \\
\text { Alaska } \\
\text { Native }\end{array}$ & Asian & $\begin{array}{c}\text { Black/ } \\
\text { African } \\
\text { American }\end{array}$ & $\begin{array}{c}\text { Native } \\
\text { Hawailan } \\
\text { or Other } \\
\text { Pacific } \\
\text { Islander }\end{array}$ & $\begin{array}{c}\text { White/ } \\
\text { Caucasian }\end{array}$ & $\begin{array}{c}\text { Hispanic/ } \\
\text { Latino }\end{array}$ & $\begin{array}{c}\text { Other } \\
\text { Mixed }\end{array}$ \\
\hline $\begin{array}{l}\text { Certified registered } \\
\text { nurse anesthetist }\end{array}$ & 512.0 & 3.5 & 12.1 & 20.0 & 1.2 & 453.4 & 3.9 & 8.0 & 9.9 \\
\hline $\begin{array}{l}\text { Certified nurse } \\
\text { midwife }\end{array}$ & 136.0 & $0.8 \%$ & $2.6 \%$ & $4.3 \%$ & $0.3 \%$ & $97.9 \%$ & $0.8 \%$ & $1.7 \%$ & $2.1 \%$ \\
\hline
\end{tabular}

Note. In some states, the position title of "clinical nurse specialist" (CNS) is not legally limited to RNs who have CNS preparation of certification. Respondents that indicated "Clinical nurse specialist" without a master's degree or higher were removed from this analysis. Respondents were asked to mark all that applied for Race/Ethnicity. However, responses were coded to be mutually exclusive. If respondents selected multiple options, they were coded as Mixed Race/Ethnicity.

Year Licensed by Race/Ethnicity

As compared to those licensed prior to 2000, newly licensed nurses were more likely to have a more diverse racial/ethnic composition. In particular, the most recent licensed cohort showed increased percentages of RNs of Asian and Hispanic/Latino descent (Table 18).

\section{TABLE 18}

\section{Year Licensed, by Race/Ethnicity}

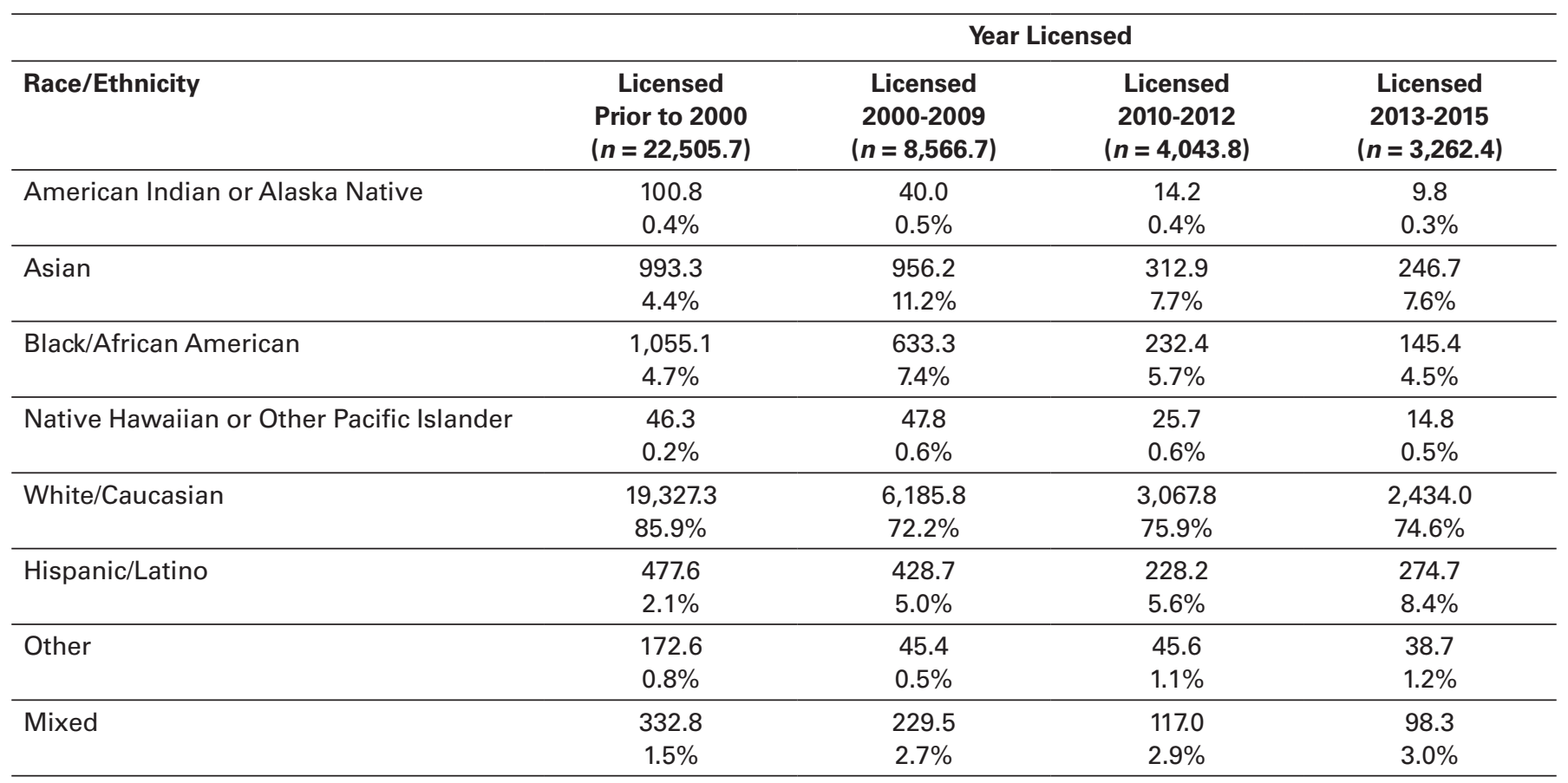

Note. Respondents were asked to mark all that applied for Race/Ethnicity. However, responses were coded to be mutually exclusive. If respondents selected multiple options, they were coded as Mixed Race/Ethnicity.

\section{Position Title by Race/Ethnicity}

An examination of primary position title by race/ethnicity found that nurse faculty had the least diversity and staff nurse had the most diversity. Specifically, $85.5 \%$ of nurse faculty identified as White/Caucasian, while this percentage dropped to $76.9 \%$ for staff nurse (Table 19). 


\section{TABLE 19}

\section{Primary Position Title, by Race/Ethnicity}

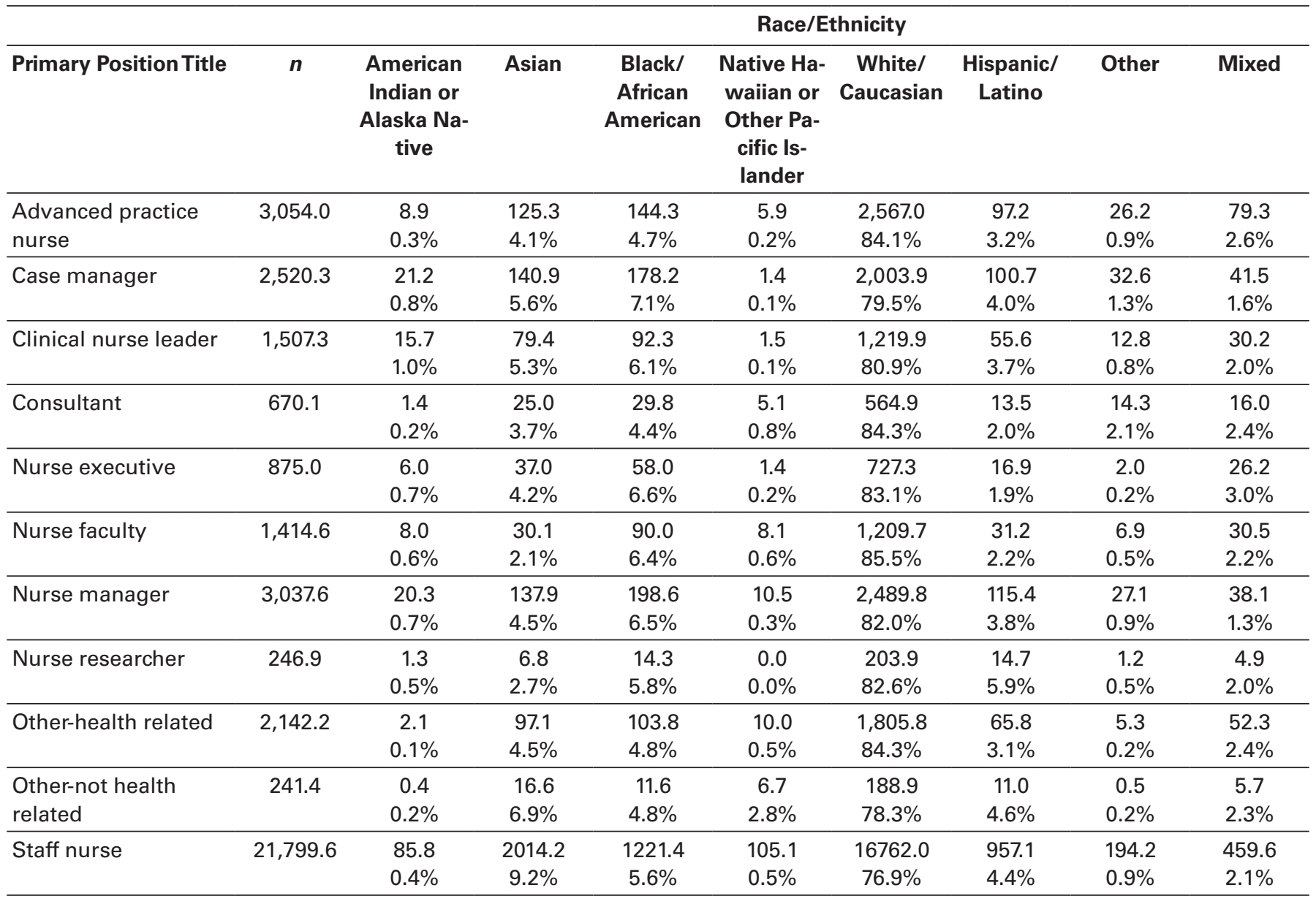

Note. Respondents were asked to mark all that applied for Race/Ethnicity. However, responses were coded to be mutually exclusive. If respondents selected multiple options they were coded as Mixed Race/Ethnicity.

\section{Education}

The current study found an increase in the percentage of respondents with a BSN as their initial nursing education. Specifically, in $2013,36 \%$ indicated a BSN as their initial nursing education, while in $201539.0 \%$ indicated this. Additionally, in the current study, almost $42 \%$ of RNs held either a BSN (39.0\%) or graduate degree (3.0\%) as their initial credential (Table 20). In comparison, in 2013, approximately $39 \%$ of RNs held either a BSN (36\%) or graduate degree (3.0\%)

\section{TABLE 20}

\section{Type of Nursing Degree/Credential That Qualified Respondents for First U.S. Nursing License}

\begin{tabular}{lcc}
\hline & $(\boldsymbol{n}=\mathbf{4 5 , 8 3 5 . 8 )}$ & Percentage \\
\hline Vocational/practical certificate-nursing & $2,442.1$ & $5.3 \%$ \\
\hline Diploma-nursing & $6,539.3$ & $14.3 \%$ \\
\hline ADN & $17,625.9$ & $38.5 \%$ \\
\hline BSN & $17,853.4$ & $39.0 \%$ \\
\hline MSN & $1,297.9$ & $2.8 \%$ \\
\hline Doctoral degree-nursing (DNP) & 45.6 & $0.1 \%$ \\
\hline Doctoral degree-nursing (PhD) & 14.8 & $0.0 \%$ \\
\hline
\end{tabular}




\section{Level of Education}

When asked to indicate highest level of education, $65 \%$ of respondents in the current study indicated that they had obtained a baccalaureate or higher degree (Table 21).

\section{TABLE 21}

\section{Highest Level of Education}

\begin{tabular}{lcc}
\hline & $(\boldsymbol{n}=\mathbf{4 4 , 5 8 6 . 2 )}$ & Percentage \\
\hline Vocational/practical certificate-nursing & -- & -- \\
\hline Diploma-nursing & $3,551.3$ & $8.0 \%$ \\
\hline ADN & $11,608.8$ & $26.0 \%$ \\
\hline Associate's degree-other field & 247.0 & $0.6 \%$ \\
\hline BSN & $16,762.5$ & $37.6 \%$ \\
\hline Baccalaureate degree-other field & $3,143.3$ & $7.1 \%$ \\
\hline MSN & $6,085.1$ & $13.6 \%$ \\
\hline Master's degree-other field & $2,199.7$ & $4.9 \%$ \\
\hline Doctoral degree-nursing practice (DNP) & 340.2 & $0.8 \%$ \\
\hline Doctoral degree-nursing (PhD) & 239.1 & $0.5 \%$ \\
\hline Doctoral degree-nursing other & 39.0 & $0.1 \%$ \\
\hline Doctoral degree-other field & 370.3 & $0.8 \%$
\end{tabular}

\section{Year Licensed by Education}

An examination of year licensed cohort by initial education suggested a decreasing trend for initial education of vocational/practical certificate-nursing and an increasing trend for ADN and BSN degrees (Table 22).

\section{TABLE 22}

\section{Year Licensed, by Initial Nursing Education}

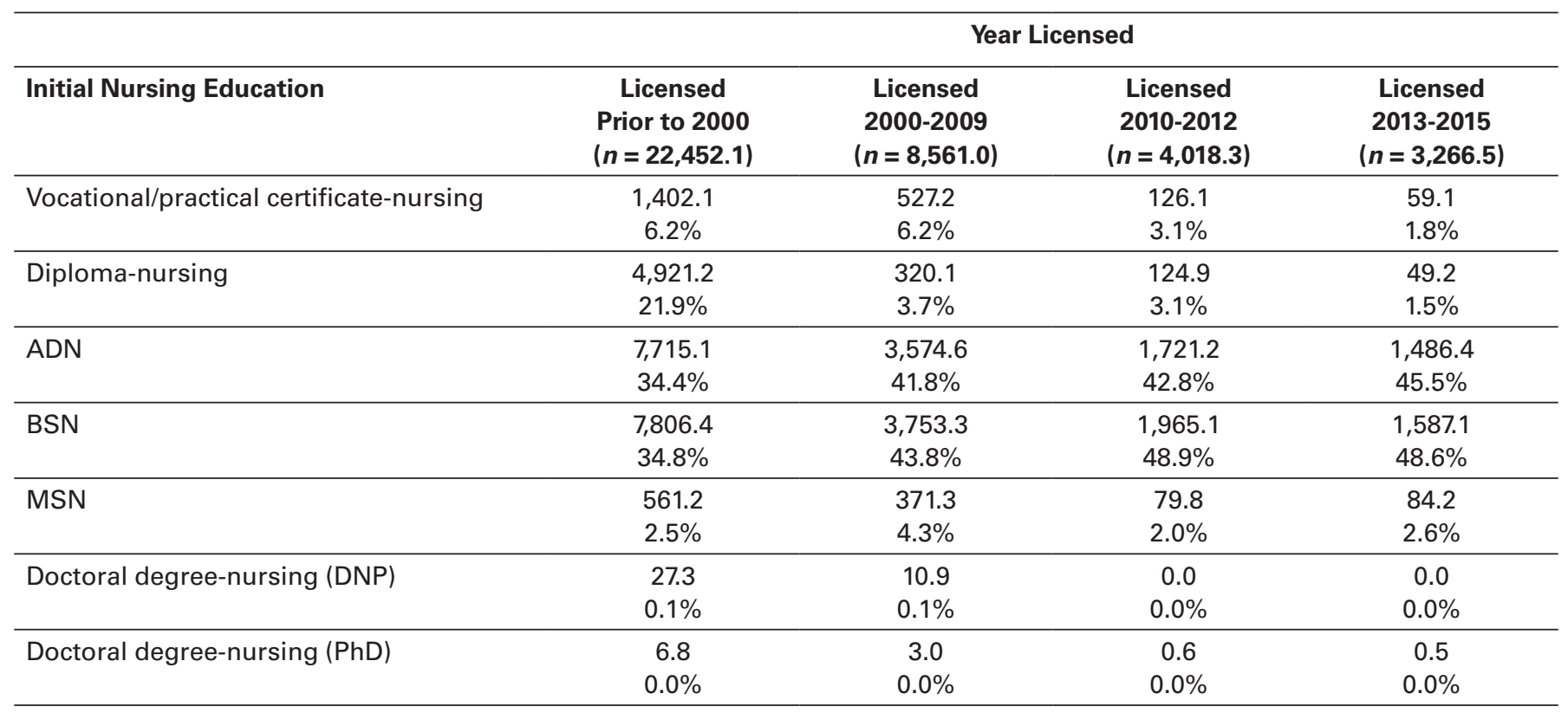


Year Licensed

Initial Nursing Education

Licensed

Prior to 2000

( $n=22,452.1)$

Doctoral degree-nursing other

7.9
$0.0 \%$

$0.0 \%$

\section{Position Title by Level of Education}

Job titles were compared with highest level of education (Table 23). Of respondents who indicated "staff nurse" as their primary nursing practice position title, $46.0 \%$ had BSN as highest level of education, while only $4.3 \%$ indicated MSN as highest level of education. In terms of nurse faculty, these respondents' highest level of education was as follows: MSN (35.8\%), DNP (4.8\%), PhD-nursing (7.8\%), doctoral-nursing other (1.1\%), doctoral-other field (4.0\%).

\section{TABLE 23}

\section{Primary Position Title, by Highest Level of Education}

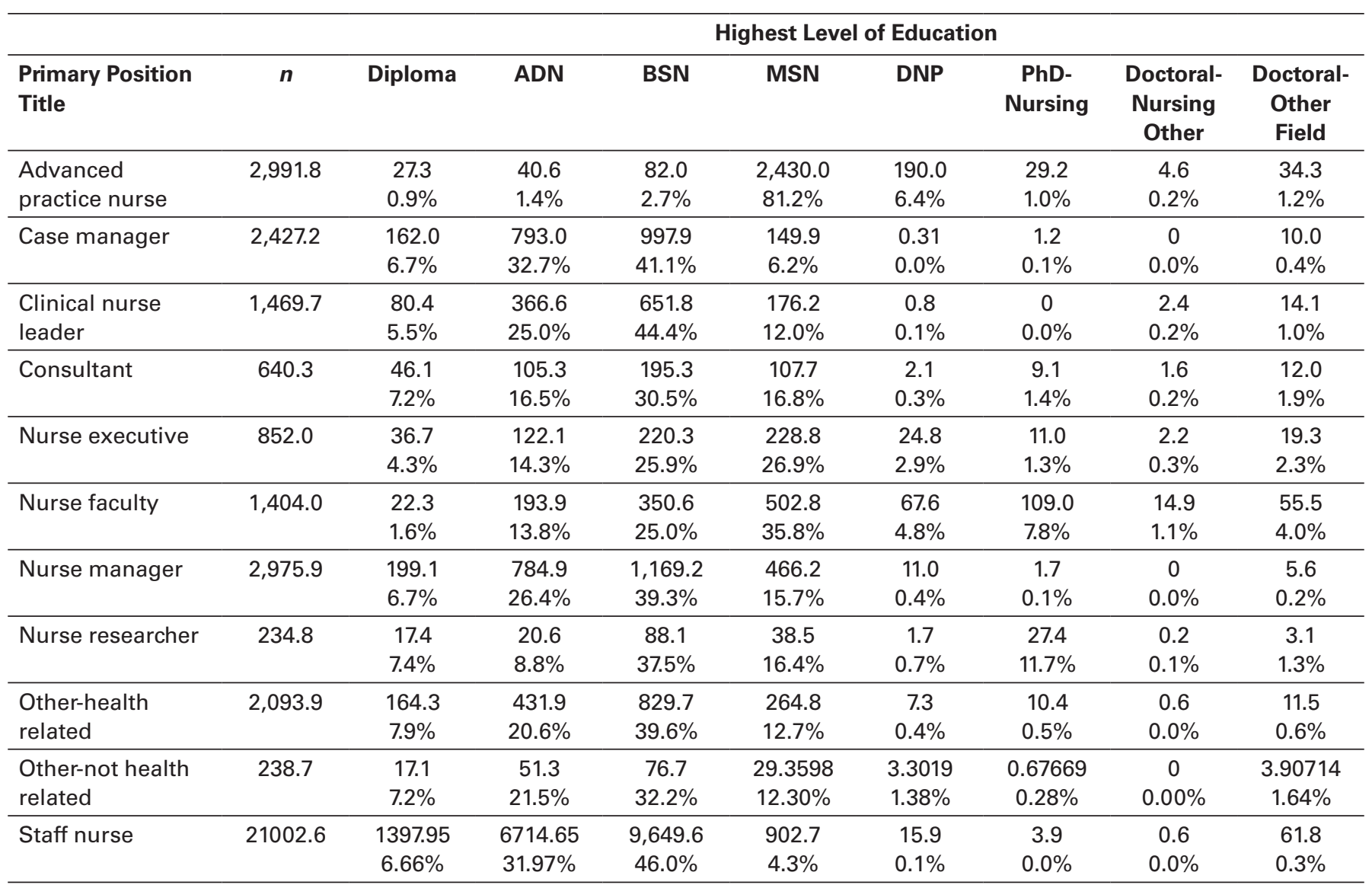

Note. Only a portion of the highest level of education categories are shown; hence, percentages will not sum to $100 \%$.

\section{Employment}

In the employment section of the survey, participants were asked about primary and secondary positions. Respondents were given the following definitions:

- Primary position: The position at which you work the most hours during your regular work year.

- Secondary position: The position at which you work the second greatest number of hours during your regular work year.

- Per diem: An arrangement wherein a nurse is employed directly on an as-needed basis and usually has no benefits. 
The current study's results revealed $81.1 \%$ of RN licensees were actively employed in nursing and $62.9 \%$ of RN licensees were employed full time (Table 24).

\section{TABLE 24}

\section{Employment Status}

\begin{tabular}{lcc}
\hline & $(\boldsymbol{n}=\mathbf{4 6 , 2 1 0 . 2 )}$ & Percentage \\
\hline Actively employed in nursing & $37,488.6$ & $81.1 \%$ \\
\hline Full time & $29,088.5$ & $62.9 \%$ \\
\hline Part time & $6,088.0$ & $13.2 \%$ \\
\hline Per diem & $3,675.2$ & $8.0 \%$ \\
\hline Actively employed in a field other than nursing & $2,752.6$ & $6.0 \%$ \\
\hline Full time & $1,576.1$ & $3.4 \%$ \\
\hline Part time & 850.8 & $1.8 \%$ \\
\hline Per diem & 377.7 & $0.8 \%$ \\
\hline Employed fully outside of nursing & $1,539.4$ & $3.3 \%$ \\
\hline Working in nursing only as a volunteer & $5.2 \%$ \\
\hline Unemployed & 564.5 & $2.3 \%$ \\
\hline Seeking work as a nurse & $3.5 \%$ \\
\hline Not seeking work as a nurse & $1,070.7$ \\
\hline Retired & $1,611.6$ & $10.8 \%$ \\
\hline Note. Respondents were asked to mark all that applied. Percentages are calculated off of responding sample. & \\
\hline
\end{tabular}

\section{The Unemployed}

Of respondents who indicated they were unemployed (although not retired), half (50.0\%) indicated the reason was because of taking care of home and family (Table 25). This was approximately the same as what was found in 2013. Only $15.5 \%$ of those who gave a reason for unemployment indicated difficulty in finding a nursing position. This was a drop from $27 \%$ in 2013.

\section{TABLE 25}

\section{Reasons for Unemployment}

\begin{tabular}{lcr}
\hline & $(\boldsymbol{n}=\mathbf{2 , 2 7 2 . 4 )}$ & Percentage \\
\hline Taking care of home and family & $1,137.3$ & $50.0 \%$ \\
\hline Disabled & 298.5 & $13.1 \%$ \\
\hline Inadequate salary & 48.2 & $2.1 \%$ \\
\hline In school & 143.1 & $6.3 \%$ \\
\hline Difficulty in finding a nursing position & 352.0 & $15.5 \%$ \\
\hline Other, please specify & 625.9 & $27.5 \%$ \\
\hline
\end{tabular}

Note. Respondents were asked to mark all that applied.

\section{Employment by Education}

Study results of respondents who indicated they were actively employed by highest level of education showed that respondents with an ADN (83.0\%), BSN (85.1\%), MSN (87.3\%), DNP (97.1\%), and PhD-nursing (83.7\%) had the highest rate of active employment in nursing (Table 26). Respondents with their highest degree in other fields tended to be less likely to have been actively employed in nursing. 


\section{TABLE 26}

\section{Employment Status by Highest Level of Education}

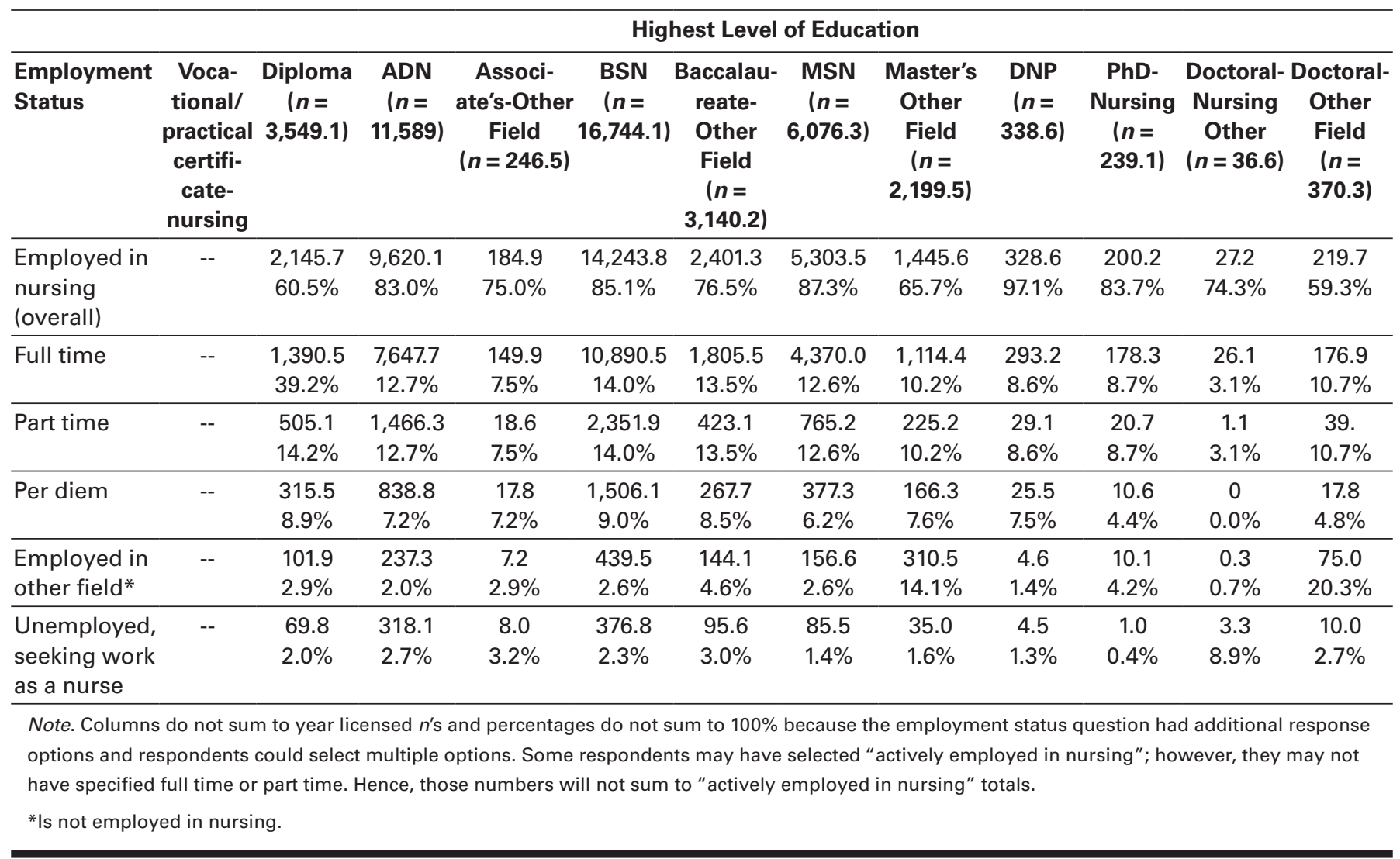

\section{Employment by Position, Setting, Title, and Specialty}

An examination of the number of positions respondents were currently employed in as an $\mathrm{RN}$ revealed that approximately $12.8 \%$ of employed licensees held more than one nursing position; $2.4 \%$ held three or more positions. Additionally, $15.0 \%$ of those with full-time jobs held two or more nursing positions and $17.2 \%$ of those with a primary part-time job held two or more positions.

The current study's results indicated $54.4 \%$ of respondents' primary employment setting was a hospital, followed by $11.2 \%$ of RNs in ambulatory care, $6.1 \%$ in home health, and $4.8 \%$ in nursing homes (Table 27). Of the respondents indicating they held a secondary nursing position, the most common (39.2\%) secondary employment setting was a hospital.

\section{TABLE 27}

\section{Primary Employment Setting}

\begin{tabular}{lcr}
\hline & (n= 37,372.1) & Percentage \\
\hline Academic & $1,357.0$ & $3.6 \%$ \\
\hline Ambulatory care & $4,201.1$ & $11.2 \%$ \\
\hline Assisted living & 233.3 & $0.6 \%$ \\
\hline Community health & 786.9 & $2.1 \%$ \\
\hline Correctional & 259.6 & $0.7 \%$ \\
\hline Home health & $2,288.0$ & $6.1 \%$ \\
\hline Hospital & $20,311.9$ & $54.4 \%$ \\
\hline Insurance & 673.7 & $1.8 \%$ \\
\hline Nursing home/extended care & $1,807.2$ & $4.8 \%$ \\
\hline Occupational health & 250.3 & $0.7 \%$ \\
\hline
\end{tabular}




\begin{tabular}{lcc}
\hline & $(\boldsymbol{n}=\mathbf{3 7 , 3 7 2 . 1 )}$ & Percentage \\
\hline Policy/regulatory/licensing & 148.7 & $0.4 \%$ \\
\hline Public health & 595.4 & $1.6 \%$ \\
\hline School health & $1,092.8$ & $2.9 \%$ \\
\hline Other & $3,366.3$ & $9.0 \%$ \\
\hline
\end{tabular}

Note. Survey participants were asked to answer this question only if they were actively employed in nursing.

The current study's results indicated $58.1 \%$ of respondents' primary job title was "staff nurse" and $8.1 \%$ of RNs identified as "advanced practice nurse" (Table 28). The largest number of secondary position titles was "staff nurse" (53.6\%), followed by $10.8 \%$ of RNs reporting a secondary position as "nurse faculty." Ten percent reported a secondary position as "advanced practice nurse."

\section{TABLE 28}

\section{Primary Position Title}

\begin{tabular}{lcc}
\hline & (n= 37,711.1) & Percentage \\
\hline Advanced practice nurse & $3,069.1$ & $8.1 \%$ \\
\hline Case manager & $2,524.8$ & $6.7 \%$ \\
\hline Clinical nurse leader & $1,514.1$ & $4.0 \%$ \\
\hline Consultant & 672.4 & $1.8 \%$ \\
\hline Nurse executive & 881.4 & $2.3 \%$ \\
\hline Nurse faculty & $1,422.2$ & $3.8 \%$ \\
\hline Nurse manager & $3,045.8$ & $8.1 \%$ \\
\hline Nurse researcher & 247.2 & $0.7 \%$ \\
\hline Other-health related & $2,171.0$ & $5.8 \%$ \\
\hline Other-not health related & 242.5 & $0.6 \%$ \\
\hline Staff nurse & $21,920.7$ & $58.1 \%$ \\
\hline
\end{tabular}

Note. Survey participants were asked to answer this question only if they were actively employed in nursing.

In the current study, $11.4 \%$ of RNs reported their primary practice specialty as acute care/critical care, followed by $10.2 \%$ who reported a medical-surgical specialty, $5.6 \%$ who reported an emergency/trauma specialty, and $6.0 \%$ who reported a perioperative care specialty (Table 29). RNs reported specializing in population-specific care - $4.8 \%$ reported a geriatric specialty and $4.3 \%$ reported a pediatric specialty; $4.8 \%$ of RNs reported maternal-child health as a specialty. All other specialty positions were reported to be less than $5 \%$. Rehabilitation and women's health were both identified as a specialty by approximately $2 \%$ of RNs. For secondary specialty, $8.2 \%$ of RNs reported secondary specialty in acute care/critical care or home health and $22.0 \%$ reported "other" as a specialty.

\section{TABLE 29}

\section{Primary Employment Specialty}

\begin{tabular}{lcc}
\hline & $(\boldsymbol{n}=\mathbf{3 6 , 4 2 4 . 1 )}$ & Percentage \\
\hline Acute care/critical care & $4,159.1$ & $11.4 \%$ \\
\hline Adult health/family health & 756.1 & $2.1 \%$ \\
\hline Anesthesia & 549.9 & $1.5 \%$ \\
\hline Community & 356.7 & $1.0 \%$ \\
\hline Emergency/trauma & $2,026.7$ & $5.6 \%$ \\
\hline Genetics & 40.6 & $0.1 \%$ \\
\hline Geriatric/gerontology & $1,754.7$ & $4.8 \%$ \\
\hline Home health & $1,604.0$ & $4.4 \%$ \\
\hline Informatics & 318.2 & $0.9 \%$ \\
\hline
\end{tabular}




\begin{tabular}{|c|c|c|}
\hline & $(n=36,424.1)$ & Percentage \\
\hline Maternal-child health & $1,633.9$ & $4.5 \%$ \\
\hline Medical-surgical & $3,695.7$ & $10.2 \%$ \\
\hline Nephrology & 476.4 & $1.3 \%$ \\
\hline Neurology/neurosurgical & 337.1 & $0.9 \%$ \\
\hline Oncology & $1,044.0$ & $2.9 \%$ \\
\hline Orthopedic & 436.1 & $1.2 \%$ \\
\hline Palliative care/hospice & 529.1 & $1.5 \%$ \\
\hline Pediatrics & $1,570.3$ & $4.3 \%$ \\
\hline Perioperative & $2,195.7$ & $6.0 \%$ \\
\hline Public health & 466.0 & $1.3 \%$ \\
\hline Radiology & 191.2 & $0.5 \%$ \\
\hline Rehabilitation & 717.3 & $2.0 \%$ \\
\hline School health & $1,025.1$ & $2.8 \%$ \\
\hline Urologic & 87.5 & $0.2 \%$ \\
\hline Women's health & 651.7 & $1.8 \%$ \\
\hline Other & $6,200.8$ & $17.0 \%$ \\
\hline
\end{tabular}

Note. Survey participants were asked to answer this question only if they were actively employed in nursing.

\section{Year Licensed by Employment Status and Setting}

Results of an analysis of year licensed cohort by employment status revealed that those most recently licensed had a higher percentage rate for employment in nursing (Table 30). Approximately 93\% of those licensed from 2013 to 2015 were employed as compared to RNs licensed prior to 2000 (74.1\%). Additionally, RNs licensed from 2013 to 2015 had the highest unemployed and seeking work as a nurse rate $(4.6 \%)$.

\section{TABLE 30}

\section{Year Licensed, by Employment Status}

\begin{tabular}{|c|c|c|c|c|}
\hline Employment Status & \multicolumn{4}{|c|}{ Year Licensed } \\
\hline Employed in nursing (overall) & $\begin{array}{c}16,763.3 \\
74.1 \%\end{array}$ & $\begin{array}{c}7,913.6 \\
92.0 \%\end{array}$ & $\begin{array}{c}3,806.4 \\
94.0 \%\end{array}$ & $\begin{array}{c}3,048.7 \\
93.1 \%\end{array}$ \\
\hline Full time & $\begin{array}{c}12,359.7 \\
54.6 \%\end{array}$ & $\begin{array}{l}6,317.2 \\
73.5 \%\end{array}$ & $\begin{array}{c}3,136.8 \\
77.5 \%\end{array}$ & $\begin{array}{c}2,748.0 \\
83.9 \%\end{array}$ \\
\hline Part time & $\begin{array}{c}3,235.01 \\
14.3 \%\end{array}$ & $\begin{array}{c}1,151.0 \\
13.4 \%\end{array}$ & $\begin{array}{l}412.7 \\
10.2 \%\end{array}$ & $\begin{array}{c}253.6 \\
7.7 \%\end{array}$ \\
\hline Per diem & $\begin{array}{c}1,815.1 \\
8.0 \%\end{array}$ & $\begin{array}{l}724.2 \\
8.4 \%\end{array}$ & $\begin{array}{l}396.4 \\
9.8 \%\end{array}$ & $\begin{array}{l}147.9 \\
4.5 \%\end{array}$ \\
\hline Employed in other field* & $\begin{array}{c}1,014.7 \\
4.5 \%\end{array}$ & $\begin{array}{l}164.8 \\
1.9 \%\end{array}$ & $\begin{array}{l}61.8 \\
1.5 \%\end{array}$ & $\begin{array}{l}48.2 \\
1.5 \%\end{array}$ \\
\hline
\end{tabular}




\begin{tabular}{|c|c|c|c|c|}
\hline \multirow[b]{2}{*}{ Employment Status } & \multicolumn{4}{|c|}{ Year Licensed } \\
\hline & $\begin{array}{c}\text { Licensed } \\
\text { Prior to } 2000 \\
(n=22,633.4)\end{array}$ & $\begin{array}{c}\text { Licensed } \\
2000-2009 \\
(n=8,599.4)\end{array}$ & $\begin{array}{c}\text { Licensed } \\
2010-2012 \\
(n=4,049.2)\end{array}$ & $\begin{array}{c}\text { Licensed } \\
2013-2015 \\
(n=3,274.6)\end{array}$ \\
\hline Unemployed, seeking work as a nurse & $\begin{array}{c}443.0 \\
2.0 \%\end{array}$ & $\begin{array}{l}192.3 \\
2.2 \%\end{array}$ & $\begin{array}{l}111.2 \\
2.7 \%\end{array}$ & $\begin{array}{l}151.9 \\
4.6 \%\end{array}$ \\
\hline
\end{tabular}

Note. Columns do not sum to year licensed $n$ 's and percentages do not sum to $100 \%$ because the employment status question had additional response options and respondents could select multiple options. Some respondents may have selected "actively employed in nursing"; however, they may not have specified full time or part time. Hence, those numbers will not sum to "actively employed in nursing" totals.

*Is not employed in nursing.

An analysis of year licensed by primary employment setting indicated that newly licensed RNs (those licensed between 2013 and 2015) were the cohort most likely to work in a hospital setting (74.0\%), compared to $45.7 \%$ of RNs licensed prior to 2000 (Table 31).

\section{TABLE 31}

\section{Year Licensed, by Primary Employment Setting}

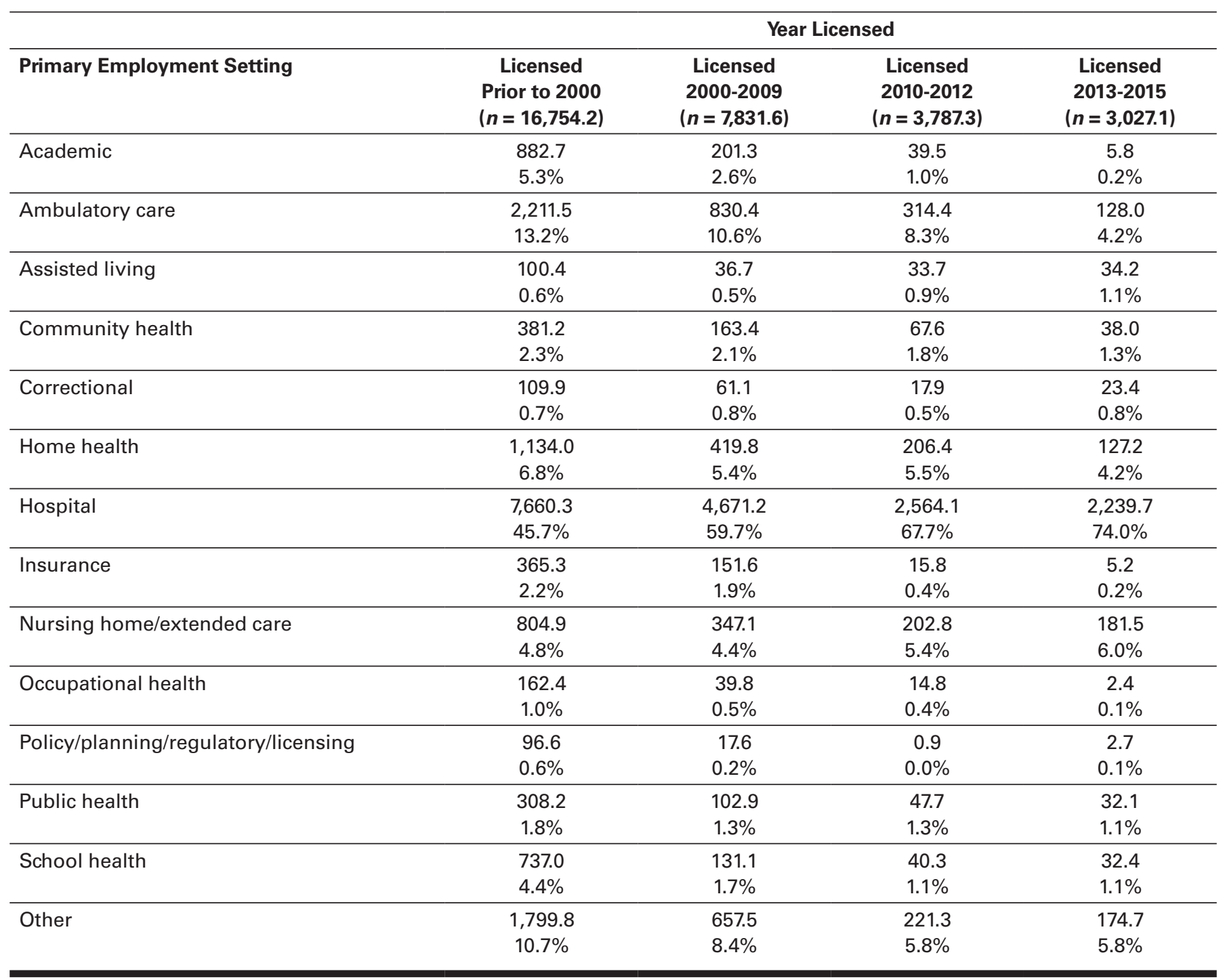




\section{Average Hours Worked}

The current study found that the average number of hours worked during a typical week was 37.2 hours. The average number of hours worked during a typical week for RNs with one nursing position was 36.6 hours; for RNs working two or more positions the average number was 42.2 hours. Analysis of average hours worked per week in all nursing positions, by age-group, indicated that respondents age 45 to 49 tended to work the most hours per week (39.1). With the exception of respondents age 65 and older (27.8 hours), there were very small differences in average hours worked per week by age-group.

In terms of average hours worked per week by highest level of education, respondents in the doctoral category, on average, worked the most hours $(M=45.9, S D=10.0)$, followed by PhD-nursing $(M=44.4, S D=11.2)$. Respondents with a diploma in nursing worked the fewest hours $(M=33.8, S D=13.0)$. Those with a diploma as their highest level of education tend to skew older and older age-cohorts are not as likely to work full time, which likely explains why diploma graduates worked the fewest hours.

An examination of average hours worked per week in respondents' primary nursing position revealed that respondents who worked in academic settings $(M=45.0, S D=8.3)$ and home health tended to work the most hours $(M=44.0, S D=9.4)$. Respondents who worked in school health tended to work the least hours $(M=40.1, S D=6.7)$. Respondents with position title of "nurse executive" worked the most hours $(M=48.1, S D=9.4)$, while those with position title of "staff nurse" worked the fewest hours $(M=29.8, S D=7.5)$.

\section{Telehealth Utilization and Communication}

Respondents were asked to indicate the percentage of time they provided nursing services to or communicated with a patient or client located somewhere different from where they were located, via phone or electronically. Those responding "Yes" to providing a service of this type were asked whether the services provided crossed a state or national border (Table 32). Results revealed that $51.2 \%$ of respondents never engaged in telehealth, while $31.4 \%$ engaged in telehealth between $1 \%$ and $25 \%$ of their time. Furthermore, of respondents who engaged in telehealth, $60.6 \%$ never engaged in telehealth across a state border, while $31.7 \%$ engaged in telehealth across a state border between $1 \%$ and $25 \%$ of their time. Lastly, of respondents who engaged in telehealth, $92.3 \%$ never engaged in telehealth across a national border, while $6.6 \%$ engaged in telehealth across a national border between $1 \%$ and $25 \%$ of their time.

\section{TABLE 32}

\section{Telehealth Utilization}

\begin{tabular}{|c|c|c|c|c|c|c|c|}
\hline & & \multicolumn{6}{|c|}{ Time Percentage } \\
\hline & $n$ & & Never & $1 \%-25 \%$ & $26 \%-50 \%$ & $51 \%-75 \%$ & $76 \%-100 \%$ \\
\hline Percent utilizing telehealth & $37,354.7$ & & $19,119.1$ & $11,710.7$ & $2,560.5$ & $1,785.3$ & 2179.1 \\
\hline \multicolumn{8}{|l|}{ Telehealth Utilization Across a State Border } \\
\hline \multirow{2}{*}{$\begin{array}{l}\text { Percent utilizing telehealth across state } \\
\text { border }\end{array}$} & \multirow[t]{2}{*}{$18,456.1$} & \multirow[t]{2}{*}{$17,800.3$} & $11,186.7$ & $5,843.2$ & 626.8 & 298.5 & 500.9 \\
\hline & & & $60.6 \%$ & $31.7 \%$ & $3.4 \%$ & $1.6 \%$ & $2.7 \%$ \\
\hline \multirow{2}{*}{$\begin{array}{l}\text { Percent utilizing telehealth across a } \\
\text { national border }\end{array}$} & \multirow[t]{2}{*}{$18,096.2$} & \multirow[t]{2}{*}{$18,482.1$} & $16,707.2$ & $1,194.7$ & 96.3 & 33.7 & 64.3 \\
\hline & & & $92.3 \%$ & $6.6 \%$ & $0.5 \%$ & $0.2 \%$ & $0.4 \%$ \\
\hline
\end{tabular}

*Did not provide nursing services or communicate with remote patients or clients.

Respondents were asked to describe the mode(s) of communication they used to provide nursing services or communicate with a remote patient or client (Table 33). Of respondents who engaged in telehealth, the large majority (97.1\%) used the telephone, followed by e-mail $(32.3 \%)$ and electronic messaging (18.6\%). 


\section{TABLE 33}

\section{Modes of Communication Used for Telehealth}

\begin{tabular}{lcc}
\hline & $(\boldsymbol{n = 1 5 , 8 6 4 . 1 )}$ & Percentage \\
\hline $\begin{array}{l}\text { Not applicable; does not provide nursing services or communicate with } \\
\text { remote patients or clients }\end{array}$ & $20,983.0$ \\
\hline Telephone & $15,406.7$ & $57.1 \%$ \\
\hline E-mail & $5,128.2$ & $32.3 \%$ \\
\hline Electronic messaging (e.g., text message, instant message) & $2,954.0$ & $18.6 \%$ \\
\hline Voice over Internet protocol (VoIP) (Skype, FaceTime) & 528.7 & $3.3 \%$ \\
\hline Video call & 463.7 & $2.9 \%$ \\
\hline Virtual ICU (also known as: tele-ICU, remote ICU, elCU) & 167.7 & $1.1 \%$ \\
\hline Other & $1,070.9$ & $6.8 \%$ \\
\hline Note. Respondents were asked to mark all that applied. & & \\
\hline
\end{tabular}

\section{Annual Earnings}

The salary of RNs was not reported in the 2013 National Workforce Survey of Registered Nurses. In the current study, 30.2\% of the overall respondents did not answer the primary nursing position earnings question; hence, item nonresponse bias could be impacting the results. Both upper and lower limits for the salary variable were set conservatively and remaining extreme values could be skewing mean values upward; the discussion of the salary figures relies on the median values as being the more accurate measure of central tendency.

The median RN pre-tax annual earnings from their primary nursing position was $\$ 65,000 ; 12.7 \%$ of the RNs also reported median pre-tax earnings of $\$ 10,000$ from a secondary nursing position (Table 34).

\section{TABLE 34}

\section{Pre-Tax Annual Earnings from Primary Nursing Position}

\begin{tabular}{lrr}
\hline & $\boldsymbol{n}$ & Median \\
\hline Overall & $32,445.0$ & $\$ 65,000$
\end{tabular}

2014 Pre-Tax Annual Earnings from Secondary Nursing Position

\begin{tabular}{|c|c|c|}
\hline & $n$ & Median \\
\hline Overall & $4,111.0$ & $\$ 10,000$ \\
\hline
\end{tabular}

\section{Annual Earnings Across States}

When broken out by state, the highest median earnings were for RNs practicing in California $(\$ 90,000)$, Hawaii (\$82,000), New York $(\$ 77,000)$ and New Jersey $(\$ 76,000)$ (Table 35). The lowest median earnings (not including the territories) were for RNs practicing in South Dakota $(\$ 51,000)$ and Iowa $(\$ 51,662)$.

\section{TABLE 35}

\section{Annual Earnings in Primary Nursing Position, by State(s) Where Currently Practicing}

\begin{tabular}{lll|lrr}
\hline & $\boldsymbol{n}$ & Median & $\boldsymbol{n}$ & Median & \\
\hline Alabama & 687.0 & $\$ 55,000$ & New Hampshire & 692.0 & $\$ 64,000$ \\
\hline Alaska & 707.0 & $\$ 70,000$ & New Jersey & 544.0 & $\$ 76,000$ \\
\hline Arizona & 738.0 & $\$ 69,000$ & New Mexico & $\$ 604.0$ & $\$ 62,000$ \\
\hline
\end{tabular}




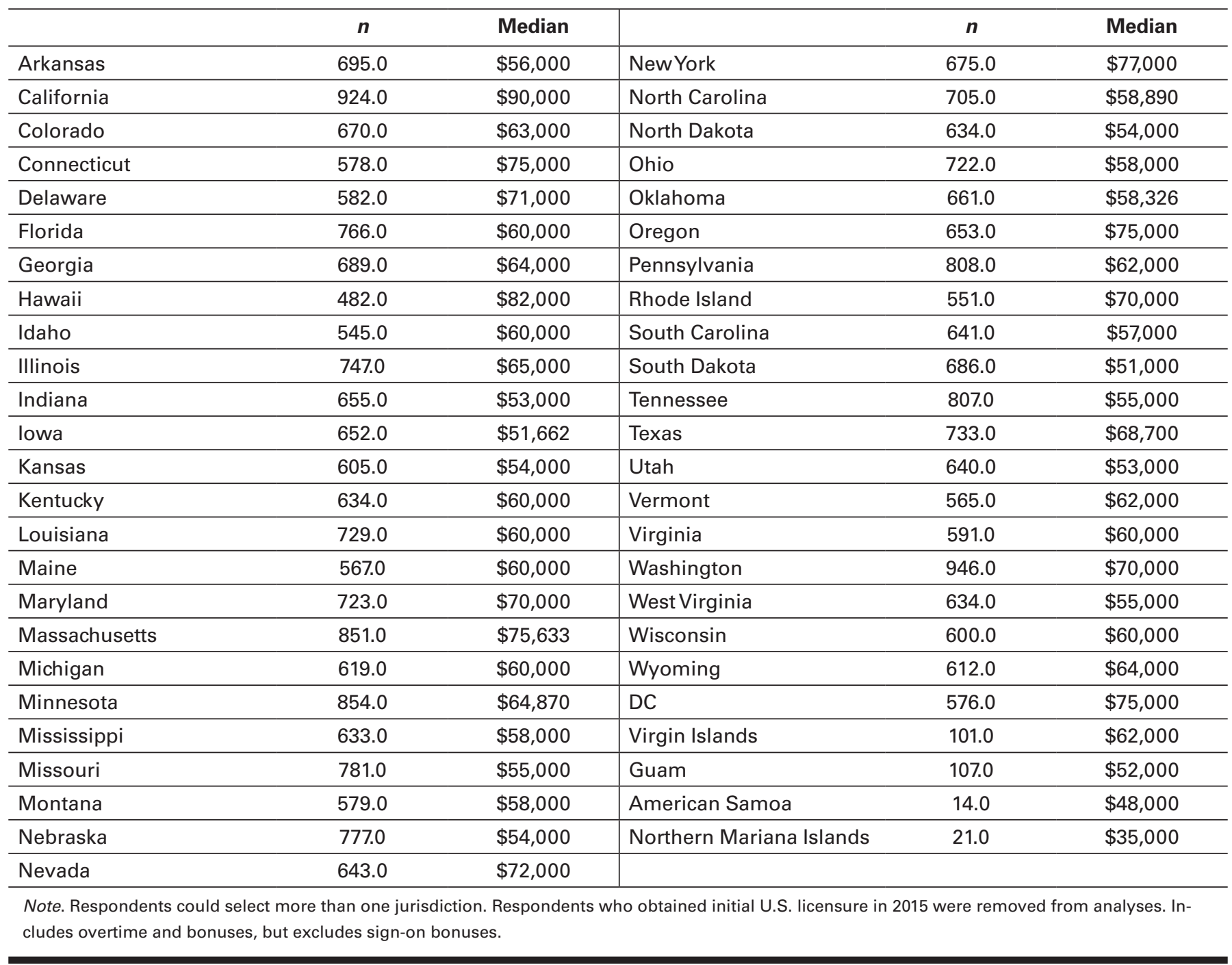

\section{Average Salary by Age, Year Licensed, Gender, and Race/Ethnicity}

When broken out by age, RN earnings from their primary position show a steady rise up to the $45-49$ age-group, where the median salary is $\$ 70,000$ (Table 36). The median salary peaks in the 55-59 age-group at $\$ 72,000$ and declines thereafter.

TABLE 36

\section{Annual Earnings in Primary Nursing Position, by Age}

\begin{tabular}{llr}
\hline & $\boldsymbol{n}$ & Median \\
\hline Younger than 30 & 2923.0 & $\$ 50,000$ \\
\hline $30-34$ & 3020.0 & $\$ 58,000$ \\
\hline $35-39$ & 2799.0 & $\$ 62,000$ \\
\hline $40-44$ & 2878.0 & $\$ 68,000$ \\
\hline $45-49$ & 2929.0 & $\$ 70,000$ \\
\hline $50-54$ & 3841.0 & $\$ 70,000$ \\
\hline $55-59$ & 4679.0 & $\$ 72,000$ \\
\hline $60-64$ & 4142.0 & $\$ 70,000$ \\
\hline 65 and older & 2200.0 & $\$ 54,797$ \\
\hline Note. Respondents who obtained initial U.S. licensure in 2015 were removed from analyses. Includes overtime and bonuses, but excludes sign-on bo-
\end{tabular}


Concerning year licensed cohort, the median earnings for RNs licensed prior to 2000 was $\$ 70,000$, while newly licensed RNs had smaller median salaries (Table 37).

\section{TABLE 37}

\section{Annual Earnings in Primary Nursing Position, by Year Licensed}

\begin{tabular}{lll}
\hline & $\boldsymbol{n}$ & Median \\
\hline Licensed prior to 2000 & $16,057.0$ & $\$ 70,000$ \\
\hline Licensed 2000-2009 & $6,373.0$ & $\$ 65,000$ \\
\hline Licensed 2010-2012 & $3,164.0$ & $\$ 54,000$ \\
\hline Licensed 2013-2015 & $2,026.0$ & $\$ 48,000$ \\
\hline
\end{tabular}

The median earnings for male RNs was $\$ 72,000$; the median earnings for female RNs was $\$ 64,000$ (Table 38).

\section{TABLE 38}

\section{Annual Earnings in Primary Nursing Position, by Gender}

\begin{tabular}{lcc}
\hline & $\boldsymbol{n}$ & Median \\
\hline Female & $28,387.0$ & $\$ 64,000$ \\
\hline Male & $2,187.0$ & $\$ 72,000$ \\
\hline
\end{tabular}

Note. Respondents who obtained initial U.S. licensure in 2015 were removed from analyses. Includes overtime and bonuses, but excludes sign-on bonuses.

The median annual earnings for White/Caucasian RNs was $\$ 62,000$; Hispanic RNs, $\$ 65,800$; Black/African American RNs, $\$ 70,000$; and Asian RNs, \$79,000 (Table 39).

\section{TABLE 39}

\section{Annual Earnings in Primary Nursing Position, by Race/Ethnicity}

\begin{tabular}{lcc}
\hline & $\boldsymbol{n}$ & Median \\
\hline American Indian or Alaska Native & 201.0 & $\$ 63,000$ \\
\hline Asian & $1,547.0$ & $\$ 79,000$ \\
\hline Black/African American & $1,529.0$ & $\$ 70,000$ \\
\hline Native Hawaiian or Other Pacific Islander & 120.0 & $\$ 80,000$ \\
\hline White/Caucasian & $27,314.0$ & $\$ 62,000$ \\
\hline Hispanic/Latino & 729.0 & $\$ 65,800$ \\
\hline Other & 244.0 & $\$ 72,000$ \\
\hline Mixed race/ethnicity & 617.0 & $\$ 70,000$
\end{tabular}

Note. Respondents who obtained initial U.S. licensure in 2015 were removed from analyses. Includes overtime and bonuses, but excludes sign-on bonuses. Respondents were asked to mark all that applied for Race/Ethnicity. However, responses were coded to be mutually exclusive. If respondents selected multiple options, they were coded as Mixed Race/Ethnicity.

\section{Annual Earnings by Level of Education and Advanced Practice Specialty}

When the findings were broken out by highest level of education, respondents with a BSN had a median salary of $\$ 62,000$; respondents with an MSN had a median salary of $\$ 85,000$; respondents with a DNP had a median salary of $\$ 92,000$; and respondents with a PhD in nursing had a median salary of $\$ 96,000$ (Table 40). 
TABLE 40

\section{Average Salary in Primary Nursing Position, by Highest Level of Education}

\begin{tabular}{lcc}
\hline & $\boldsymbol{n}$ & Median \\
\hline Vocational/practical certificate-nursing & -- & - \\
\hline Diploma & $\$ 1,862.0$ & $\$ 60,000$ \\
\hline ADN & $8,298.0$ & $\$ 60,000$ \\
\hline Associate's-other field & 149.0 & $\$ 65,000$ \\
\hline BSN & $12,175.0$ & $\$ 62,000$ \\
\hline Baccalaureate-other field & $2,029.0$ & $\$ 62,000$ \\
\hline MSN & $4,682.0$ & $\$ 85,000$ \\
\hline Master's-other field & $1,366.0$ & $\$ 76,000$ \\
\hline DNP & 292.0 & $\$ 92,500$ \\
\hline PhD-nursing & 200.0 & $\$ 96,000$ \\
\hline Doctoral-nursing other & 33.0 & $\$ 104,000$ \\
\hline Doctoral-other field & 221.0 & $\$ 80,000$ \\
\hline
\end{tabular}

Note. Respondents who obtained initial U.S. licensure in 2015 were removed from analyses. Includes overtime and bonuses, but excludes sign-on bonuses.

Among the advanced practice registered nurse (APRN) specialty areas, the certified registered nurse anesthetist had the highest median earnings $(\$ 150,000)$, while the median earnings for the other three specialty areas $(\$ 85,000$ to $\$ 90,000)$ were relatively similar (Table 41 ).

\section{TABLE 41}

\section{Annual Earnings in Primary Nursing Position, by APRN Certification/Licensure}

\begin{tabular}{lcc}
\hline & $\boldsymbol{n}$ & Median \\
\hline Nurse practitioner & $2,463.0$ & $\$ 90,000$ \\
\hline Clinical nurse specialist & 391 & $\$ 89,000$ \\
\hline Certified registered nurse anesthetist & 472 & $\$ 150,000$ \\
\hline Certified nurse midwife & 140 & $\$ 85,000$ \\
\hline $\begin{array}{l}\text { Note. Respondents who obtained initial U.S. licensure in 2015 were removed from analyses. Includes overtime and bonuses, but excludes sign-on bo- } \\
\text { nuses. }\end{array}$ &
\end{tabular}

\section{Annual Earnings Across Setting, Position Title, and Specialty}

Concerning employment setting, RNs working in policy/regulatory agencies $(\$ 75,000)$ and insurance claims/benefits $(\$ 70,000)$ made the highest median salaries, while those working in school health $(\$ 45,000)$ made the lowest (Table 42$)$.

\section{TABLE 42}

\section{Annual Earnings in Primary Nursing Position, by Primary Employment Setting}

\begin{tabular}{lcr}
\hline & $\boldsymbol{n}$ & Median \\
\hline Academic & $1,318.0$ & $\$ 66,000$ \\
\hline Ambulatory care & $3,754.0$ & $\$ 65,000$ \\
\hline Assisted living & 239.0 & $\$ 55,000$ \\
\hline Community health & 776.0 & $\$ 60,000$ \\
\hline Correctional & 224.0 & $\$ 66,000$ \\
\hline Home health & $1,846.0$ & $\$ 60,000$ \\
\hline
\end{tabular}




\begin{tabular}{lcc}
\hline & $\boldsymbol{n}$ & Median \\
\hline Hospital & $16,599.0$ & $\$ 65,000$ \\
\hline Insurance & 631.0 & $\$ 70,000$ \\
\hline Nursing home/extended care & $1,637.0$ & $\$ 60,000$ \\
\hline Occupational health & 260.0 & $\$ 65,000$ \\
\hline Policy/regulatory/licensing & 134.0 & $\$ 75,000$ \\
\hline Public health & 591.0 & $\$ 55,000$ \\
\hline School health & $1,008.0$ & $\$ 45,000$ \\
\hline Other & $2,884.0$ & $\$ 64,000$ \\
\hline
\end{tabular}

Note. Respondents who obtained initial U.S. licensure in 2015 were removed from analyses. Includes overtime and bonuses, but excludes sign-on bonuses.

Nurse executives $(\$ 100,000)$ and APRNs $(\$ 96,000)$ made the highest median salaries, while those with title of "staff nurse" $(\$ 59,000)$ or "nurse faculty" $(\$ 57,500)$ made the lowest (Table 43).

\section{TABLE 43}

\section{Annual Earnings in Primary Nursing Position, by Primary Position Title}

\begin{tabular}{lcc}
\hline & $\boldsymbol{n}$ & Median \\
\hline Advanced practice nurse & $2,685.0$ & $\$ 96,000$ \\
\hline Case manager & $2,250.0$ & $\$ 66,000$ \\
\hline Clinical nurse leader & $1,345.0$ & $\$ 72,000$ \\
\hline Consultant & 587.0 & $\$ 70,000$ \\
\hline Nurse executive & 837.0 & $\$ 100,000$ \\
\hline Nurse faculty & $1,363.0$ & $\$ 57,500$ \\
\hline Nurse manager & $2,716.0$ & $\$ 75,000$ \\
\hline Nurse researcher & 225.0 & $\$ 72,000$ \\
\hline Staff nurse & $18,043.0$ & $\$ 59,000$ \\
\hline Other-health related & $1,940.0$ & $\$ 66,000$ \\
\hline Other-not health related & 148.0 & $\$ 68,000$ \\
\hline Note. Respondents who obtained initial U.S. licensure in 2015 were removed from analyses. Includes overtime and bonuses, but excludes sign-on bo- & &
\end{tabular}

RNs with the employment specialties of anesthesia $(\$ 150,000)$ and informatics $(\$ 82,500)$ made the highest median salaries, while those with specialties of genetics $(\$ 51,070)$ and school health $(\$ 45,000)$ made the lowest (Table 44).

\section{TABLE 44}

\section{Annual Earnings in Primary Nursing Position, by Primary Employment Specialty}

\begin{tabular}{lcc}
\hline & $\boldsymbol{n}$ & Median \\
\hline Acute care/critical care & $3,334.0$ & $\$ 67,000$ \\
\hline Adult health/family health & 737.0 & $\$ 75,000$ \\
\hline Anesthesia & 501.0 & $\$ 150,000$ \\
\hline Community & 322.0 & $\$ 60,000$ \\
\hline Emergency/trauma & $1,625.0$ & $\$ 66,000$ \\
\hline Genetics & 45.0 & $\$ 51,070$ \\
\hline Geriatric/gerontology & $1,702.0$ & $\$ 60,000$ \\
\hline Home health & $1,272.0$ & $\$ 60,000$ \\
\hline Informatics & 302.0 & $\$ 82,500$ \\
\hline
\end{tabular}




\begin{tabular}{|c|c|c|}
\hline & $n$ & Median \\
\hline Maternal-child health & $1,437.0$ & $\$ 62,000$ \\
\hline Medical-surgical & $2,916.0$ & $\$ 60,000$ \\
\hline Nephrology & 369.0 & $\$ 70,000$ \\
\hline Neurology/neurosurgical & 267.0 & $\$ 70,000$ \\
\hline Oncology & 843.0 & $\$ 65,000$ \\
\hline Orthopedic & 383.0 & $\$ 60,300$ \\
\hline Palliative care/hospice & 446.0 & $\$ 63,000$ \\
\hline Pediatrics & $1,277.0$ & $\$ 60,000$ \\
\hline Perioperative & $1,919.0$ & $\$ 65,000$ \\
\hline Radiology & 150.0 & $\$ 65,000$ \\
\hline Rehabilitation & 551.0 & $\$ 60,000$ \\
\hline School health & 942.0 & $\$ 45,000$ \\
\hline Urologic & 73.0 & $\$ 63,000$ \\
\hline Women's health & 587.0 & $\$ 64,000$ \\
\hline Other & $5,436.0$ & $\$ 67,000$ \\
\hline
\end{tabular}

\section{Nurse Faculty}

In the current study, $50.3 \%$ of respondents who held a principal position as full-time faculty were age 50 and older (Table 45 ). Of those with a secondary faculty position, $44.7 \%$ were age 50 and older, and $9.1 \%$ were younger than age 40 . One hundred nine (7.8\%) of nurse faculty reported having a PhD and an additional 15 (1.1\%) reported having a DNP. However, 55.5 (4.0\%) reported having a doctoral degree in a field other than nursing; $35.8 \%$ held an MSN.

\section{Age Distribution}

\section{TABLE 45}

\section{Age Distribution of RNs with “Nurse Faculty" as Primary or Secondary Position Title}

\begin{tabular}{|c|c|c|}
\hline \multirow[b]{2}{*}{ Age } & \multicolumn{2}{|c|}{ Faculty Position } \\
\hline & $\begin{array}{l}\text { Primary Position } \\
\qquad(n=1,280.7)\end{array}$ & $\begin{array}{l}\text { Secondary Position } \\
\qquad(n=558.9)\end{array}$ \\
\hline $30-34$ & $138.1(10.8 \%)$ & $47.8(8.6 \%)$ \\
\hline $35-39$ & $116.2(9.1 \%)$ & $65.1(11.6 \%)$ \\
\hline $45-49$ & $134.8(10.5 \%)$ & $76.3(13.7 \%)$ \\
\hline $50-54$ & $135.3(10.6 \%)$ & $67.4(12.1 \%)$ \\
\hline $55-59$ & $189.0(14.8 \%)$ & $92.2(16.5 \%)$ \\
\hline $60-64$ & $189.0(14.8 \%)$ & $61.4(11.0 \%)$ \\
\hline 65 and older & $129.0(10.1 \%)$ & $28.7(5.1 \%)$ \\
\hline
\end{tabular}


Primary and Secondary Positions and Hours Worked

In addition to the $1,422.2(3.8 \%)$ respondents who reported their primary nursing position as faculty in an academic nursing program, there were $609.6(10.8 \%)$ RNs who were employed as faculty in their secondary nursing position. Of the 609.6 RNs employed as faculty in a secondary nursing position, $23.8 \%$ reported their principal nursing position as staff nurse, $17.1 \%$ reported their primary nursing position as nurse manager/executive or advanced practice nurse, and $10.8 \%$ reported their principal nursing position as nurse faculty (Table 46).

\section{TABLE 46}

\section{RNs Employed as Faculty in a Secondary Position Title, by Primary Position Title}

\begin{tabular}{lcr}
\hline & \multicolumn{2}{c}{ Faculty in Secondary Position Title } \\
\hline Primary Position Title & $(\boldsymbol{n}=\mathbf{5 9 6 . 6 )}$ & Percentage \\
\hline Advanced practice nurse & 64.8 & $7.2 \%$ \\
\hline Case manager & 39.9 & $4.5 \%$ \\
\hline Clinical nurse leader & 26.7 & $3.0 \%$ \\
\hline Consultant & 19.9 & $2.2 \%$ \\
\hline Nurse executive & 21.1 & $2.4 \%$ \\
\hline Nurse faculty & 96.9 & $10.8 \%$ \\
\hline Nurse manager & 67.4 & $7.5 \%$ \\
\hline Nurse researcher & 6.1 & $0.7 \%$ \\
\hline Other-health related & 33.5 & $3.7 \%$ \\
\hline Other-not health related & 7.6 & $0.9 \%$ \\
\hline Staff nurse & 212.7 & $23.7 \%$
\end{tabular}

In response to the question on hours worked per week by RNs who were faculty in their principal nursing position, $37.4 \%$ reported working 37 to 40 hours per week, with an additional 18.2\% reporting they work 41 to 50 hours per week, and $10.2 \%$ reported working over 50 hours per week (Table 47).

\section{TABLE 47}

\section{Hours Worked per Week, by RNs With “Nurse Faculty" as Primary or Secondary Position Title}

\begin{tabular}{lcr}
\hline Hours Worked per Week & Faculty Position \\
\hline $1-15$ & $\begin{array}{c}\text { Primary Position } \\
(\boldsymbol{n}=\mathbf{1 , 3 4 4 . 2 )}\end{array}$ & $\begin{array}{c}\text { Secondary Position } \\
(\boldsymbol{n}=\mathbf{5 7 8 . 1})\end{array}$ \\
\hline $16-36$ & $95.0(7.0 \%)$ & $27.2(4.7 \%)$ \\
\hline $37-40$ & $361.0(26.7 \%)$ & $148.0(25.6 \%)$ \\
\hline $41-50$ & $504.8(37.4 \%)$ & $122.4(21.2 \%)$ \\
\hline $51-60$ & $245.1(18.2 \%)$ & $163.0(28.2 \%)$ \\
\hline $60+$ & $104.5(7.7 \%)$ & $109.3(18.9 \%)$ \\
\hline
\end{tabular}

\section{Advanced Practice Registered Nurses}

In the current study, 4,455.8 (10.4\%) of RNs reported also being licensed/certified as an APRN (Table 48). Of those identifying themselves as an APRN, 70.4\% identified themselves as nurse practitioners (NPs), 13.0\% as clinical nurse specialists (CNSs), $12.9 \%$ as certified registered nurse anesthetists (CRNAs), and 3.8\% as certified nurse-midwives (CNMs). 
TABLE 48

\section{Currently Licensed/Certified as an APRN}

\begin{tabular}{lccc}
\hline & $(\boldsymbol{n}=\mathbf{4 3 , 0 4 5 . 1 )}$ & Overall percentage & Percentage of APRNs \\
\hline Nurse practitioner & 3129.4 & $7.3 \%$ & $70.4 \%$ \\
\hline Clinical nurse specialist & 576.8 & $1.3 \%$ & $13.0 \%$ \\
\hline Certified registered nurse anesthetist & 571.9 & $1.3 \%$ & $12.9 \%$ \\
\hline Certified nurse midwife & 167.7 & $0.4 \%$ & $3.8 \%$ \\
\hline Not licensed/certified as any of the above & 38599.3 & $89.6 \%$ & \\
\hline
\end{tabular}

Note. In some states, the position title "clinical nurse specialist" is not legally limited to RNs who have clinical nurse specialist preparation of certification. Respondents who indicated "clinical nurse specialist" without a master's degree or higher were removed from this analysis.

\section{Nurse Practitioners}

Age, Education, Employment Setting, and Specialty

The current survey found that $34 \%$ of NPs were age 55 or older (Table 49). Nine percent of working NPs were age 65 or older.

\section{TABLE 49}

\section{Age Distribution of NPs}

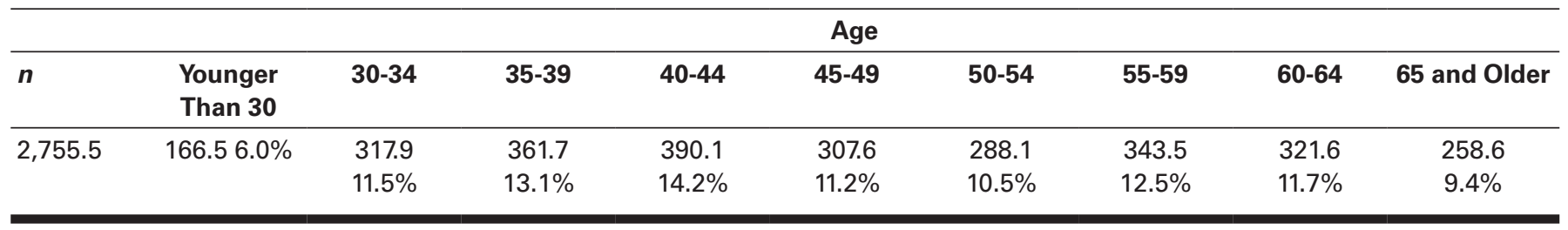

In terms of NPs' highest level of education, $91 \%$ of NPs had a master's degree or higher (Table 50).

\section{TABLE 50}

\section{Highest Level of Education of NPs}

\begin{tabular}{lcr}
\hline & & NPs \\
\hline Highest Level of Education & $(\boldsymbol{n = 3 , 0 4 9 . 1 )}$ & Percentage \\
\hline Diploma & 30.5 & $1.0 \%$ \\
\hline ADN & 78.0 & $2.6 \%$ \\
\hline Associate's-other field & 0.2 & $0.0 \%$ \\
\hline BSN & 131.3 & $4.3 \%$ \\
\hline Baccalaureate-other field & 22.0 & $0.7 \%$ \\
\hline MSN & $2,405.0$ & $78.9 \%$ \\
\hline Master's-other field & 43.7 & $1.4 \%$ \\
\hline DNP & 214.2 & $7.0 \%$ \\
\hline PhD-nursing & 70.0 & $2.3 \%$ \\
\hline Doctoral-nursing other & 13.7 & $0.5 \%$ \\
\hline Doctoral-other field & 39.6 & $1.3 \%$ \\
\hline
\end{tabular}

NPs were asked which setting best described their primary employment setting (Table 51). Hospitals accounted for $28 \%$ of the practice settings; $36.8 \%$ of NPs worked in ambulatory care and other community-based settings; and $7.8 \%$ worked in academic settings. 


\section{TABLE 51}

\section{Primary Employment Setting of NPs}

\begin{tabular}{|c|c|c|}
\hline \multirow[b]{2}{*}{ Primary Employment Setting } & \multicolumn{2}{|c|}{ NPs } \\
\hline & $(n=2,839.5)$ & Percentage \\
\hline Academic & 222.7 & $7.8 \%$ \\
\hline Assisted living & 8.0 & $0.3 \%$ \\
\hline Community health & 185.2 & $6.5 \%$ \\
\hline Home health & 50.5 & $1.8 \%$ \\
\hline Hospital & 813.2 & $28.6 \%$ \\
\hline Insurance & 5.6 & $0.2 \%$ \\
\hline Nursing home/extended care & 105.2 & $3.7 \%$ \\
\hline Occupational health & 36.6 & $1.3 \%$ \\
\hline Other & 420.1 & $14.8 \%$ \\
\hline
\end{tabular}

In terms of job titles, $78.2 \%$ of NPs reported having a job title of "advanced practice nurse." In terms of clinical specialties, $14.5 \%$ of NPs in this survey reported primary care as their principal clinical specialty (Table 52). Other settings where NPs were working included $11.1 \%$ in adult/family health, $9.3 \%$ in pediatrics/neonatal, and $6.8 \%$ in acute care/critical care.

\section{TABLE 52}

\section{Primary Employment Specialty of NPs}

\begin{tabular}{|c|c|c|}
\hline \multirow[b]{2}{*}{ Primary Employment Specialty } & \multicolumn{2}{|c|}{ NPs } \\
\hline & $(n=2,776.2)$ & Percentage \\
\hline Acute care/critical care & 188.8 & $6.8 \%$ \\
\hline Anesthesia & 24.5 & $0.9 \%$ \\
\hline Community & 9.3 & $0.3 \%$ \\
\hline Genetics & 0.9 & $0.0 \%$ \\
\hline Geriatric/gerontology & 137.1 & $4.9 \%$ \\
\hline Home health & 22.0 & $0.8 \%$ \\
\hline Informatics & 3.9 & $0.1 \%$ \\
\hline Maternal-child health & 34.3 & $1.2 \%$ \\
\hline Neurology/neurosurgical & 57.4 & $2.1 \%$ \\
\hline Occupational health & 30.8 & $1.1 \%$ \\
\hline Oncology & 81.8 & $3.0 \%$ \\
\hline Orthopedic & 26.7 & $1.0 \%$ \\
\hline Palliative care/hospice & 43.7 & $1.6 \%$ \\
\hline Pediatrics & 195.2 & $7.0 \%$ \\
\hline
\end{tabular}




\begin{tabular}{|c|c|c|}
\hline & \multicolumn{2}{|c|}{ NPs } \\
\hline Primary Employment Specialty & $(n=2,776.2)$ & Percentage \\
\hline Perioperative & 18.9 & $0.7 \%$ \\
\hline Psychiatric/mental health/substance abuse & 162.0 & $5.8 \%$ \\
\hline Public health & 15.6 & $0.6 \%$ \\
\hline Rehabilitation & 6.9 & $0.3 \%$ \\
\hline School health & 44.2 & $1.6 \%$ \\
\hline Urologic & 14.6 & $0.5 \%$ \\
\hline Women's health & 174.6 & $6.3 \%$ \\
\hline Other & 492.0 & $17.7 \%$ \\
\hline
\end{tabular}

For NPs who identified primary care as their primary specialty area, $51.1 \%$ worked in ambulatory care settings, $15.5 \%$ worked in public/community health settings, and $1.5 \%$ worked in hospitals (Table 53).

\section{TABLE 53}

\section{NPs Whose Primary Employment Specialty is Primary Care, by Primary Employment Setting}

\begin{tabular}{|c|c|c|}
\hline & NPs in primary & \\
\hline Primary Employment Setting & $(n=394.0)$ & Percentage \\
\hline Academic & 26.0 & $6.58 \%$ \\
\hline Assisted living & 0.0 & $0.0 \%$ \\
\hline Community health & 56.2 & $14.3 \%$ \\
\hline Hospital & 5.8 & $1.5 \%$ \\
\hline Insurance & 0.0 & $0.0 \%$ \\
\hline Nursing home/extended care & 3.9 & $1.0 \%$ \\
\hline Occupational health & 3.7 & $0.9 \%$ \\
\hline Other & 76.306 & $19.4 \%$ \\
\hline
\end{tabular}

\section{Certified Nurse Midwives}

Age, Education, Employment Setting, and Specialty

The current study found $25.5 \%$ of CNMs were younger than age 40 and $56.4 \%$ were age 50 or older (Table 54 ).

\section{TABLE 54}

\section{Age Distribution of CNMs}

\begin{tabular}{lccccccccc}
\hline \multicolumn{10}{c}{ Age } \\
\hline $\boldsymbol{n}$ & $\begin{array}{c}\text { Younger } \\
\text { Than 30 }\end{array}$ & $\mathbf{3 0 - 3 4}$ & $\mathbf{3 5 - 3 9}$ & $\mathbf{4 0 - 4 4}$ & $\mathbf{4 5 - 4 9}$ & $\mathbf{5 0 - 5 4}$ & $\mathbf{5 5 - 5 9}$ & $\mathbf{6 0 - 6 4}$ & $\begin{array}{c}\mathbf{6 5} \text { and } \\
\text { Older }\end{array}$ \\
\hline 146.5 & 3.1 & 18.3 & 15.6 & 15.3 & 11.5 & 12.1 & 23.6 & 26.8 & 20.3 \\
& $2.1 \%$ & $12.5 \%$ & $10.6 \%$ & $10.5 \%$ & $7.9 \%$ & $8.2 \%$ & $16.1 \%$ & $18.3 \%$ & $13.8 \%$ \\
\hline
\end{tabular}


CNMs were asked to indicate their highest level of education (Table 55). Seventy-five percent of CNMs hold graduate degrees.

\section{TABLE 55}

\section{Highest Level of Education of CNMs}

\begin{tabular}{lcr}
\hline & & CNMs \\
\hline Highest Level of Education & $(\boldsymbol{n}=\mathbf{1 5 6 . 8})$ & Percentage \\
\hline Diploma & 14.8 & $9.4 \%$ \\
\hline ADN & 10.6 & $6.8 \%$ \\
\hline Associate's-other field & 0.1 & $0.1 \%$ \\
\hline BSN & 13.3 & $8.5 \%$ \\
\hline Baccalaureate-other field & 0.1 & $0.1 \%$ \\
\hline MSN & 107.2 & $68.4 \%$ \\
\hline Master's-other field & 3.4 & $2.1 \%$ \\
\hline DNP & 2.9 & $1.9 \%$ \\
\hline PhD-nursing & 3.4 & $2.2 \%$ \\
\hline Doctoral-nursing other & 0.0 & $0.0 \%$ \\
\hline Doctoral-other field & 1.0 & $0.6 \%$ \\
\hline
\end{tabular}

Less than half of CNMs worked in hospital settings (43\%), and $13.6 \%$ were working in ambulatory-care settings. Table 56 lists employment settings for CNMs.

\section{TABLE 56}

\section{Primary Employment Setting of CNMs}

\begin{tabular}{|c|c|c|}
\hline \multirow[b]{2}{*}{ Primary Employment Setting } & \multicolumn{2}{|c|}{ CNMs } \\
\hline & $(n=136.2)$ & Percentage \\
\hline Academic & 9.5 & $7.0 \%$ \\
\hline Assisted living & 4.5 & $3.3 \%$ \\
\hline Community health & 15.3 & $11.2 \%$ \\
\hline Home health & 4.0 & $2.9 \%$ \\
\hline Hospital & 58.5 & $43.0 \%$ \\
\hline Insurance & 0.0 & $0.0 \%$ \\
\hline Nursing home/extended care & 0.5 & $0.3 \%$ \\
\hline Occupational health & 0.0 & $0.0 \%$ \\
\hline School health & 8.6 & $6.3 \%$ \\
\hline Other & 11.2 & $8.2 \%$ \\
\hline
\end{tabular}

In terms of job title of CNMs, the majority (71.8\%) had an "advanced practice nurse" title, while $17.7 \%$ had a "staff nurse" title. The large majority of CNMs with an "advanced practice nurse" title work in clinical specialties related to women's health. Eighty-one percent of CNMs indicated working in maternal-child or women's health specialties (Table 57). 


\section{TABLE 57}

\section{Primary Employment Specialties of CNMs}

\begin{tabular}{lcc}
\hline & & CNMs \\
\hline Primary Employment Specialty & $(\boldsymbol{n = 1 2 7 . 0 )}$ & Percentage \\
\hline Maternal-child health & 46.6 & $36.7 \%$ \\
\hline Pediatrics/neonatal & 0.3 & $0.3 \%$ \\
\hline Women's health & 56.7 & $44.6 \%$ \\
\hline Other & 7.2 & $5.7 \%$ \\
\hline
\end{tabular}

Note. Not all employment specialties are displayed; hence, percentages will not sum to $100 \%$.

\section{Certified Registered Nurse Anesthetists}

Age and Education

Compared to other APRN groups, CRNAs tend to be younger than their colleagues; specifically, 28.2\% were younger than age 40, while $33.2 \%$ were age 55 or older; $11.0 \%$ of CRNAs age 65 or older continue to work (Table 58).

\section{TABLE 58}

\section{Age Distribution of CRNAs}

\begin{tabular}{|c|c|c|c|c|c|c|c|c|c|}
\hline \multirow[b]{2}{*}{$n$} & \multicolumn{9}{|c|}{ Age } \\
\hline & $\begin{array}{l}\text { Younger } \\
\text { Than } 30\end{array}$ & $30-34$ & $35-39$ & $40-44$ & $45-49$ & $50-54$ & $55-59$ & $60-64$ & $\begin{array}{c}65 \text { and } \\
\text { Older }\end{array}$ \\
\hline & $3.6 \%$ & $14.4 \%$ & $10.2 \%$ & $12.8 \%$ & $10,0 \%$ & $15.8 \%$ & $11.1 \%$ & $11.1 \%$ & $11.0 \%$ \\
\hline
\end{tabular}

Seventy-five percent of CRNAs in this sample reported having a master's or doctoral degree. The primary employment setting of CRNAs is predominantly a hospital (81.8\%), followed by ambulatory care (12\%) and academic settings (2.9\%).

\section{TABLE 59}

\section{Highest Level of Education of CRNAs}

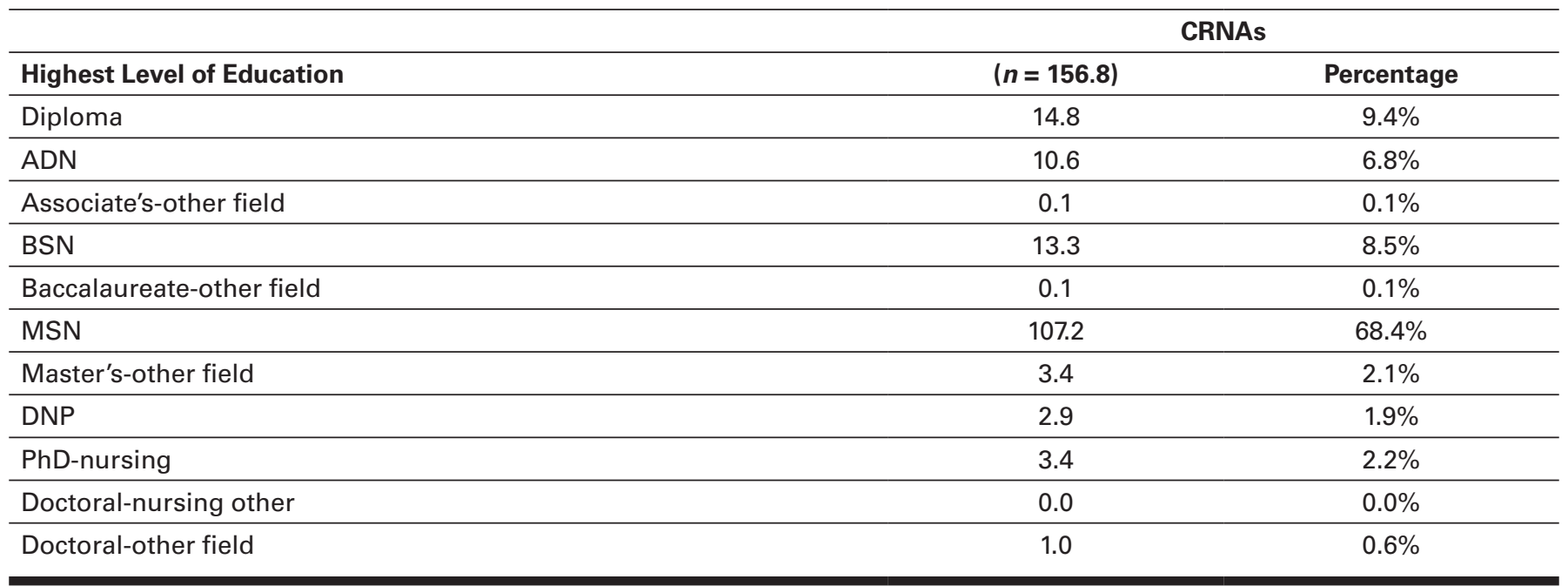


Age, Education, Employment Setting, and Specialty

In the current study, only $9 \%$ of CNSs were younger than age 40 , while $26.6 \%$ were age 55 or older, and $9.3 \%$ were age 65 or older (Table 60).

\section{TABLE 60}

\section{Age Distribution of CNSs}

\begin{tabular}{lccccccccc}
\hline \multicolumn{10}{c}{ Age } \\
\hline $\boldsymbol{n}$ & $\begin{array}{c}\text { Younger } \\
\text { Than } \mathbf{3 0}\end{array}$ & $\mathbf{3 0 - 3 4}$ & $\mathbf{3 5 - 3 9}$ & $\mathbf{4 0 - 4 4}$ & $\mathbf{4 5 - 4 9}$ & $\mathbf{5 0 - 5 4}$ & $\mathbf{5 5 - 5 9}$ & $\mathbf{6 0 - 6 4}$ & $\begin{array}{c}\mathbf{6 5} \text { and } \\
\text { Older }\end{array}$ \\
\hline 505.8 & 2.9 & 26.5 & 37.3 & 49.2 & 33.1 & 63.3 & 92.6 & 99.6 & 101.2 \\
& $0.9 \%$ & $3.6 \%$ & $4.5 \%$ & $5.8 \%$ & $4.3 \%$ & $6.7 \%$ & $8.4 \%$ & $9.1 \%$ & $9.3 \%$ \\
\hline
\end{tabular}

Note. In some states, the position title of "clinical nurse specialist" is not legally limited to RNs who have CNS preparation of certification. Respondents who indicated "clinical nurse specialist" without a master's degree or higher were removed from this analysis.

In the current study, $14.8 \%$ of CNSs reported having a doctoral degree (Table 61).

\section{TABLE 61}

\section{Highest Level of Education of CNSs}

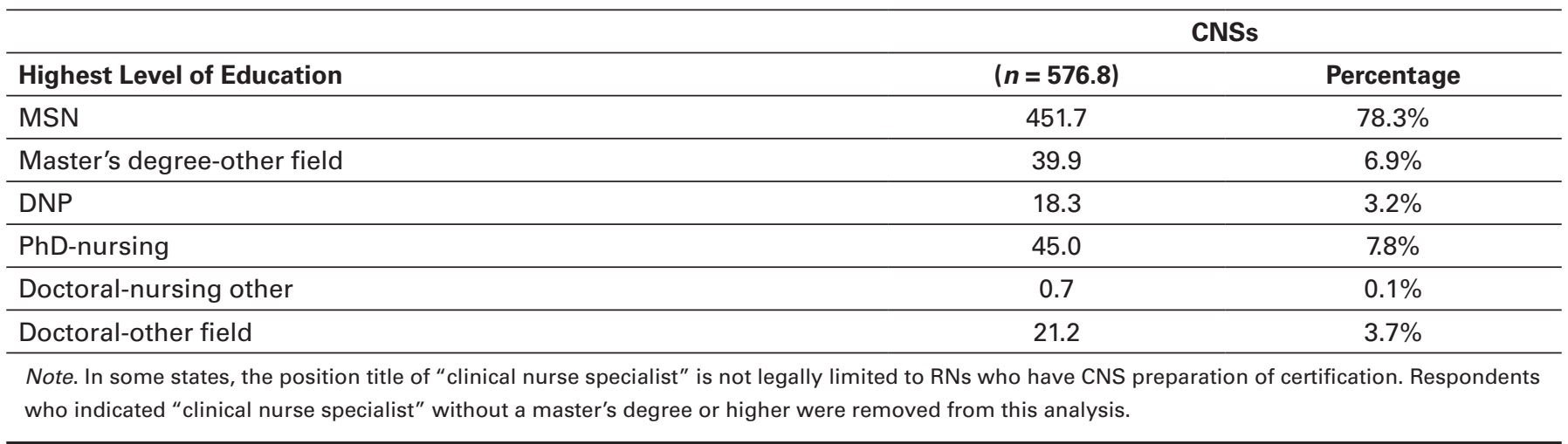

Almost half of the CNSs (44.4\%) worked in hospital settings, while $18.7 \%$ reported working in academic settings, and $11.3 \%$ worked in ambulatory-care environments (Table 62). Others reported working in nursing homes, home health, public and community health, schools, and policy/regulatory agencies.

\section{TABLE 62}

\section{Primary Employment Setting of CNSs}

\begin{tabular}{|c|c|c|}
\hline \multirow[b]{2}{*}{ Primary Employment Setting } & \multicolumn{2}{|c|}{ CNSs } \\
\hline & $(n=464.9)$ & Percentage \\
\hline Academic & 86.8 & $18.7 \%$ \\
\hline Assisted living & 0.3 & $0.1 \%$ \\
\hline Community health & 12.7 & $2.7 \%$ \\
\hline Home health & 17.7 & $3.8 \%$ \\
\hline Hospital & 206.4 & $44.4 \%$ \\
\hline Insurance & 1.3 & $0.3 \%$ \\
\hline Nursing home/extended care & 10.2 & $2.2 \%$ \\
\hline
\end{tabular}




\begin{tabular}{|c|c|c|}
\hline & \multicolumn{2}{|c|}{ CNSs } \\
\hline Primary Employment Setting & $(n=464.9)$ & Percentage \\
\hline Occupational health & 7.0 & $1.5 \%$ \\
\hline Public health & 12.7 & $2.7 \%$ \\
\hline School health & 7.7 & $1.7 \%$ \\
\hline
\end{tabular}

Note. In some states, the position title of "clinical nurse specialist" is not legally limited to RNs who have CNS preparation of certification. Respondents who indicated "clinical nurse specialist" without a master's degree or higher were removed from this analysis.

There has been a change in the use of the "advanced practice nurse" and "staff nurse" job titles for CNSs. Specifically, $41.4 \%$ of CNSs reported having the job title "advanced practice nurse" (Table 63), up from 38\% in 2013. Additionally, $11.1 \%$ of CNSs indicated having a "staff nurse" job title, down from $20 \%$ in 2013.

\section{TABLE 63}

\section{Primary Position Titles of CNSs}

\begin{tabular}{|c|c|c|}
\hline \multirow[b]{2}{*}{ Primary position title } & \multicolumn{2}{|c|}{ CNSs } \\
\hline & $(n=458.9)$ & Percentage \\
\hline Advanced practice nurse & 190.2 & $41.4 \%$ \\
\hline Clinical nurse leader & 23.4 & $5.1 \%$ \\
\hline Consultant & 19.6 & $4.3 \%$ \\
\hline Nurse faculty & 63.7 & $13.9 \%$ \\
\hline Nurse manager & 27.0 & $5.9 \%$ \\
\hline Nurse researcher & 17.8 & $3.9 \%$ \\
\hline Other-health related & 31.7 & $6.9 \%$ \\
\hline Other-not health related & 2.6 & $0.6 \%$ \\
\hline
\end{tabular}

Note. In some states, the position title of "clinical nurse specialist" is not legally limited to RNs who have CNS preparation of certification. Respondents who indicated "clinical nurse specialist" without a master's degree or higher were removed from this analysis.

\section{Foreign-Educated Nurses}

The majority (93.3\%) of RNs received their entry-level education in the United States. Just over 3\% of respondents received their entry-level education in the Philippines, followed by Canada $(0.6 \%)$ and India $(0.4 \%)$.

Age, Gender, and Education of Foreign-Educated Nurses

An analysis of foreign-educated nurses by age revealed that fewer were younger than age 40 and more were between the ages of 40 and 50 when compared to U.S.-educated nurses (Table 64).

TABLE 64

\section{Foreign-Educated Status, by Age}

\begin{tabular}{|c|c|c|c|c|c|c|c|c|c|c|}
\hline & & & & & & Age & & & & \\
\hline $\begin{array}{l}\text { Foreign- } \\
\text { Educated } \\
\text { Status }\end{array}$ & $n$ & $\begin{array}{l}\text { Younger } \\
\text { Than } 30\end{array}$ & $30-34$ & $35-39$ & $40-44$ & $45-49$ & $50-54$ & $55-59$ & $60-64$ & $\begin{array}{c}65 \text { and } \\
\text { Older }\end{array}$ \\
\hline $\begin{array}{l}\text { U.S.- } \\
\text { educated }\end{array}$ & 38017.5 & $\begin{array}{c}3,790.2 \\
10.0 \%\end{array}$ & $\begin{array}{c}3,920.9 \\
10.3 \%\end{array}$ & $\begin{array}{c}3,674.9 \\
9.7 \%\end{array}$ & $\begin{array}{c}3,724.1 \\
9.8 \%\end{array}$ & $\begin{array}{c}3,925.6 \\
10.3 \%\end{array}$ & $\begin{array}{c}4,293.4 \\
11.3 \%\end{array}$ & $\begin{array}{c}5,186.5 \\
13.6 \%\end{array}$ & $\begin{array}{c}4,839.9 \\
12.7 \%\end{array}$ & $\begin{array}{c}4,661.9 \\
12.3 \%\end{array}$ \\
\hline
\end{tabular}

S46 Journal of Nursing Regulation 


\begin{tabular}{|c|c|c|c|c|c|c|c|c|c|c|}
\hline \multirow[b]{2}{*}{$\begin{array}{l}\text { Foreign- } \\
\text { Educated } \\
\text { Status }\end{array}$} & \multirow[b]{2}{*}{$n$} & \multicolumn{9}{|c|}{ Age } \\
\hline & & $\begin{array}{l}\text { Younger } \\
\text { Than } 30\end{array}$ & $30-34$ & $35-39$ & $40-44$ & $45-49$ & $50-54$ & $55-59$ & $60-64$ & $\begin{array}{c}65 \text { and } \\
\text { Older }\end{array}$ \\
\hline Foreign- & 2518.0 & 97.5 & 154.4 & 223.5 & 429.4 & 395.2 & 321.3 & 340.7 & 281.9 & 274.0 \\
\hline educated & & $3.9 \%$ & $6.1 \%$ & $8.9 \%$ & $17.1 \%$ & $16.0 \%$ & $12.8 \%$ & $13.5 \%$ & $11.2 \%$ & $10.9 \%$ \\
\hline
\end{tabular}

An analysis of foreign-educated status by gender indicated a higher percentage of foreign-educated nurses were male (12.0\%) compared to U.S.-educated nurses $(7.8 \%$ ) (Table 65).

\section{TABLE 65}

Foreign-Educated Status, by Gender

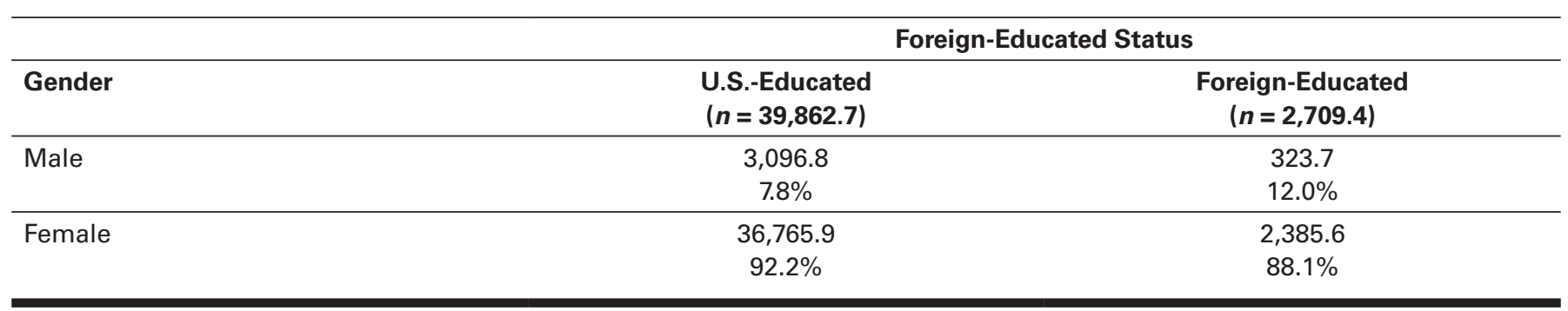

An analysis of initial nursing education revealed that foreign-educated nurses have higher rates of receiving a BSN for their initial nursing licensure when compared to U.S.-educated nurses (Table 66). For example, for nurses licensed between 2013 and $2015,72.2 \%$ of foreign-educated nurses received a BSN, while $47.2 \%$ of U.S.-educated nurses received a BSN.

\section{TABLE 66}

\section{Year Licensed and Foreign-Educated Status, by Initial Nursing Education}

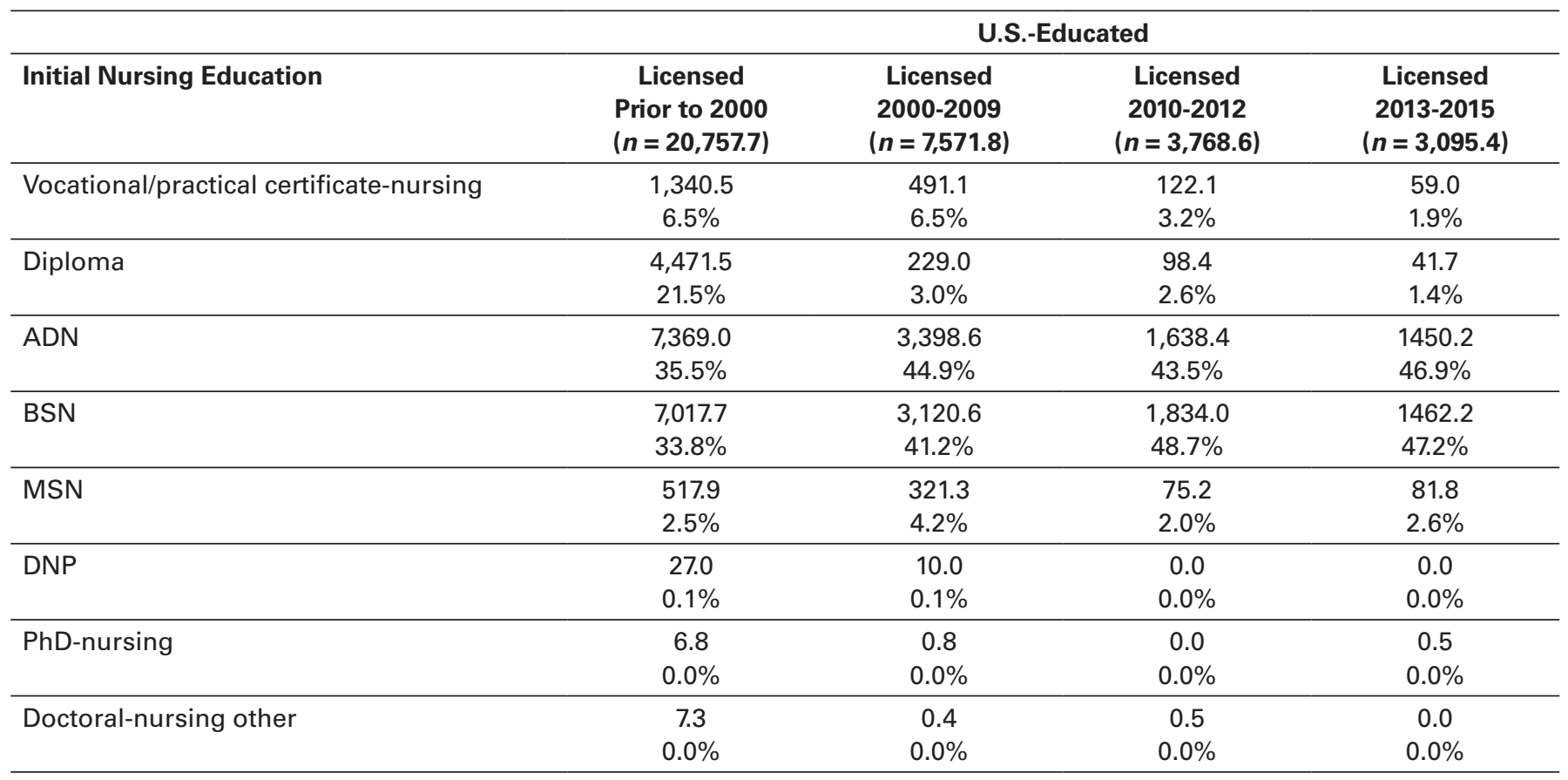




\begin{tabular}{|c|c|c|c|c|}
\hline & \multicolumn{4}{|c|}{ Foreign-Educated } \\
\hline & $\begin{array}{c}\text { Licensed } \\
\text { Prior to } 2000 \\
(n=1,117.5)\end{array}$ & $\begin{array}{c}\text { Licensed } \\
2000-2009 \\
(n=892.1)\end{array}$ & $\begin{array}{c}\text { Licensed } \\
2010-2012 \\
(n=229.6)\end{array}$ & $\begin{array}{c}\text { Licensed } \\
2013-2015 \\
(n=142.4)\end{array}$ \\
\hline \multirow[t]{2}{*}{ Vocational/practical certificate-nursing } & 24.0 & 28.1 & 4.1 & 0.2 \\
\hline & $2.2 \%$ & $3.2 \%$ & $1.8 \%$ & $0.1 \%$ \\
\hline Diploma & 304.5 & 80.0 & 23.9 & 7.5 \\
\hline \multirow[t]{2}{*}{ ADN } & 143.0 & 122.3 & 73.0 & 29.5 \\
\hline & $12.8 \%$ & $13.7 \%$ & $31.8 \%$ & $20.7 \%$ \\
\hline \multirow[t]{2}{*}{ BSN } & 615.5 & 616.7 & 123.4 & 102.9 \\
\hline & $55.1 \%$ & $69.1 \%$ & $53.8 \%$ & $72.2 \%$ \\
\hline \multirow[t]{2}{*}{ MSN } & 30.5 & 41.5 & 4.6 & 2.4 \\
\hline & $2.7 \%$ & $4.7 \%$ & $2.0 \%$ & $1.7 \%$ \\
\hline PhD-nursing & $0.0 \%$ & $0.3 \%$ & $0.3 \%$ & $0.0 \%$ \\
\hline \multirow[t]{2}{*}{ Doctoral-nursing other } & 0.0 & 0.3 & 0.0 & 0.0 \\
\hline & $0.0 \%$ & $0.0 \%$ & $0.0 \%$ & $0.0 \%$ \\
\hline
\end{tabular}

In terms of highest level of education, $77.8 \%$ of foreign-educated nurses had a baccalaureate degree or higher, while $64.8 \%$ of U.S.-educated nurses did (Table 67).

\section{TABLE 67}

\section{Foreign-Educated Status, by Highest Level of Education}

\begin{tabular}{|c|c|c|}
\hline \multirow[b]{2}{*}{ Highest Level of Education } & \multicolumn{2}{|c|}{ Foreign-Educated Status } \\
\hline & $\begin{array}{l}\text { U.S.-Educated } \\
(n=40,922.2)\end{array}$ & $\begin{array}{l}\text { Foreign-Educated } \\
\quad(n=2,831.7)\end{array}$ \\
\hline \multirow[t]{2}{*}{ Diploma } & 3087.0 & 342.6 \\
\hline & $7.5 \%$ & $12.1 \%$ \\
\hline \multirow[t]{2}{*}{ Associate's-other field } & 223.9 & 20.5 \\
\hline & $0.5 \%$ & $0.7 \%$ \\
\hline \multirow[t]{2}{*}{ BSN } & $14,991.5$ & $1,531.3$ \\
\hline & $36.6 \%$ & $54.1 \%$ \\
\hline Baccalaureate-other field & $2,927.6$ & 149.1 \\
\hline \multirow[t]{2}{*}{ Master's-other field } & $2,008.7$ & 153.6 \\
\hline & $4.9 \%$ & $5.4 \%$ \\
\hline \multirow[t]{2}{*}{ DNP } & 321.5 & 11.9 \\
\hline & $0.8 \%$ & $0.4 \%$ \\
\hline \multirow[t]{2}{*}{ PhD-nursing } & 222.1 & 14.6 \\
\hline & $0.5 \%$ & $0.5 \%$ \\
\hline \multirow[t]{2}{*}{ Doctoral-nursing other } & 36.3 & 0.2 \\
\hline & $0.1 \%$ & $0.0 \%$ \\
\hline \multirow[t]{2}{*}{ Doctoral-other field } & 297.0 & 64.2 \\
\hline & $0.7 \%$ & $2.3 \%$ \\
\hline
\end{tabular}


Foreign-educated nurses worked more hours (39.5 hours; SD 11.7) compared to U.S.-educated nurses (37.0 hours; SD 14.2). The number of positions in which the respondents were employed as a nurse were similar to the numbers for U.S.-educated nurses; specifically, $15.1 \%$ of U.S.-educated nurses and $16.3 \%$ of foreign-educated nurses worked two or more nursing jobs.

An analysis of primary employment setting revealed that foreign-educated nurses were more likely to be employed in a hospital setting as compared to U.S.-educated nurses (Table 68). Additionally, foreign-educated nurses were more likely to be employed in nursing home/extended care settings $(10.5 \%)$ as compared to U.S.-educated nurses $(4.4 \%)$.

\section{TABLE 68}

\section{Foreign-Educated Status, by Primary Employment Setting}

\begin{tabular}{|c|c|c|}
\hline \multirow[b]{2}{*}{ Primary Employment Setting } & \multicolumn{2}{|c|}{ Foreign-Educated Status } \\
\hline & $\begin{array}{l}\text { U.S.-Educated } \\
(n=34,290.4)\end{array}$ & $\begin{array}{l}\text { Foreign-Educated } \\
\quad(n=2,454.1)\end{array}$ \\
\hline Academic & $3.8 \%$ & $1.8 \%$ \\
\hline \multirow[t]{2}{*}{ Ambulatory care } & 3947.2 & 182.9 \\
\hline & $11.5 \%$ & $7.5 \%$ \\
\hline Assisted living & $0.6 \%$ & $1.0 \%$ \\
\hline \multirow[t]{2}{*}{ Community health } & 730.9 & 43.8 \\
\hline & $2.1 \%$ & $1.8 \%$ \\
\hline \multirow[t]{2}{*}{ Correctional } & 225.5 & 28.5 \\
\hline & $0.7 \%$ & $1.2 \%$ \\
\hline Hospital & $54.0 \%$ & $61.0 \%$ \\
\hline \multirow[t]{2}{*}{ Insurance } & 631.3 & 26.0 \\
\hline & $1.8 \%$ & $1.1 \%$ \\
\hline \multirow[t]{2}{*}{ Nursing home/extended care } & $1,501.3$ & 258.2 \\
\hline & $4.4 \%$ & $10.5 \%$ \\
\hline \multirow[t]{2}{*}{ Occupational health } & 239.7 & 4.5 \\
\hline & $0.7 \%$ & $0.2 \%$ \\
\hline \multirow[t]{2}{*}{ Policy/regulatory/licensing } & 145.1 & 0 \\
\hline & $0.4 \%$ & $0.0 \%$ \\
\hline Public health & 551.5 & 36.1 \\
\hline
\end{tabular}

An analysis of primary position titles indicated that a substantially larger percentage of foreign-educated nurses were staff nurses (72.6\%) compared to U.S.-educated nurses (57.2\%) (Table 69). 
TABLE 69

\section{Foreign-Educated Status, by Primary Position Title}

\begin{tabular}{|c|c|c|}
\hline \multirow[b]{2}{*}{ Primary Position Title } & \multicolumn{2}{|c|}{ Foreign-Educated Status } \\
\hline & $\begin{array}{l}\text { U.S.-Educated } \\
(n=34,571.3)\end{array}$ & $\begin{array}{l}\text { Foreign-Educated } \\
\quad(n=2,516.2)\end{array}$ \\
\hline Advanced practice nurse & $8.5 \%$ & $3.4 \%$ \\
\hline \multirow[t]{2}{*}{ Case manager } & $2,317.5$ & 150.1 \\
\hline & $6.7 \%$ & $6.0 \%$ \\
\hline Clinical nurse leader & $4.0 \%$ & $3.8 \%$ \\
\hline \multirow[t]{2}{*}{ Consultant } & 626.0 & 32.6 \\
\hline & $1.8 \%$ & $1.3 \%$ \\
\hline \multirow[t]{2}{*}{ Nurse executive } & 825.0 & 44.5 \\
\hline & $2.4 \mathrm{An} \%$ & $1.8 \%$ \\
\hline Nurse manager & $8.1 \%$ & $5.8 \%$ \\
\hline \multirow[t]{2}{*}{ Nurse researcher } & 234.8 & 8.6 \\
\hline & $0.7 \%$ & $0.3 \%$ \\
\hline \multirow[t]{2}{*}{ Other-health related } & $2,045.7$ & 91.0 \\
\hline & $5.9 \%$ & $3.6 \%$ \\
\hline \multirow[t]{2}{*}{ Other-not health related } & 234.7 & 7.8 \\
\hline & $0.7 \%$ & $0.3 \%$ \\
\hline \multirow[t]{2}{*}{ Staff nurse } & $19,779.1$ & $1,825.6$ \\
\hline & $57.2 \%$ & $72.6 \%$ \\
\hline
\end{tabular}

\section{Discussion and Implications}

This study presents a national, randomized survey of 140,154 licensed RNs. Data collected from the 46,476 responders (34.3\%) provide the most recent and detailed information on characteristics of today's RN workforce. These data not only illustrate current characteristics and trends of the nursing workforce but also provide valuable information with which to assess progress towards certain goals and priorities outlined by the Institute of Medicine's (2010) The Future of Nursing report, including RNs achieving higher levels of education and increased diversity of the nurse workforce.

As of June 2015, an estimated 3,852,881 individuals held an active RN license (up from 3,530,174 in 2013) in the United States and its territories, representing an increase of 322,707 RN licensees from 2013. (At the time of publication [February 2016], there were approximately, 3,764,491 active $\mathrm{RN}$ licensees).

The average age of the RNs in this study (49) falls between HRSA's most recently reported (2013) average age (44.6) and the average age reported in the 2013 National Nursing Workforce Survey (50). The current study did not indicate an impending shortage of nurses due to large age cohorts retiring. In fact, there was not a disproportionate number of older RNs; further, RNs in the older age cohorts were less likely to be employed in nursing full time. However, among APRNs, the age of CNMs and CNSs has increased more than that of NPs and CRNAs. However, data did suggest an aging nurse faculty. Approximately $50 \%$ of full-time faculty were age 50 and older; only $9.4 \%$ of nurse faculty were younger than age 40 . Of those with a secondary faculty position, $44.7 \%$ were age 50 and older, and $9.1 \%$ were younger than age 40. These data differ slightly from those of HRSA (2010), which found that almost $60 \%$ of nurse faculty were older than age 50 , and only $15 \%$ were younger than age 40 .

Evidence on the progress towards the IOM recommendation of increasing the proportion of nurses with a baccalaureate degree to $80 \%$ by the year 2020 has been steadily accumulating over the past 5 years. This study found that $65 \%$ of all RNs had obtained a baccalaureate or higher degree, up from 2013, when $61 \%$ had obtained a baccalaureate or higher degree. Newly licensed RNs, those licensed from 2013 to 2015, were more likely to have obtained a BSN as their initial education (48.6\%) versus RNs licensed prior to 2000 (34.8\%). This trend toward a higher percentage of RNs with a BSN as their initial education was further illustrated by an increase in the percentage of respondents with a BSN degree as their initial nursing education (39.0\%), as compared to the 
2013 data (36\%). This consistent growth aligns with HRSA (2013) results, which found a 135\% growth (from 2001 to 2011) in BSN-prepared first-time NCLEX-RN ${ }^{\circledR}$ test takers. Among RNs with initial education at the diploma level, $46.3 \%$ obtained additional degrees after licensure, the most common being a BSN (14.3\%).

Buerhaus, Auerbach, and Staiger (2014) investigated the growth of the number of graduates from ADN, BSN, and graduate programs in nursing. Results revealed for the first time ever, in 2011, the number of nurses who earned BSN degrees was greater than the number of nurses with ADN degrees. The number of graduates from both types of programs increased from 2002 to 2012; however, the percentage of degrees awarded at the BSN level increased from 45\% in 2002 to $53 \%$ in 2012. Influencing this change was the rapid growth of accelerated RN-to-BSN nursing education programs and growth of nursing education programs in general.

The current study found that approximately $6.7 \%$ of the $\mathrm{RN}$ workforce obtained their entry-level nursing education outside of the United States. HRSA (2010) showed that 5\% of the RNs licensed prior to 2004 were foreign-educated nurses, and 8\% since then. In 2013, 6\% of the respondents were foreign-educated, indicating a slight upward trend. For nurses licensed between 2013 and 2015, foreign-educated graduates were more likely to have obtained a BSN to qualify them for their first U.S. license (72.2\%) as compared to U.S.-educated graduates (47.2\%). More broadly, in terms of highest level of education, $77.8 \%$ of foreign-educated nurses had a baccalaureate degree or above, while $64.8 \%$ of U.S.-educated nurses did.

In 2015, the IOM released a report in brief, Assessing Progress on the Institute of Medicine Report The Future of Nursing (IOM, 2015). A specific recommendation was to promote diversity in the profession to better represent the patient population it serves, including gender, race, and ethnic diversity. The current study indicated that male RNs (8.0\%) were better represented in the nursing workforce compared to 2013 results (7\%). While this percentage is lower than the $9.2 \%$ reported by HRSA (2015), our data indicated a substantially higher proportion of males in the more recently licensed cohorts (12.7\%), as opposed to those licensed prior to $2000(4.7 \%)$, suggesting higher percentages of men in the nursing workforce in the future. In terms of racial and ethnic minority diversity, minority groups accounted for approximately $19.5 \%$ of the RN respondents in the 2015 and 2013 surveys; HRSA's brief on gender and racial/ethnic diversity of U.S. health occupations for 2010-2012 (HRSA, 2015) found 21.4\%. These estimates are below the almost $40 \%$ of ethnic minorities in the U.S. population (U.S. Census Bureau, 2015). The current study's data indicate that, when compared with White/Caucasian nurses, ethnic minorities are better represented in younger age-groups and more recently licensed RNs than older RNs and RNs licensed prior to 2000. Again suggesting that as older RNs retire, the $\mathrm{RN}$ workforce may become more racially/ethnically diverse.

The Future of Nursing report also recommended doubling the number of nurses with a doctorate degree by 2020 (IOM, 2010). In this study, 2.2\% reported their highest education degree was a doctorate or a DNP. Less than $4 \%$ of respondents were full-time nurse faculty. Among nurse faculty, slightly less than $13 \%$ held a doctorate in a nursing-related or other field; approximately $5 \%$ of this group had a DNP, $8 \%$ had a PhD-nursing, while 36\% had an MSN as their highest education. Of all study respondents with a secondary position in nursing, almost $11 \%$ indicated they were nurse faculty. The national shortage of doctorally prepared nurse faculty contributed to many qualified nursing school applicants in 2014 being turned down (American Association of Colleges of Nursing, 2015). While more full-time and primary nurse faculty are needed, RNs who work part time as nurse faculty in a secondary position are one avenue of increasing nurse faculty numbers.

The percentage of APRNs in the nursing workforce increased from $7 \%$ to $9 \%$ in 2013 and to between $8.5 \%$ and $10 \%$ in the current study. Seventy percent of APRNs were NPs; $13 \%$ were CNSs; approximately $4 \%$ were CNMs; and $13 \%$ were CRNAs. In terms of age, of those indicating "advanced practice nurse" as primary position title, $56.9 \%$ were younger than age 50 and $43.1 \%$ were age 50 and older. Data suggested an aging trend in CNMs more so than any other APRN group, a finding supported when data are compared with HRSA's 2010 and 2013 reports. Over 90\% of APRNs have a master's degree or higher, a finding unchanged since HRSA's 2010 findings. Since 2011, the number of CNMs actively working toward a master's degree or doctorate has substantially increased compared to HRSA's 2010 findings. Seventy-five percent of CNMs now hold graduate degrees compared to $56 \%$ in 2008. Almost $80 \%$ of all APRNs have the job title "advanced practice nurse."

Approximately $70 \%$ of CNMs had an "advanced practice nurse" title, while $17.7 \%$ had a "staff nurse" title. This is a shift from HRSA's 2010 results, where 42\% of CNMs had an "advanced practice nurse" title and 38\% had a "staff nurse" title.

Compared to other APRN groups, CRNAs tend to be younger than their colleagues; however, the percentage of CRNAs younger than age 40 has decreased from 2008 (HRSA, 2010), and the percentage older than age 55 is higher-11.0\% of CRNAs age 65 or older continue to work. Prior to 2008, CRNAs were not required to have graduate-level education; the number of CRNAs with graduate-level preparation has increased to $70 \%$ as compared to $65 \%$ reported by HRSA in 2010.

Approximately $80 \%$ of the responding licensed RNs reported being actively employed in nursing and $63 \%$ are employed full time. In 2010, HRSA estimated that $85 \%$ of licensed RNs were employed in nursing. In this study, RNs worked approximately 40 hours per week. Over $50 \%$ of RNs' primary employment setting was a hospital, down from $62 \%$ in 2008 (HRSA, 2010), and 
newly licensed RNs were most likely to be found in a hospital setting. Nurses' work setting is changing due in part to the growing use and acceptance of technology (American Well, 2015; HIMSS Analytics, 2015).

Telehealth is a growing trend in health care delivery and has the potential to affect the nursing workforce as well as nurse licensure issues. For these reasons, the current survey added additional items related to telehealth practice by nurses. When looking at telehealth usage results, it is important to consider how the question was worded and how that may have influenced how RNs responded. Respondents were asked to indicate the percentage of time they provided nursing services or communicated with a patient or client located somewhere different from where they were located, via phone or electronically. Results revealed that nearly half of RNs have provided nurse services using telehealth technologies. Of those, $39.4 \%$ provided these services across a state border and $7.7 \%$ across a national border.

These data raise important questions for employers and regulators. The NCSBN National Licensure Compact (NLC) is working with states to advance a multistate licensure model that replaces the one-license, one-state model and would allow nurses to communicate and provide services remotely and over long distances. NCSBN is working with states to adopt the NLC, which will provide a multistate license to eligible nurses. This would be issued by their state of residence and allow them to practice across state lines in other Compact states without the time and expense of obtaining additional licenses.

The median RN pre-tax annual earnings from a primary nursing position was \$65,000. In 2010, HRSA reported a mean salary of $\$ 66,973$. It should be noted that a direct comparison of median salary with mean salary has many limitations, as the mean is more sensitive to outliers. Further data, on salary in this study revealed that the difference in median earnings for male $($ at $\$ 72,000)$ and female RNs (at \$64,000) was consistent with other studies (Buerhaus, Auerbach \& Staiger, 2014; Muench, Sindelar, Busch, \& Buerhaus, 2015). In the current study, median salaries differed greatly based on geographic region; for instance, RNs in California reported the highest median salary $(\$ 90,000)$, while RNs practicing in South Dakota reported the lowest $(\$ 51,000)$. Additionally, a breakdown of salary by race/ethnicity showed that White/Caucasian RNs exhibited the lowest median salary, although this may be a function of the geographic distribution of race/ethnicity across the United States; racial/ethnic minority RNs tend to be more predominately located in states with higher salaries.

\section{Limitations}

The current study had a few limitations. First, the response rate was $34.3 \%$ for RNs. In 2013, the overall RN response rate was $39 \%$. The current study used a different mailing method and included a $\$ 1$ incentive, which could be reasons for the lower response rate. Another reason could be the addition of the salary question, which has the potential to suppress response rates. Response rates are one measure of survey quality; however, they may not be a good measure of response bias. A formal nonresponse bias analysis was conducted following the close of the survey. An analysis of basic demographic data (i.e., gender, age, race/ethnicity, number of years since graduation, number of years since first licensed) for all $\mathrm{RN}$ licensees sampled from the Nursys database was used to compare the survey respondents and nonrespondents to determine the representativeness of the survey participants. Results revealed that the following groups of nurses may have been slightly overrepresented: White/Caucasian, female, age 60 or older. Because of missing data on race/ethnicity, only gender and age were used to make nonresponse weighting adjustments. Additionally, since the sampling was stratified by state, to prevent smaller states from being overrepresented in the overall analysis, a weighting variable was constructed to adjust for differing nursing population sizes across states.

Second, in certain categories such as annual earnings data were missing or incomplete, causing inconsistent statistics. The large sample size of the study partially compensated for this problem; for the variable of salary, we determined that median salary was the most accurate measure of central tendency. Of the overall respondents, $30.2 \%$ did not answer the primary nursing position earnings question; hence, item nonresponse bias could be impacting the results. Both upper and lower limits have been set on the provided salary figures and extreme values could be skewing mean values upward; the discussion of the salary figures relies on the median values as being the more accurate measure of central tendency.

The data on telehealth cannot be directly compared to other studies on this topic, as the wording necessary for our purposes was not congruent with other studies. Future data collection efforts should involve consistent wording of questions so trends can be compared to earlier findings.

The data presented on male nurses, foreign-educated nurses, and APRNs represent smaller sample sizes. In general, caution should be taken in interpreting any statistics from a small group or cell size.

Finally, to illustrate trends in workforce supply, the current study's results, as appropriate, were compared to the 2013 National Nursing Workforce Study (Budden et al., 2013), in which data were from 2013; to HRSA 2010 results, which were RN workforce data from 2008; and to HRSA 2013 findings, which were from 2008-2010. While the current study used a sample of all RN licensees, which included individuals who were not actively employed in nursing, the other studies may not have. When comparing the current study's results to those of HRSA 2013, which contained data from the U.S. Census Bureau's American Community 
Survey, it should be noted the data were from individuals who reported their current occupation as nursing and who currently had or were seeking a job. The HRSA 2015 data cited were for the U.S. working-age population age 16 or older who were currently employed or who were recently employed and were seeking employment (e.g., individuals who were recently laid off). Thus, the comparisons of statistics from various studies presented should be interpreted with the above considerations in mind.

\section{Conclusion}

This national randomized survey provides a cross-sectional view of the current RN nursing workforce. The data generated contribute to a better understanding of the supply of nurses today and identify important trends in the national workforce. The workforce of today will change as older nurses retire and sufficient numbers of nurses step in to fill their shoes; the workforce of tomorrow is slightly younger, more diverse, and has a higher initial nursing education. Advances in technology will continue to raise important questions for employers and regulators. This study also contributes information with which to assess progress towards the goals outlined in the Future of Nursing report (IOM, 2010), including achieving higher levels of education, promoting diversity, and improving data collection concerning the national health workforce.

\section{Licensed Practical Nurse/Vocational Nurse Results}

Of the 120,783 LPN/VNs in the sample, 32,263 responded, for a response rate of 28.0\%; 29,500 (91.4\%) responded via paper surveys and 2,763 (8.6\%) responded online. Mailed surveys marked undeliverable $(5,493)$ were returned. Individuals with LPN/ $\mathrm{VN}$ licenses that indicated they held an RN and/or APRN credential were removed from analyses.

\section{Age}

The average age of LPN/VNs was 47.8 ( $M$ 48; SD 13.1). The reported age of respondents was similar across all age categories; gender, by age-group, was similar for male and female LPN/VNs (Table 70).

TABLE 70

\section{Age Distribution and Gender by Age}

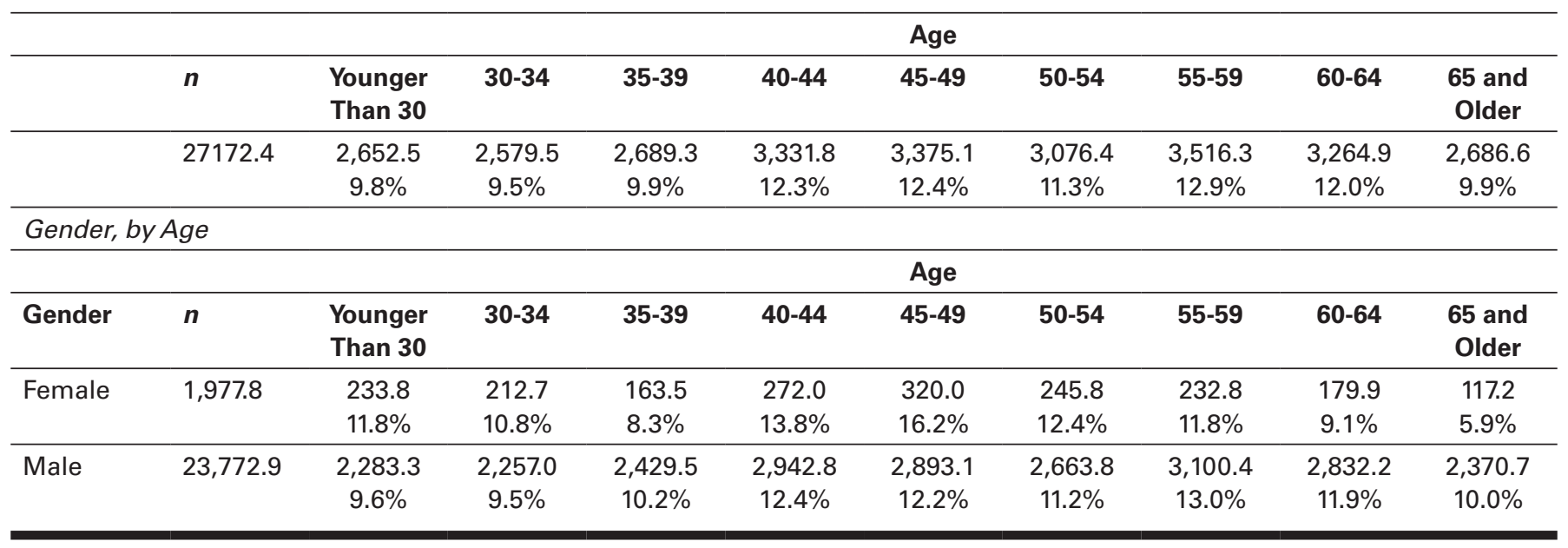

\section{Race/Ethnicity by Age}

In terms of race/ethnicity by age-group, larger percentages of minorities are younger as compared to those nearing retirement (Table 71). For instance, $33.1 \%$ of Asians reported being younger than age 35, while $9.7 \%$ reported being age 60 or older. While $17.8 \%$ of White/Caucasians reported being younger than age 35, 25\% reported being age 60 or older. 


\section{TABLE 71}

\section{Race/Ethnicity, by Age}

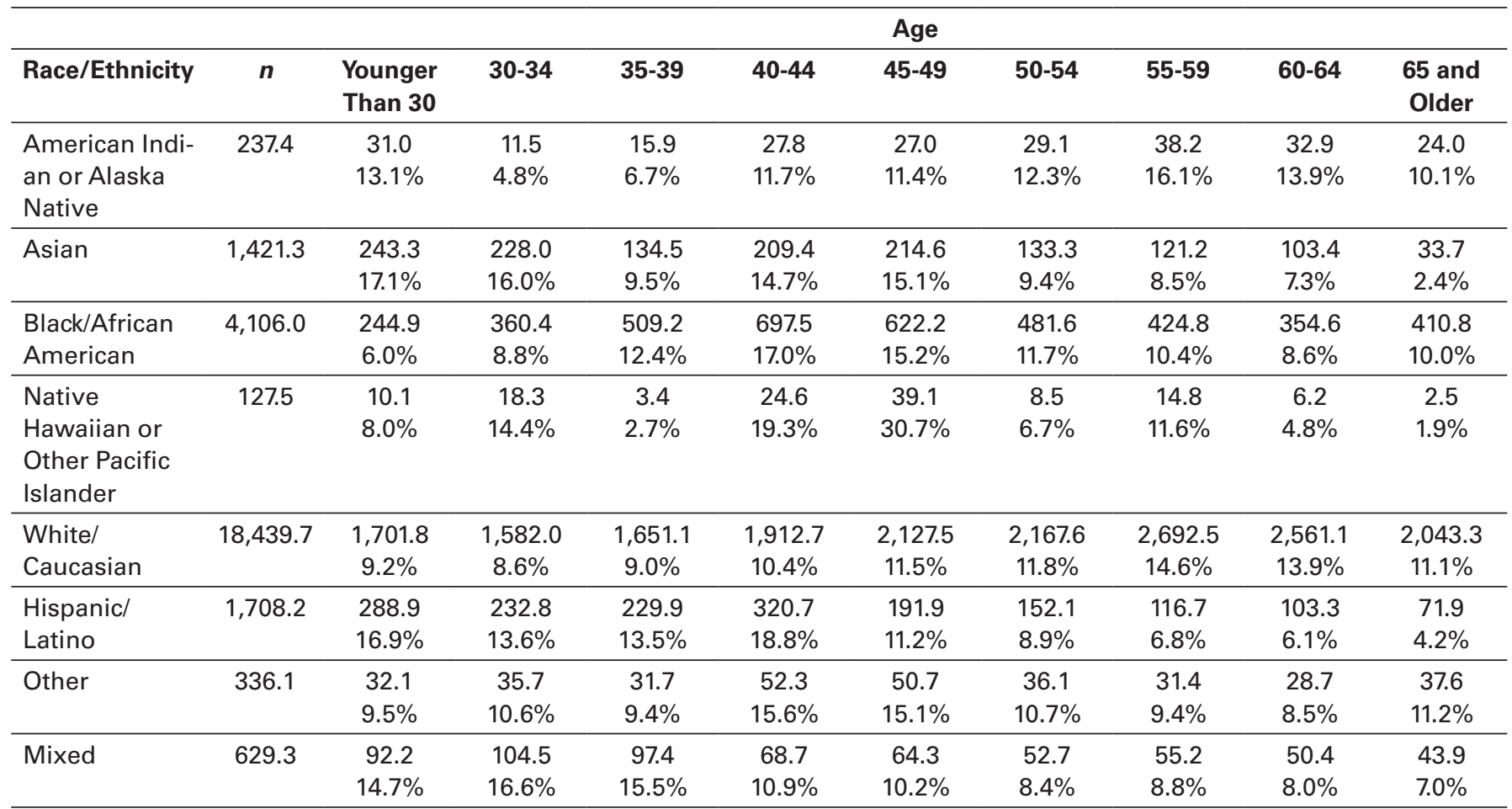

Note. Respondents were asked to mark all that applied for Race/Ethnicity. However, responses were coded to be mutually exclusive. If respondents selected multiple options, they were coded as Mixed Race/Ethnicity.

\section{Initial Nursing Education by Age}

An examination of initial nursing education by age-group revealed that those age 60 and older showed a higher percentage of receiving a vocational/practical certificate-nursing (23.2\%) versus those younger than age 35 (18.8\%) (Table 72$)$.

\section{TABLE 72}

\section{Initial Nursing Education, by Age}

\begin{tabular}{|c|c|c|c|c|c|c|c|c|c|c|}
\hline & & & & & & Age & & & & \\
\hline $\begin{array}{l}\text { Initial Nursing } \\
\text { Education }\end{array}$ & $n$ & $\begin{array}{l}\text { Younger } \\
\text { Than } 30 \\
\end{array}$ & $30-34$ & $35-39$ & $40-44$ & $45-49$ & $50-54$ & $55-59$ & $60-64$ & $\begin{array}{c}65 \text { and } \\
\text { Older }\end{array}$ \\
\hline Diploma & $3,283.19$ & $\begin{array}{l}318.0 \\
9.7 \% \\
\end{array}$ & $\begin{array}{l}384.7 \\
11.7 \% \\
\end{array}$ & $\begin{array}{l}382.6 \\
11.7 \% \\
\end{array}$ & $\begin{array}{c}447.0 \\
13.6 \% \\
\end{array}$ & $\begin{array}{l}458.4 \\
14.0 \% \\
\end{array}$ & $\begin{array}{l}430.3 \\
13.1 \% \\
\end{array}$ & $\begin{array}{l}345.9 \\
10.5 \% \\
\end{array}$ & $\begin{array}{l}287.2 \\
8.8 \% \\
\end{array}$ & $\begin{array}{l}229.2 \\
7.0 \% \\
\end{array}$ \\
\hline ADN & $1,022.35$ & $\begin{array}{r}116.2 \\
11.4 \% \\
\end{array}$ & $\begin{array}{c}131.4 \\
12.9 \% \\
\end{array}$ & $\begin{array}{l}120.2 \\
11.8 \% \\
\end{array}$ & $\begin{array}{r}148.6 \\
14.5 \% \\
\end{array}$ & $\begin{array}{r}124.6 \\
12.2 \% \\
\end{array}$ & $\begin{array}{l}120.6 \\
11.8 \% \\
\end{array}$ & $\begin{array}{l}121.1 \\
11.8 \% \\
\end{array}$ & $\begin{array}{l}80.9 \\
7.9 \% \\
\end{array}$ & $\begin{array}{l}58.8 \\
5.8 \% \\
\end{array}$ \\
\hline BSN & 111.35 & $\begin{array}{c}23.6 \\
21.2 \%\end{array}$ & $\begin{array}{c}2.8 \\
2.6 \%\end{array}$ & $\begin{array}{c}3.0 \\
2.7 \%\end{array}$ & $\begin{array}{c}21.9 \\
19.7 \%\end{array}$ & $\begin{array}{c}25.1 \\
22.5 \%\end{array}$ & $\begin{array}{c}6.6 \\
5.9 \%\end{array}$ & $\begin{array}{c}11.4 \\
10.2 \%\end{array}$ & $\begin{array}{c}11.7 \\
10.5 \%\end{array}$ & $\begin{array}{c}5.3 \\
4.8 \%\end{array}$ \\
\hline
\end{tabular}

\section{Employment Status by Age}

An analysis of age-group by employment status revealed that a much lower percentage of LPN/VNs were employed in nursing between the ages of 60 and $64(68.0 \%)$ and 65 and older (42.0\%) as compared to LPN/VNs younger than age 30 (85.0\%) (Table 73). Additionally, LPN/VNs younger than age 30 had the highest unemployed rate (9.2\%).

S54 Journal of Nursing Regulation 


\section{TABLE 73}

\section{Age, by Employment Status}

\begin{tabular}{|c|c|c|c|c|c|c|c|c|c|}
\hline & & & & & Age & & & & \\
\hline Employment Status & $\begin{array}{c}\text { Younger } \\
\text { Than } 30 \\
(n=2,651.6)\end{array}$ & $\begin{array}{c}30-34 \\
(n= \\
2,579.0)\end{array}$ & $\begin{array}{c}35-39 \\
(n= \\
2,687.4)\end{array}$ & $\begin{array}{c}40-44 \\
(n= \\
3,322.0)\end{array}$ & $\begin{array}{c}45-49 \\
(n= \\
3,368.9)\end{array}$ & $\begin{array}{c}50-54 \\
(n= \\
3,066.4)\end{array}$ & $\begin{array}{c}55-59 \\
(n= \\
3,512.5)\end{array}$ & $\begin{array}{c}60-64 \\
(n= \\
3,261.3)\end{array}$ & $\begin{array}{c}65 \text { and } \\
\text { Older } \\
(n=2,679.8)\end{array}$ \\
\hline $\begin{array}{l}\text { Employed in nursing } \\
\text { (overall) }\end{array}$ & $\begin{array}{l}2,254.1 \\
85.0 \% \\
\end{array}$ & $\begin{array}{c}2,246.8 \\
87.1 \% \\
\end{array}$ & $\begin{array}{c}2,303.0 \\
85.7 \% \\
\end{array}$ & $\begin{array}{c}2,916.0 \\
87.8 \% \\
\end{array}$ & $\begin{array}{c}2,884.8 \\
85.6 \% \\
\end{array}$ & $\begin{array}{c}2,529.4 \\
82.5 \% \\
\end{array}$ & $\begin{array}{c}2,728.4 \\
77.7 \% \\
\end{array}$ & $\begin{array}{c}2,218.8 \\
68.0 \% \\
\end{array}$ & $\begin{array}{l}1,125.5 \\
42.0 \% \\
\end{array}$ \\
\hline Full time & $\begin{array}{c}1,756.4 \\
66.2 \%\end{array}$ & $\begin{array}{l}1,822.6 \\
70.7 \%\end{array}$ & $\begin{array}{c}1,864.8 \\
69.4 \%\end{array}$ & $\begin{array}{c}2,483.6 \\
74.8 \%\end{array}$ & $\begin{array}{l}2,441.6 \\
72.5 \%\end{array}$ & $\begin{array}{c}2,171.3 \\
70.8 \%\end{array}$ & $\begin{array}{c}2,178.4 \\
62.0 \%\end{array}$ & $\begin{array}{c}1,699.6 \\
52.1 \%\end{array}$ & $\begin{array}{c}540.1 \\
20.2 \%\end{array}$ \\
\hline Part time & $\begin{array}{l}342.1 \\
12.9 \%\end{array}$ & $\begin{array}{c}316.4 \\
12.3 \%\end{array}$ & $\begin{array}{l}342.8 \\
12.8 \%\end{array}$ & $\begin{array}{l}322.3 \\
9.7 \%\end{array}$ & $\begin{array}{l}348.2 \\
10.3 \%\end{array}$ & $\begin{array}{l}304.5 \\
9.9 \%\end{array}$ & $\begin{array}{l}426.3 \\
12.1 \%\end{array}$ & $\begin{array}{l}389.1 \\
11.9 \%\end{array}$ & $\begin{array}{l}452.3 \\
16.9 \%\end{array}$ \\
\hline Per diem & $\begin{array}{l}242.2 \\
9.1 \%\end{array}$ & $\begin{array}{l}246.9 \\
9.6 \% \\
\end{array}$ & $\begin{array}{l}203.2 \\
7.6 \% \\
\end{array}$ & $\begin{array}{l}218.7 \\
6.6 \% \\
\end{array}$ & $\begin{array}{l}212.1 \\
6.3 \% \\
\end{array}$ & $\begin{array}{l}150.8 \\
4.9 \% \\
\end{array}$ & $\begin{array}{l}262.4 \\
7.5 \% \\
\end{array}$ & $\begin{array}{l}231.9 \\
7.1 \% \\
\end{array}$ & $\begin{array}{l}198.6 \\
7.4 \% \\
\end{array}$ \\
\hline $\begin{array}{l}\text { Employed in other } \\
\text { field* }^{*}\end{array}$ & $\begin{array}{l}83.5 \\
3.1 \% \\
\end{array}$ & $\begin{array}{l}73.1 \\
2.8 \% \\
\end{array}$ & $\begin{array}{l}133.1 \\
5.0 \% \\
\end{array}$ & $\begin{array}{l}141.4 \\
4.3 \% \\
\end{array}$ & $\begin{array}{l}211.0 \\
6.3 \% \\
\end{array}$ & $\begin{array}{l}208.2 \\
6.8 \% \\
\end{array}$ & $\begin{array}{l}218.3 \\
6.2 \% \\
\end{array}$ & $\begin{array}{l}219.5 \\
6.7 \% \\
\end{array}$ & $\begin{array}{l}96.1 \\
3.6 \% \\
\end{array}$ \\
\hline
\end{tabular}

Note. Columns do not sum to age $n$ 's and percentages do not sum to $100 \%$ because the employment status question had additional response options and respondents could select multiple options. Some respondents may have selected "actively employed in nursing"; however, they may not have specified full time or part time. Hence, those numbers will not sum to "actively employed in nursing" totals.

${ }^{*}$ Is not employed in nursing.

\section{Gender}

The current study indicated $7.5 \%$ of the LPN/VN workforce was male and $92.5 \%$ were female.

\section{Year Licensed by Gender}

An examination of gender of LPN/VNs by year licensed cohort revealed a trend toward an increase in the proportion of males in the workforce (Table 74). Specifically, for respondents licensed prior to 2000, 4.7\% were male; of those licensed from 2010 to 2012 , $10.3 \%$ were male; and of those licensed from 2013 to $2015,12.7 \%$ were male.

\section{TABLE 74}

\section{Year Licensed, by Gender}

\begin{tabular}{|c|c|c|c|c|}
\hline \multirow[b]{2}{*}{ Gender } & \multicolumn{4}{|c|}{ Year Licensed } \\
\hline & $\begin{array}{c}\text { Licensed } \\
\text { Prior to } 2000 \\
(n=11,119.2)\end{array}$ & $\begin{array}{c}\text { Licensed } \\
2000-2009 \\
(n=6,339.7)\end{array}$ & $\begin{array}{c}\text { Licensed } \\
2010-2012 \\
(n=3,306.2)\end{array}$ & $\begin{array}{c}\text { Licensed } \\
2013-2015 \\
(n=3,104.1)\end{array}$ \\
\hline Female & $\begin{array}{c}10,597.5 \\
95.3 \%\end{array}$ & $\begin{array}{c}5,806.8 \\
91.6 \%\end{array}$ & $\begin{array}{c}2,965.1 \\
89.7 \%\end{array}$ & $\begin{array}{c}2,709.3 \\
87.3 \%\end{array}$ \\
\hline Male & $\begin{array}{l}521.2 \\
4.7 \%\end{array}$ & $\begin{array}{c}532.9 \\
8.4 \%\end{array}$ & $\begin{array}{c}341.1 \\
10.3 \%\end{array}$ & $\begin{array}{c}394.8 \\
12.7 \%\end{array}$ \\
\hline
\end{tabular}

Education, Employment Setting, and Position Title by Gender

Results of highest level of education of LPN/VNs employed in nursing by gender indicated men were most prevalent in the master'sother field category (35.6\%) (Table 75). 


\section{TABLE 75}

\section{Highest Level of Education of LPN/VNs Employed in Nursing, by Gender}

\begin{tabular}{|c|c|c|c|}
\hline \multirow[b]{2}{*}{ Highest Level of Education } & \multirow[b]{2}{*}{$n$} & \multicolumn{2}{|c|}{ Gender } \\
\hline & & Men & Women \\
\hline Vocational/practical certificate-nursing & $13,927.7$ & 874.4 & $13,053.3$ \\
\hline \multirow[t]{2}{*}{ Diploma } & $2,957.0$ & 167.2 & $2,789.8$ \\
\hline & & $5.7 \%$ & $94.4 \%$ \\
\hline \multirow[t]{2}{*}{ Associate's-other field } & $1,645.7$ & 177.4 & $1,468.4$ \\
\hline & & $10.8 \%$ & $89.2 \%$ \\
\hline \multirow[t]{2}{*}{ BSN } & 225.7 & 43.4 & 182.3 \\
\hline & & $19.2 \%$ & $80.8 \%$ \\
\hline Baccalaureate-other field & $1,254.4$ & 245.5 & $1,008.9$ \\
\hline \multirow[t]{2}{*}{ Master's-other field } & 219.0 & 77.9 & 141.2 \\
\hline & & $35.6 \%$ & $64.4 \%$ \\
\hline \multirow[t]{2}{*}{ DNP } & 0.0 & 0.0 & 0.0 \\
\hline & & $0.0 \%$ & $0.0 \%$ \\
\hline \multirow[t]{2}{*}{ PhD-nursing } & 0.0 & 0.0 & 0.0 \\
\hline & & $0.0 \%$ & $0.0 \%$ \\
\hline \multirow[t]{2}{*}{ Doctoral-nursing other } & 0.0 & 0.0 & 0.0 \\
\hline & & $0.0 \%$ & $0.0 \%$ \\
\hline \multirow[t]{2}{*}{ Doctoral-other field } & 26.0 & 4.6 & 21.4 \\
\hline & & $17.8 \%$ & $82.3 \%$ \\
\hline
\end{tabular}

Results of primary employment settings by gender indicated men were more prevalent in correctional facilities (17.4\%), academic settings (11.0\%), and hospitals (10.9\%) (Table 76).

\section{TABLE 76}

\section{Primary Employment Setting, by Gender}

\begin{tabular}{|c|c|c|c|}
\hline \multirow[b]{2}{*}{ Primary Employment Setting } & \multirow[b]{2}{*}{$n$} & \multicolumn{2}{|c|}{ Gender } \\
\hline & & Men & Women \\
\hline Academic & 132.1 & 14.6 & 117.5 \\
\hline \multirow[t]{2}{*}{ Ambulatory care } & $1,940.6$ & 101.7 & $1,838.9$ \\
\hline & & $5.2 \%$ & $94.8 \%$ \\
\hline \multirow[t]{2}{*}{ Community health } & 866.0 & 56.4 & 809.5 \\
\hline & & $6.5 \%$ & $93.5 \%$ \\
\hline \multirow[t]{2}{*}{ Correctional } & 617.3 & 107.7 & 509.7 \\
\hline & & $17.4 \%$ & $82.6 \%$ \\
\hline Home health & $3,262.6$ & 254.2 & $3,008.4$ \\
\hline
\end{tabular}

S56 Journal of Nursing Regulation 


\begin{tabular}{|c|c|c|c|}
\hline \multirow[b]{2}{*}{ Primary Employment Setting } & \multirow[b]{2}{*}{$n$} & \multicolumn{2}{|c|}{ Gender } \\
\hline & & Men & Women \\
\hline Insurance & 244.0 & 11.9 & 232.1 \\
\hline \multirow[t]{2}{*}{ Nursing home/extended care } & $6,511.8$ & 559.1 & $5,952.2$ \\
\hline & & $8.6 \%$ & $91.4 \%$ \\
\hline \multirow[t]{2}{*}{ Policy/regulatory/licensing } & 30.4 & 0.0 & 30.4 \\
\hline & & $0.0 \%$ & $100.0 \%$ \\
\hline \multirow[t]{2}{*}{ Public health } & 387.5 & 9.8 & 377.6 \\
\hline & & $2.5 \%$ & $97.5 \%$ \\
\hline School health & 652.5 & 15.8 & 636.6 \\
\hline
\end{tabular}

Analysis of primary position title by gender indicated that men were more prevalent in the nurse executive (20.7\%) and consultant $(11.6 \%)$ positions (Table 77$)$.

\section{TABLE 77}

\section{Primary Position Title, by Gender}

\begin{tabular}{|c|c|c|c|}
\hline \multirow[b]{2}{*}{ Position Title } & \multirow[b]{2}{*}{$n$} & \multicolumn{2}{|c|}{ Gender } \\
\hline & & Men & Women \\
\hline Advanced practice nurse & 369.5 & 14.7 & 354.8 \\
\hline \multirow[t]{2}{*}{ Case manager } & 542.6 & 57.1 & 485.6 \\
\hline & & $10.5 \%$ & $89.5 \%$ \\
\hline \multirow[t]{2}{*}{ Consultant } & 131.6 & 15.3 & 116.3 \\
\hline & & $11.6 \%$ & $88.4 \%$ \\
\hline \multirow[t]{2}{*}{ Nurse executive } & 129.1 & 26.8 & 102.3 \\
\hline & & $20.7 \%$ & $79.3 \%$ \\
\hline Nurse faculty & 899.1 & 56.1 & 843.0 \\
\hline \multirow[t]{2}{*}{ Nurse researcher } & 60.3 & 0.0 & 60.3 \\
\hline & & $0.0 \%$ & $100.0 \%$ \\
\hline \multirow[t]{2}{*}{ Other-health related } & $2,405.1$ & 168.6 & $2,236.5$ \\
\hline & & $7.0 \%$ & $93.0 \%$ \\
\hline \multirow[t]{2}{*}{ Other-not health related } & 210.2 & 19.6 & 190.6 \\
\hline & & $9.3 \%$ & $90.7 \%$ \\
\hline \multirow[t]{2}{*}{ Staff nurse } & $15,323.1$ & $1,260.5$ & $14,062.1$ \\
\hline & & $8.2 \%$ & $91.8 \%$ \\
\hline
\end{tabular}

\section{Race/Ethnicity}

The current study found that $31.9 \%$ of responding LPN/VNs were minorities, while $68.1 \%$ of the respondents were White/ Caucasian (Table 78). The largest reporting minority group was Black/African American (15.3\%). 


\section{TABLE 78}

\section{Race/Ethnicity}

\begin{tabular}{lcc}
\hline & $(\boldsymbol{n}=\mathbf{3 0 , 6 2 0 . 8 )}$ & Percentage \\
\hline American Indian or Alaska Native & 267.6 & $0.9 \%$ \\
\hline Asian & $1,583.2$ & $5.2 \%$ \\
\hline Black/African American & $4,689.5$ & $15.3 \%$ \\
\hline Native Hawaiian or Other Pacific Islander & 144.4 & $0.5 \%$ \\
\hline White/Caucasian & $20,839.7$ & $68.1 \%$ \\
\hline Hispanic/Latino & $1,964.6$ & $6.4 \%$ \\
\hline Other & 429.2 & $1.4 \%$ \\
\hline Mixed & 702.6 & $2.3 \%$ \\
\hline
\end{tabular}

Note. Respondents were asked to mark all that applied for Race/Ethnicity. However, responses were coded to be mutually exclusive. If respondents selected multiple options, they were coded as Mixed Race/Ethnicity.

\section{Employment by Age and Race/Ethnicity}

An examination of age of LPN/VNs employed in nursing by race/ethnicity found that Hispanic/Latinos were, on average, the youngest, while White/Caucasians were the oldest (Table 79).

\section{TABLE 79}

\section{Age of LPN/VNs Employed in Nursing, by Race/Ethnicity}

\begin{tabular}{|c|c|c|c|c|c|c|}
\hline & $n$ & $M$ & $S D$ & Min & Max & Median \\
\hline American Indian or Alaska Native & 313.0 & 48.8 & 11.5 & 20.0 & 79.0 & 50.0 \\
\hline Asian & 879.0 & 42.3 & 15.2 & 21.0 & 82.0 & 42.0 \\
\hline Native Hawaiian or Other Pacific Islander & 115.0 & 44.0 & 11.2 & 24.0 & 74.0 & 45.0 \\
\hline White/Caucasian & $20,515.0$ & 49.0 & 12.5 & 19.0 & 105.0 & 50.0 \\
\hline Other & 271.0 & 47.2 & 14.7 & 20.0 & 87.0 & 45.0 \\
\hline Mixed & 676.0 & 43.5 & 12.6 & 19.0 & 93.0 & 41.0 \\
\hline
\end{tabular}

Note. Respondents were asked to mark all that applied for Race/Ethnicity. However, responses were coded to be mutually exclusive. If respondents selected multiple options, they were coded as Mixed Race/Ethnicity.

\section{Year Licensed by Race/Ethnicity}

Compared to those licensed prior to 2000, newly licensed LPN/VNs were more likely to have a more diverse racial/ethnic composition (Table 80). In particular, of LPN/VNs licensed prior to 2000, $78.8 \%$ were White/Caucasian, while $55.6 \%$ of LPN/VNs licensed from 2013 to 2015 were White/Caucasian.

\section{TABLE 80}

\section{Year Licensed, by Race/Ethnicity}

\begin{tabular}{lcccc}
\hline & \multicolumn{3}{c}{ Year Licensed } \\
\hline Race/Ethnicity & Licensed & Licensed & Licensed & Licensed \\
& Prior to 2000 & $\mathbf{2 0 0 0 - 2 0 0 9}$ & $\mathbf{2 0 1 0 - 2 0 1 2}$ & $\mathbf{2 0 1 3 - 2 0 1 5}$ \\
& $(\boldsymbol{n}=\mathbf{1 1 , 8 0 9 . 7 )}$ & $(\boldsymbol{n = 6 , 5 6 2 . 6 )}$ & $(\boldsymbol{n = 3 , 4 8 9 . 4 )}$ & $(\boldsymbol{n = 3 , 2 4 3 . 1 )}$ \\
\hline American Indian or Alaska Native & 101.3 & 44.1 & 41.0 & 23.7 \\
& $0.9 \%$ & $0.7 \%$ & $1.2 \%$ & $0.7 \%$ \\
\hline
\end{tabular}




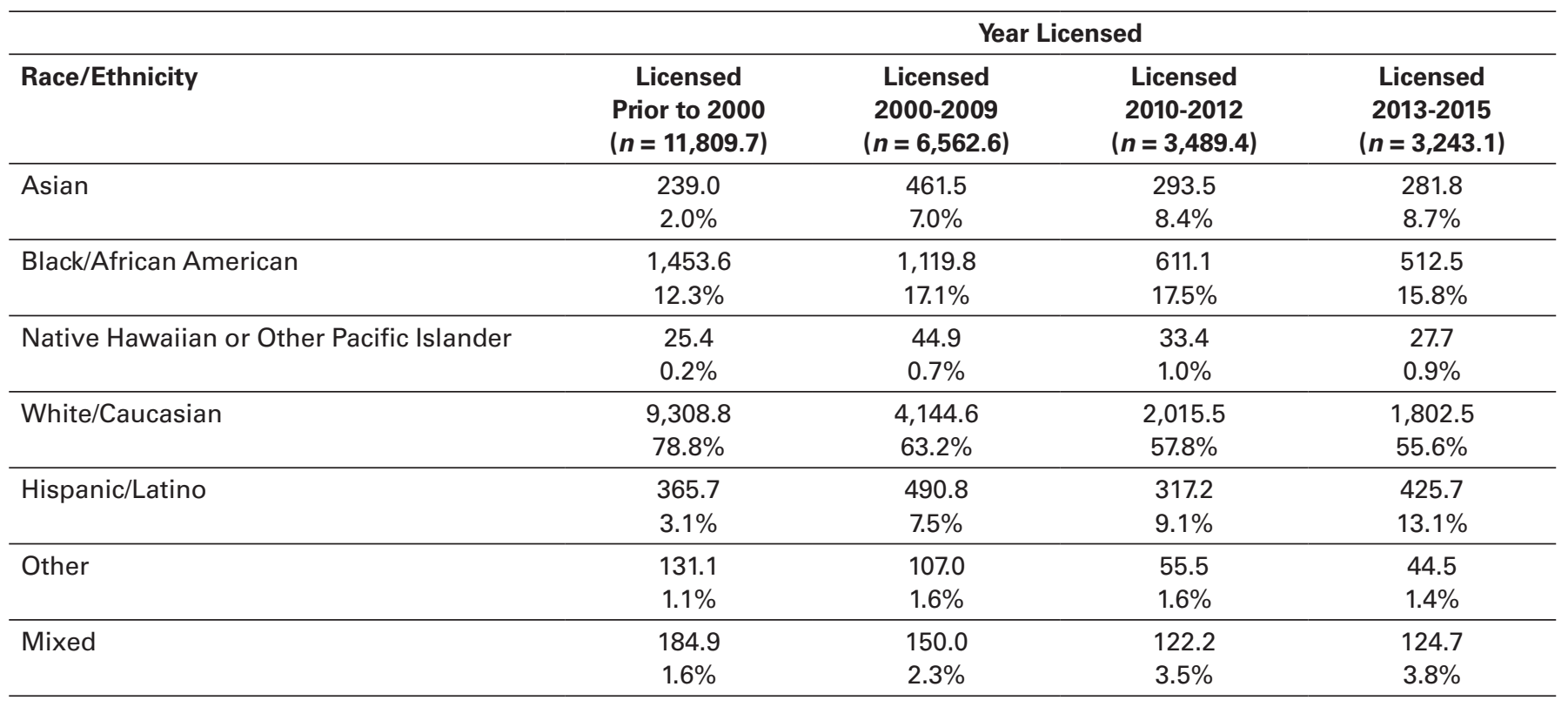

Note. Respondents were asked to mark all that applied for Race/Ethnicity. However, responses were coded to be mutually exclusive. If respondents selected multiple options they were coded as Mixed Race/Ethnicity.

\section{Education and Position Title by Race/Ethnicity}

Data suggest that LPN/VNs with their highest level of education as BSN had lower percentages of White/Caucasian as compared to those with certificate, diploma, and ADN education (Table 81).

\section{TABLE 81}

\section{Highest Level of Education of LPN/VNs Employed in Nursing, by Race/Ethnicity}






\begin{tabular}{|c|c|c|c|c|c|c|c|c|c|}
\hline \multirow[b]{2}{*}{$\begin{array}{l}\text { Highest Level of } \\
\text { Education }\end{array}$} & \multirow[b]{2}{*}{$n$} & \multicolumn{8}{|c|}{ Race/Ethnicity } \\
\hline & & $\begin{array}{c}\text { American } \\
\text { Indian or } \\
\text { Alaska } \\
\text { Native }\end{array}$ & Asian & $\begin{array}{c}\text { Black/ } \\
\text { African } \\
\text { American }\end{array}$ & $\begin{array}{c}\text { Native } \\
\text { Hawaiian } \\
\text { or Other } \\
\text { Pacific } \\
\text { Islander }\end{array}$ & $\begin{array}{c}\text { White/ } \\
\text { Caucasian }\end{array}$ & $\begin{array}{c}\text { Hispanic/ } \\
\text { Latino }\end{array}$ & Other & Mixed \\
\hline PhD-nursing & 0.0 & $\begin{array}{c}0.0 \\
0.0 \%\end{array}$ & $\begin{array}{c}0.0 \\
0.0 \%\end{array}$ & $\begin{array}{c}0.0 \\
0.0 \%\end{array}$ & $\begin{array}{c}0.0 \\
0.0 \%\end{array}$ & $\begin{array}{c}0.0 \\
0.0 \%\end{array}$ & $\begin{array}{c}0.0 \\
0.0 \%\end{array}$ & $\begin{array}{c}0.0 \\
0.0 \%\end{array}$ & $\begin{array}{c}0.0 \\
0.0 \%\end{array}$ \\
\hline $\begin{array}{l}\text { Doctoral-other } \\
\text { field }\end{array}$ & 26.1 & $\begin{array}{c}0.0 \\
0.0 \%\end{array}$ & $\begin{array}{c}12.6 \\
48.3 \%\end{array}$ & $\begin{array}{c}3.3 \\
12.6 \%\end{array}$ & $\begin{array}{c}0.0 \\
0.0 \%\end{array}$ & $\begin{array}{c}2.8 \\
10.7 \%\end{array}$ & $\begin{array}{c}7.4 \\
28.4 \%\end{array}$ & $\begin{array}{c}0.0 \\
0.0 \%\end{array}$ & $\begin{array}{c}0.0 \\
0.0 \%\end{array}$ \\
\hline
\end{tabular}

An analysis of primary position title by race/ethnicity shows that LPN/VNs hold a wide variety of titles (Table 82).

\section{TABLE 82}

\section{Primary Position Title, by Race/Ethnicity}

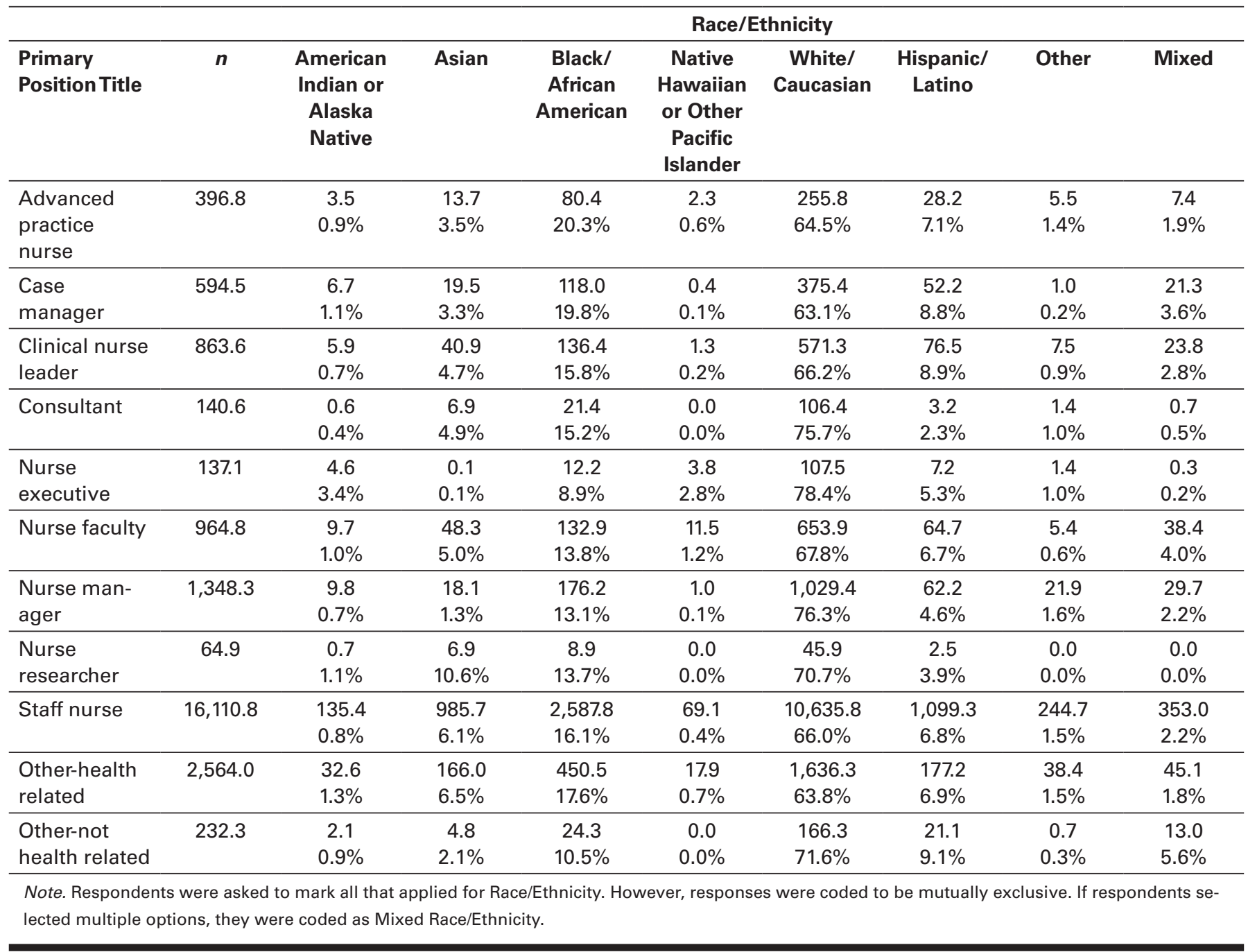




\section{Education}

When asked to indicate highest level of education, $64.9 \%$ of respondents in the current study indicated that they had obtained a vocational/practical certificate in nursing (Table 83).

\section{TABLE 83}

\section{Highest Level of Education}

\begin{tabular}{lcc}
\hline & $(\boldsymbol{n}=\mathbf{3 0 , 0 1 7 . 9 )}$ & Percentage \\
\hline Vocational/practical certificate-nursing & $19,481.3$ & $64.9 \%$ \\
\hline Diploma-nursing & $3,882.5$ & $12.9 \%$ \\
\hline ADN & $1,888.6$ & $6.3 \%$ \\
\hline Associate's degree-other field & $2,243.9$ & $7.5 \%$ \\
\hline BSN & 308.5 & $1.0 \%$ \\
\hline Baccalaureate degree-other field & $1,795.4$ & $6.0 \%$ \\
\hline MSN & 13.9 & $0.0 \%$ \\
\hline Master's degree-other field & 352.2 & $1.2 \%$ \\
\hline Doctoral degree-nursing practice (DNP) & 0.6 & $0.0 \%$ \\
\hline Doctoral degree-nursing (PhD) & 0.0 & $0.0 \%$ \\
\hline Doctoral degree-nursing other & 1.0 & $0.0 \%$ \\
\hline Doctoral degree-other field & 50.0 & $0.2 \%$
\end{tabular}

The majority (95.1\%) of LPNs received their entry-level education in the United States, while $4.9 \%$ received their entry-level education in other countries, such as the Philippines (1.9\%), Canada (0.1\%), India (0.2\%), and other countries (2.8\%).

\section{Year Licensed by Education}

An examination of year licensed cohort by initial nursing education revealed a decreasing trend of those with certificates as initial nursing education (Table 84).

\section{TABLE 84}

\section{Year Licensed, by Initial Nursing Education}

\begin{tabular}{|c|c|c|c|c|}
\hline \multirow[b]{2}{*}{ Initial Nursing Education } & \multicolumn{4}{|c|}{ Year Licensed } \\
\hline & $\begin{array}{c}\text { Licensed } \\
\text { Prior to } 2000 \\
(n=11,644.8)\end{array}$ & $\begin{array}{c}\text { Licensed } \\
2000-2009 \\
(n=6,513.6)\end{array}$ & $\begin{array}{c}\text { Licensed } \\
2010-2012 \\
(n=3,427.1)\end{array}$ & $\begin{array}{c}\text { Licensed } \\
2013-2015 \\
(n=3,204.4)\end{array}$ \\
\hline Vocational/practical certificate-nursing & $\begin{array}{c}10,175.8 \\
87.4 \%\end{array}$ & $\begin{array}{c}5,280.1 \\
81.1 \%\end{array}$ & $\begin{array}{c}2,756.9 \\
80.5 \%\end{array}$ & $\begin{array}{l}2,541.1 \\
79.3 \%\end{array}$ \\
\hline Diploma-nursing & $\begin{array}{c}1,124.9 \\
9.7 \% \\
\end{array}$ & $\begin{array}{c}911.0 \\
14.0 \% \\
\end{array}$ & $\begin{array}{l}488.1 \\
14.2 \% \\
\end{array}$ & $\begin{array}{l}473.8 \\
14.8 \% \\
\end{array}$ \\
\hline ADN & $\begin{array}{l}305.3 \\
2.6 \% \\
\end{array}$ & $\begin{array}{l}279.2 \\
4.3 \% \\
\end{array}$ & $\begin{array}{l}179.2 \\
5.2 \% \\
\end{array}$ & $\begin{array}{l}165.9 \\
5.2 \% \\
\end{array}$ \\
\hline BSN & $\begin{array}{l}38.6 \\
0.3 \%\end{array}$ & $\begin{array}{l}43.2 \\
0.7 \%\end{array}$ & $\begin{array}{c}2.8 \\
0.1 \%\end{array}$ & $\begin{array}{l}23.6 \\
0.7 \%\end{array}$ \\
\hline
\end{tabular}

\section{Employment}

The current study's results revealed $77.0 \%$ of licensees were actively employed in nursing and $61.2 \%$ of licensees were employed full time (Table 85 ). Of note, results indicated $10.3 \%$ were unemployed; however, only $5.1 \%$ were actively seeking work as a nurse. 


\section{TABLE 85}

\section{Employment Status}

\begin{tabular}{lcc}
\hline & $(\boldsymbol{n}=\mathbf{3 0 , 7 6 6 . 0})$ & Percentage \\
\hline Actively employed in nursing & $23,680.0$ & $77.0 \%$ \\
\hline Full time & $18,823.4$ & $61.2 \%$ \\
\hline Part time & $3,714.0$ & $12.1 \%$ \\
\hline Per diem & $2,179.4$ & $7.1 \%$ \\
\hline Actively employed in a field other than nursing & $2,690.8$ & $8.7 \%$ \\
\hline Full time & $1,504.3$ & $4.9 \%$ \\
\hline Part time & 868.5 & $2.8 \%$ \\
\hline Per diem & 386.7 & $1.3 \%$ \\
\hline Working in nursing only as a volunteer & 366.1 & $1.2 \%$ \\
\hline Unemployed & & \\
\hline Seeking work as a nurse & $1,558.7$ & $5.1 \%$ \\
\hline Not seeking work as a nurse & $1,588.9$ & $5.2 \%$ \\
\hline Retired & $2,927.1$ & $9.5 \%$ \\
\hline
\end{tabular}

Note. Respondents were asked to mark all that applied. Percentages are calculated off of responding sample.

\section{The Unemployed}

Of respondents who indicated they were unemployed, $3.3 \%$ indicated the reason was because of taking care of home and family (Table 86). Another $23.1 \%$ indicated difficulty in finding a nursing position as their reason for unemployment.

\section{TABLE 86}

\section{Reasons for Unemployment}

\begin{tabular}{lcc}
\hline & $(\boldsymbol{n}=\mathbf{2 , 6 4 4 . 5 )}$ & Percentage \\
\hline Taking care of home and family & $1,033.0$ & $39.1 \%$ \\
\hline Disabled & 463.3 & $17.5 \%$ \\
\hline Inadequate salary & 77.9 & $2.9 \%$ \\
\hline In school & 393.9 & $14.9 . \%$ \\
\hline Difficulty in finding a nursing position & 610.4 & $23,1 \%$ \\
\hline Other, please specify & 636.8 & $24.1 . \%$ \\
\hline
\end{tabular}

Note. Respondents were asked to mark all that applied.

\section{Year Licensed by Employment Status}

Results of year licensed cohort by employment status revealed a higher employed in nursing rate for those licensed after 2010 (Table 87), approximately $87 \%$, as compared to LPN/VNs licensed prior to 2000 (69.7\%). Additionally, LPN/VNs licensed from 2013 to 2015 had the highest unemployed and seeking work as a nurse rate $(8.4 \%)$. 


\section{TABLE 87}

\section{Year Licensed, by Employment Status}

\begin{tabular}{|c|c|c|c|c|}
\hline \multirow[b]{2}{*}{ Employment Status } & \multicolumn{4}{|c|}{ Year Licensed } \\
\hline & $\begin{array}{c}\text { Licensed } \\
\text { Prior to } 2000 \\
(n=11,867.0)\end{array}$ & $\begin{array}{c}\text { Licensed } \\
2000-2009 \\
(n=6,602.1)\end{array}$ & $\begin{array}{c}\text { Licensed } \\
2010-2012 \\
(n=3,501.6)\end{array}$ & $\begin{array}{c}\text { Licensed } \\
2013-2015 \\
(n=3,260.4)\end{array}$ \\
\hline Employed in nursing (overall) & $\begin{array}{c}8,276.9 \\
69.7 \%\end{array}$ & $\begin{array}{c}5,544.0 \\
84.0 \%\end{array}$ & $\begin{array}{c}3,052.0 \\
87.2 \%\end{array}$ & $\begin{array}{c}2,830.6 \\
86.8 \%\end{array}$ \\
\hline Full time & $\begin{array}{c}6,472.1 \\
54.5 \%\end{array}$ & $\begin{array}{c}4,701.2 \\
71.2 \%\end{array}$ & $\begin{array}{l}2442.3 \\
69.7 \%\end{array}$ & $\begin{array}{c}2,120.8 \\
65.0 \%\end{array}$ \\
\hline Part time & $\begin{array}{c}1,413.5 \\
11.9 \%\end{array}$ & $\begin{array}{l}637.8 \\
9.7 \%\end{array}$ & $\begin{array}{l}448.5 \\
12.8 \%\end{array}$ & $\begin{array}{c}527.0 \\
16.2 \%\end{array}$ \\
\hline Per diem & $\begin{array}{l}732.3 \\
6.2 \% \\
\end{array}$ & $\begin{array}{c}432.9 \\
6.6 \% \\
\end{array}$ & $\begin{array}{l}327.0 \\
9.3 \% \\
\end{array}$ & $\begin{array}{c}347.8 \\
10.7 \% \\
\end{array}$ \\
\hline Employed in other field* & $\begin{array}{l}774.5 \\
6.5 \%\end{array}$ & $\begin{array}{l}282.9 \\
4.3 \%\end{array}$ & $\begin{array}{l}141.2 \\
4.0 \%\end{array}$ & $\begin{array}{l}110.1 \\
3.4 \%\end{array}$ \\
\hline
\end{tabular}

Note. Columns do not sum to year licensed $n$ 's and percentages do not sum to $100 \%$ because the employment status question had additional response options and respondents could select multiple options. Some respondents may have selected "actively employed in nursing"; however, they may not have specified full time or part time. Hence, those numbers will not sum to "actively employed in nursing" totals.

*Is not employed in nursing.

\section{Practice Specialty}

In the current study, $27.6 \%$ of LPN/VNs reported their primary practice specialty as geriatric/gerontology, followed by other $(15.5 \%)$, primary care $(7.7 \%)$, and pediatric specialty $(6.0 \%)$ (Table 88$)$.

\section{TABLE 88}

\section{Primary Employment Specialty}

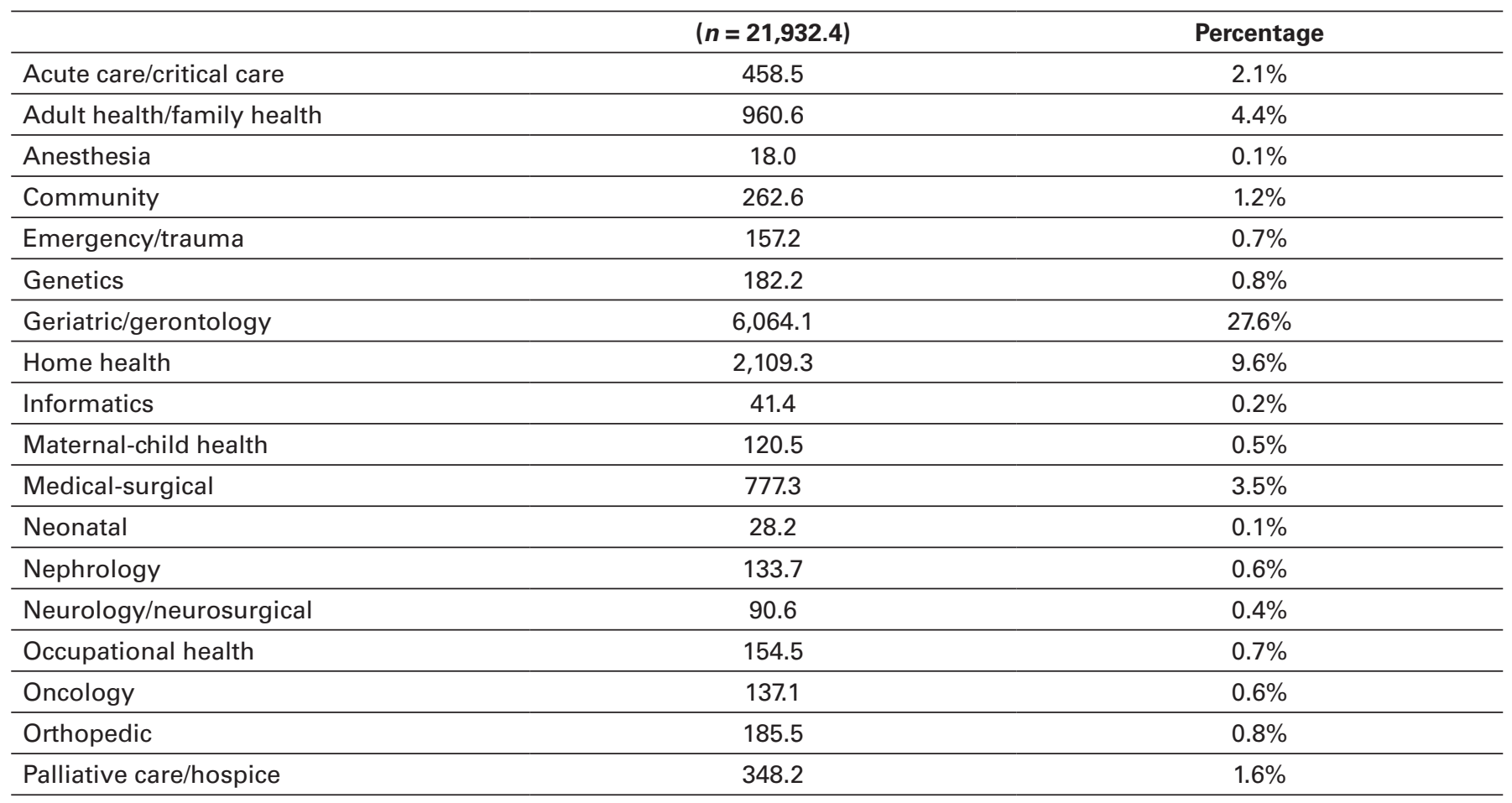




\begin{tabular}{lcc}
\hline & $(\boldsymbol{n}=\mathbf{2 1 , 9 3 2 . 4 )}$ & Percentage \\
\hline Pediatrics & $1,326.0$ & $6.0 \%$ \\
\hline Perioperative & 93.1 & $0.4 \%$ \\
\hline Primary care & $1,695.5$ & $7.7 \%$ \\
\hline Psychiatric/mental health/substance abuse & $1,084.8$ & $4.9 \%$ \\
\hline Public health & 173.1 & $0.8 \%$ \\
\hline Radiology & 24.2 & $0.1 \%$ \\
\hline Rehabilitation & 847.7 & $3.9 \%$ \\
\hline School health & 612.9 & $2.8 \%$ \\
\hline Urologic & 102.1 & $0.5 \%$ \\
\hline Women's health & 342.8 & $1.6 \%$ \\
\hline Other & $3,400.7$ & $15.5 \%$ \\
\hline
\end{tabular}

Note. Survey participants were asked to answer this question only if they were actively employed in nursing.

\section{Average Hours Worked}

The current study found that the average number of hours worked during a typical week for LPN/VNs was 37.9 hours $($ SD = 13.0). Those LPN/VNs who worked one nursing job worked an average of 37.1 hours per week $(S D=11.2)$. Respondents age 45 to 49 tended to work the most hours per week (39.6). With the exception of respondents age 65 and older (28.9 hours), there were very small differences in average hours worked per week.

An examination of average hours worked per week by age-group revealed a similar number of hours per week across age-groups (i.e., 40.7-42.8 hours). However, primary employment setting by age-group could vary; for example, in public health, $26.4 \%$ of public health nurses were younger than age 35 , while $8.1 \%$ were age 60 or older.

\section{Telehealth Utilization and Communication}

Respondents were asked to indicate the percentage of time they provided nursing services or communicated with a patient or client located somewhere different from where they were located, via phone or electronically. Those who reported providing telehealth services were asked to indicate if services were provided across a state or national border (Table 89). Results revealed that $53.9 \%$ of respondents never engaged in telehealth, while $23.3 \%$ engaged in telehealth between $1 \%$ and $25 \%$ of their time. Of respondents who engaged in telehealth, $66.2 \%$ never engaged in telehealth across a state border, while $27.5 \%$ engaged in telehealth across a state border between $1 \%$ and $25 \%$ of their time. Of respondents who engaged in telehealth, $92.0 \%$ never engaged in telehealth across a national border, while $5.7 \%$ engaged in telehealth across a national border between $1 \%$ and $25 \%$ of their time

\section{TABLE 89}

\section{Telehealth Utilization}

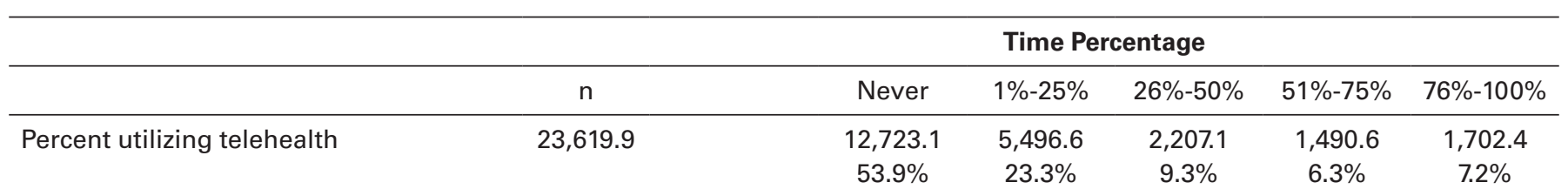

\section{Telehealth Utilization Across a State Border}

\begin{tabular}{lccccccc}
\hline & \multicolumn{3}{c}{ Time Percentage } \\
\hline & $\boldsymbol{n}$ & $\begin{array}{c}\text { Not } \\
\text { Applicable* }\end{array}$ & Never & $\mathbf{1 \% - 2 5 \%}$ & $\mathbf{2 6 \% - 5 0 \%}$ & $\mathbf{5 1 \% - 7 5 \%}$ & $\mathbf{7 6 \% - 1 0 0 \%}$ \\
\hline $\begin{array}{l}\text { Percent utilizing telehealth across state } \\
\text { border }\end{array}$ & $11,421.5$ & $11,387.9$ & $7,566.5$ & $3,140.4$ & 371.1 & 180.4 & 163.1 \\
& & & $66.2 \%$ & $27.5 \%$ & $3.2 \%$ & $1.6 \%$ & $1.4 \%$
\end{tabular}




\begin{tabular}{lccccccc}
\hline & \multicolumn{5}{c}{ Time Percentage } \\
\hline & $\boldsymbol{n}$ & $\begin{array}{c}\text { Not } \\
\text { Applicable* }\end{array}$ & Never & $\mathbf{1 \% - 2 5 \%}$ & $\mathbf{2 6 \% - 5 0 \%}$ & $\mathbf{5 1 \% - 7 5 \%}$ & $\mathbf{7 6 \% - 1 0 0 \%}$ \\
\hline Percent utilizing telehealth across a na- & $11,089.2$ & $12,029.2$ & $10,201.8$ & 633.3 & 129.0 & 82.0 & 43.1 \\
tional border & & & $92.0 \%$ & $5.7 \%$ & $1.2 \%$ & $0.7 \%$ & $0.4 \%$ \\
\hline
\end{tabular}

*Does not provide nursing services or communicate with remote patients or clients.

Respondents were asked to describe the mode(s) of communication they used to provide nursing services or communicate with a remote patient or client (Table 90). Of respondents who engaged in telehealth, the large majority (58.9\%) used the telephone, followed by e-mail (18.2\%) and electronic messaging (13.5\%).

\section{TABLE 90}

\section{Modes of Communication Used for Telehealth}

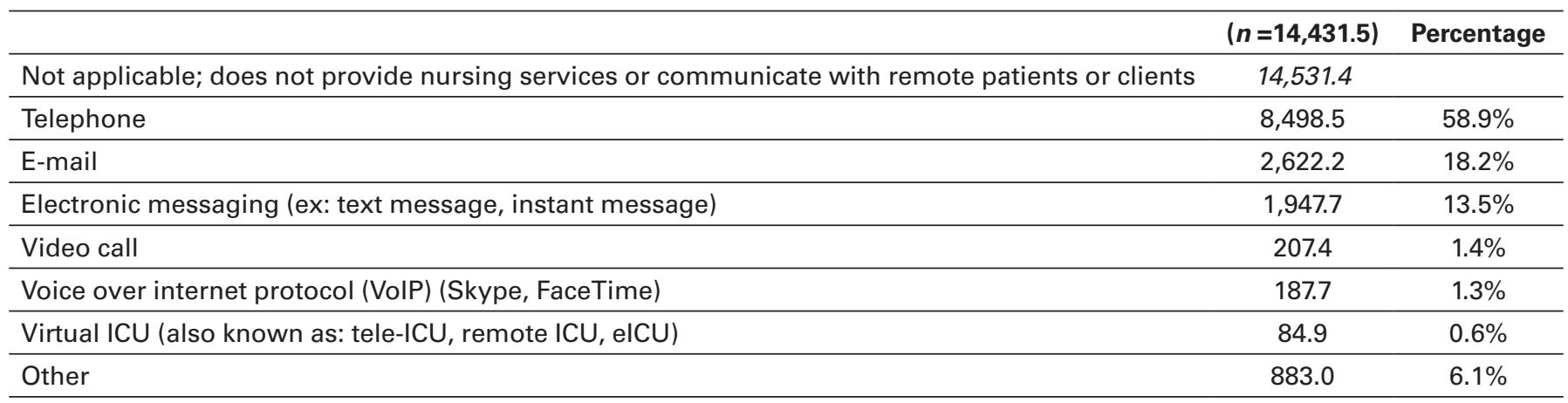

Note. Respondents were asked to mark all that applied

\section{Annual Earnings}

The salary of LPN/VNs was not reported in the 2013 National Workforce Survey of Registered Nurses, but was reported in the HRSA (2010) survey. Please see Appendix D or HRSA (2010) for specific item wording. In the current study, $30.2 \%$ of the overall respondents did not answer the primary nursing position earnings question; hence, item nonresponse bias could be impacting the results. Both upper and lower limits for the salary variable were set conservatively and remaining extreme values could be skewing mean values upward; the discussion of the salary figures relies on the median values as being the more accurate measure of central tendency.

The median LPN/VN pre-tax annual earnings from their primary nursing position was $\$ 38,000$; LPN/VNs also reported median earnings of $\$ 10,000$ from a secondary nursing position (Table 91).

\section{TABLE 91}

\section{Pre-Tax Annual Earnings from Primary Nursing Position}

\begin{tabular}{lcrr}
\hline & $\boldsymbol{n}$ & Median & \\
\hline Overall & $19,084.0$ & $\$ 38,000.00$ & \\
\hline
\end{tabular}

2014 Pre-Tax Annual Earnings from Secondary Nursing Position

\begin{tabular}{|c|c|c|}
\hline & $n$ & Median \\
\hline Overall & $2,392.0$ & $\$ 10,000.00$ \\
\hline
\end{tabular}

Note. Respondents who obtained initial U.S. licensure in 2015 were removed from analyses. Includes overtime and bonuses, but excludes sign-on bonuses. 
When broken out by age, LPN/VN earnings from their primary position show a steady rise up to the 40-45 age-group, where the median salary peaks at $\$ 40,000$ (Table 92 ).

\section{TABLE 92}

\section{Annual Earnings in Primary Nursing Position, by Age}

\begin{tabular}{lrr}
\hline & $\boldsymbol{n}$ & Median \\
\hline Younger than 30 & $1,438.0$ & $\$ 32,000.00$ \\
\hline $30-34$ & $1,510.0$ & $\$ 36,000.00$ \\
\hline $35-39$ & $1,599.0$ & $\$ 36,000.00$ \\
\hline $40-44$ & $1,853.0$ & $\$ 40,000.00$ \\
\hline $45-49$ & $1,908.0$ & $\$ 40,000.00$ \\
\hline $50-54$ & $2,422.0$ & $\$ 40,000.00$ \\
\hline $55-59$ & $2,864.0$ & $\$ 40,000.00$ \\
\hline 65 and older & $2,479.0$ & $\$ 40,000.00$ \\
\hline Note. Respondents who obtained initial U.S. licensure in 2015 were removed from analyses. Includes overtime and bonuses, but excludes sign-on bo-
\end{tabular}

The median salary for LPN/VNs licensed prior to 2010 was \$40,000, while more newly licensed LPN/VNs made lower median salaries (Table 93).

\section{TABLE 93}

\section{Annual Earnings in Primary Nursing Position, by Year Licensed}

\begin{tabular}{llr}
\hline & $\boldsymbol{n}$ & Median \\
\hline Licensed prior to 2000 & $8,393.0$ & $\$ 40,000.00$ \\
\hline Licensed 2000-2009 & $4,131.0$ & $\$ 40,000.00$ \\
\hline Licensed 2010-2012 & $2,190.0$ & $\$ 36,000.00$ \\
\hline Licensed 2013-2015 & $1,539.0$ & $\$ 30,000.00$ \\
\hline
\end{tabular}

Note. Respondents who obtained initial U.S. licensure in 2015 were removed from analyses. Includes overtime and bonuses, but excludes sign-on bonuses.

The median earnings for male LPN/VNs was \$43,200, while the median earnings for female LPN/VNs was \$38,000 (Table 94).

\section{TABLE 94}

\section{Average Salary in Primary Nursing Position, by Gender}

\begin{tabular}{lcr}
\hline & $\boldsymbol{n}$ & \multicolumn{1}{c}{ Median } \\
\hline Female & $16,964.0$ & $\$ 38,000.00$ \\
\hline Male & $1,044.0$ & $\$ 43,200.00$ \\
\hline
\end{tabular}

Note. Respondents who obtained initial U.S. licensure in 2015 were removed from analyses. Includes overtime and bonuses, but excludes sign-on bonuses.

The median earnings for White/Caucasian LPN/VNs was \$37,000; Hispanic LPN/VNs, \$40,000; Black/African American LPN/VNs, \$40,000; and Asian LPN/VNs, \$45,000 (Table 95). The fact that White/Caucasian LPN/VNs exhibited the lowest median salary may be a function of the geographic distribution of races across the United States, with White/Caucasian nurses more predominantly located in states with lower salaries. 


\section{TABLE 95}

\section{Average Salary in Primary Nursing Position, by Race/Ethnicity}

\begin{tabular}{lcc}
\hline & $\boldsymbol{n}$ & Median \\
\hline American Indian or Alaska Native & 217.0 & $\$ 40,000.00$ \\
\hline Asian & 613.0 & $\$ 45,000.00$ \\
\hline Black/African American & $2,476.0$ & $\$ 40,000.00$ \\
\hline Native Hawaiian or Other Pacific Islander & 70.0 & $\$ 50,000.00$ \\
\hline White/Caucasian & $14,304.0$ & $\$ 37,000.00$ \\
\hline Hispanic/Latino & 656.0 & $\$ 40,000.00$ \\
\hline Other & 181.0 & $\$ 40,000.00$ \\
\hline Mixed & 473.0 & $\$ 39,600.00$ \\
\hline $\begin{array}{l}\text { Note. Respondents who obtained initial U.S. licensure in 2015 were removed from analyses. Includes overtime and bonuses, but excludes sign-on bo- } \\
\text { nuses. Respondents were asked to mark all that applied for Race/Ethnicity. However, responses were coded to be mutually exclusive. If respondents se- } \\
\text { lected multiple options, they were coded as Mixed Race/Ethnicity. }\end{array}$ &
\end{tabular}

\section{Average Salary by Education}

When broken out by highest level of education, the highest median earnings were for LPN/VNs with a BSN or master's-other field (\$45,000) (Table 96).

\section{TABLE 96}

\section{Average Salary in Primary Nursing Position, by Highest Level of Education}

\begin{tabular}{lcr}
\hline & $\boldsymbol{n}$ & Median \\
\hline Vocational/practical certificate-nursing & $11,669.0$ & $\$ 38,000.00$ \\
\hline Diploma & $2,737.0$ & $\$ 37,000.00$ \\
\hline ADN & $1,518.0$ & $\$ 38,000.00$ \\
\hline Associate's-other field & $1,388.0$ & $\$ 38,000.00$ \\
\hline BSN & 140.0 & $\$ 45,000.00$ \\
\hline Baccalaureate-other field & $1,015.0$ & $\$ 40,000.00$ \\
\hline MSN & 3.0 & $\$ 32,000.00$ \\
\hline Master's-other field & 171.0 & $\$ 45,000.00$ \\
\hline Doctoral-other field & 13.0 & $\$ 35,000.00$ \\
\hline Note. Respondents who obtained initial U.S. licensure in 2015 were removed from analyses. Includes overtime and bonuses, but excludes sign-on bo- \\
nuses.
\end{tabular}

Average Salary Across States, Employment Status, Employment Setting, Position Title, and Specialty

When broken out by state, the highest median earnings were for LPN/VNs practicing in Alaska (\$50,000) and Washington, DC (\$53,000). The lowest median earnings (not including the territories) were for LPN/VNs practicing in South Dakota (\$30,000) and West Virginia $(\$ 32,000)$ (Table 97).

\section{TABLE 97}

\section{Average Salary in Primary Nursing Position, by State(s) Where Currently Practicing}

\begin{tabular}{|c|c|c|c|c|c|}
\hline & $n$ & Median & & $n$ & Median \\
\hline Alabama & 552.0 & $\$ 33,000.00$ & New Hampshire & 381.0 & $\$ 42,000.00$ \\
\hline Alaska & 99.0 & $\$ 50,000.00$ & New Jersey & 344.0 & $\$ 45,000.00$ \\
\hline
\end{tabular}




\begin{tabular}{|c|c|c|c|c|c|}
\hline & $n$ & Median & & $n$ & Median \\
\hline Arkansas & 488.0 & $\$ 33,500.00$ & New York & 294.0 & $\$ 40,000.00$ \\
\hline California & 420.0 & $\$ 45,000.00$ & North Carolina & 465.0 & $\$ 38,000.00$ \\
\hline Connecticut & 274.0 & $\$ 49,000.00$ & Ohio & 448.0 & $\$ 34,000.00$ \\
\hline Delaware & 257.0 & $\$ 45,000.00$ & Oklahoma & 428.0 & $\$ 35,000.00$ \\
\hline Georgia & 421.0 & $\$ 36,000.00$ & Pennsylvania & 513.0 & $\$ 39,000.00$ \\
\hline Hawaii & 207.0 & $\$ 45,000.00$ & Rhode Island & 208.0 & $\$ 45,000.00$ \\
\hline Idaho & 303.0 & $\$ 32,560.00$ & South Carolina & 445.0 & $\$ 37,124.00$ \\
\hline Illinois & 449.0 & $\$ 40,000.00$ & South Dakota & 348.0 & $\$ 30,000.00$ \\
\hline Indiana & 384.0 & $\$ 36,000.00$ & Tennessee & 536.0 & $\$ 34,000.00$ \\
\hline Kentucky & 397.0 & $\$ 35,000.00$ & Vermont & 258.0 & $\$ 37,128.00$ \\
\hline Louisiana & 471.0 & $\$ 35,000.00$ & Virginia & 356.0 & $\$ 36,000.00$ \\
\hline Maine & 278.0 & $\$ 36,000.00$ & Washington & 468.0 & $\$ 44,000.00$ \\
\hline Maryland & 369.0 & $\$ 45,000.00$ & West Virginia & 295.0 & $\$ 32,000.00$ \\
\hline Massachusetts & 468.0 & $\$ 48,000.00$ & Wisconsin & 386.0 & $\$ 35,000.00$ \\
\hline Michigan & 398.0 & $\$ 35,000.00$ & Wyoming & 166.0 & $\$ 40,000.00$ \\
\hline Minnesota & 550.0 & $\$ 33,000.00$ & $\mathrm{DC}$ & 93.0 & $\$ 53,000.00$ \\
\hline Mississippi & 402.0 & $\$ 35,000.00$ & Virgin Islands & 7.0 & $\$ 35,000.00$ \\
\hline Missouri & 428.0 & $\$ 34,000.00$ & Guam & 22.0 & $\$ 34,000.00$ \\
\hline
\end{tabular}

Note. Respondents could select more than one jurisdiction. Respondents who obtained initial U.S. licensure in 2015 were removed from analyses. Includes overtime and bonuses, but excludes sign-on bonuses.

LPN/VNs working full time $(\$ 40,000)$ made a higher median salary versus those working part time $(\$ 25,000)$ or per diem $(\$ 28,000)$ (Table 98).

\section{TABLE 98}

\section{Average Salary in Primary Nursing Position, by Employment Status}

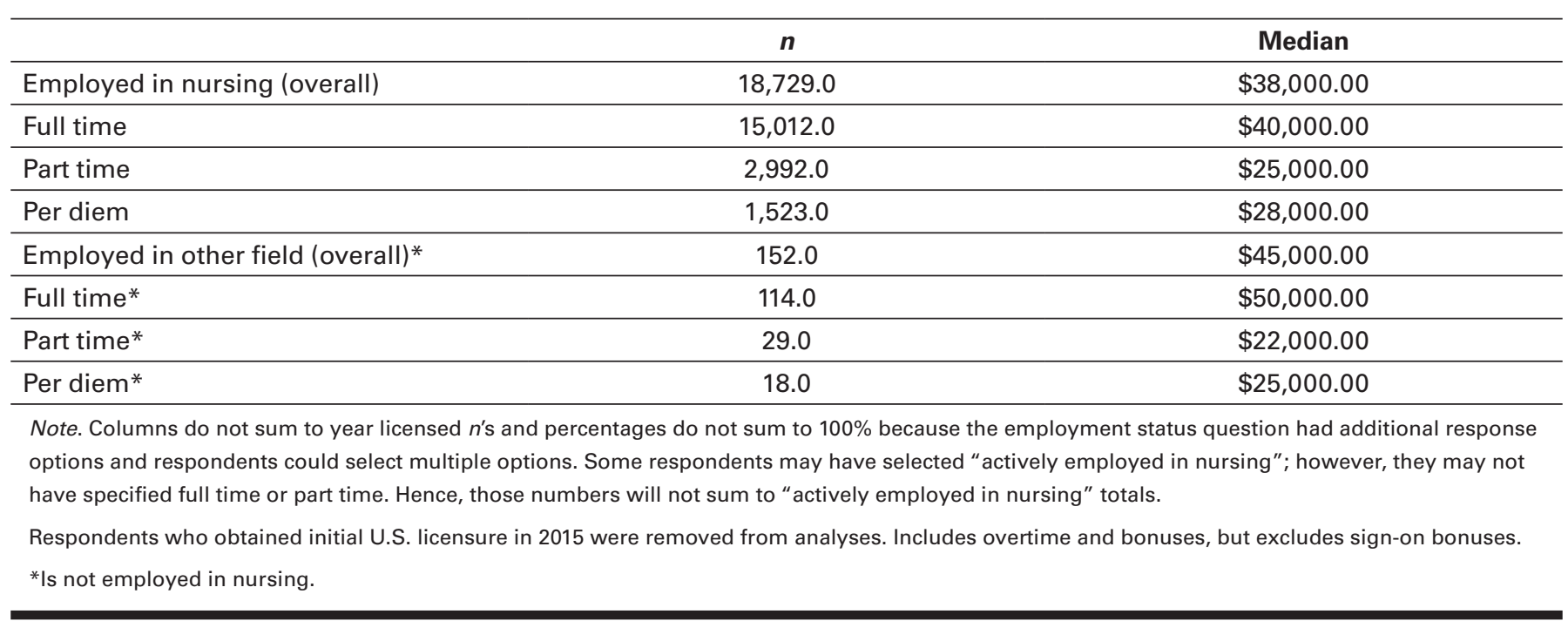


When broken out by employment setting, LPN/VNs working in insurance $(\$ 52,000)$ and policy/regulatory agencies $(\$ 52,000)$ made the highest median salaries, while those working in school health $(\$ 25,000)$ made the lowest (Table 99).

\section{TABLE 99}

\section{Average Salary in Primary Nursing Position, by Primary Employment Setting}

\begin{tabular}{lcc}
\hline & $\boldsymbol{n}$ & Median \\
\hline Academic & 97.0 & $\$ 36,000.00$ \\
\hline Ambulatory care & $2,014.0$ & $\$ 40,000.00$ \\
\hline Assisted living & $1,013.0$ & $\$ 38,000.00$ \\
\hline Community health & 831.0 & $\$ 34,000.00$ \\
\hline Correctional & 471.0 & $\$ 42,000.00$ \\
\hline Home health & $2,185.0$ & $\$ 36,000.00$ \\
\hline Hospital & $1,999.0$ & $\$ 39,860.00$ \\
\hline Insurance & 205.0 & $\$ 52,000.00$ \\
\hline Nursing home/extended care & $5,597.0$ & $\$ 40,000.00$ \\
\hline Occupational health & 145.0 & $\$ 40,000.00$ \\
\hline Policy/regulatory/licensing & 23.0 & $\$ 50,000.00$ \\
\hline Public health & 308.0 & $\$ 32,000.00$ \\
\hline School health & 495.0 & $\$ 25,000.00$ \\
\hline Other & $2,838.0$ & $\$ 37,000.00$ \\
\hline
\end{tabular}

Note. Respondents who obtained initial U.S. licensure in 2015 were removed from analyses. Includes overtime and bonuses, but excludes sign-on bonuses.

Nurse executives $(\$ 62,000)$ and consultants $(\$ 50,000)$ made the highest median salaries, while those with titles of "staff nurse" $(\$ 37,000)$ or "nurse faculty" (\$34,000) made the lowest (Table 100).

\section{TABLE 100}

\section{Average Salary in Primary Nursing Position, by Primary Position Title}

\begin{tabular}{lcc}
\hline & $\boldsymbol{n}$ & Median \\
\hline Advanced practice nurse & 277.0 & $\$ 40,000.00$ \\
\hline Case manager & 407.0 & $\$ 46,000.00$ \\
\hline Clinical nurse leader & 691.0 & $\$ 40,000.00$ \\
\hline Consultant & 77.0 & $\$ 50,000.00$ \\
\hline Nurse executive & 92.0 & $\$ 62,000.00$ \\
\hline Nurse faculty & 651.0 & $\$ 34,000.00$ \\
\hline Nurse manager & $1,089.0$ & $\$ 46,000.00$ \\
\hline Nurse researcher & 49.0 & $\$ 42,000.00$ \\
\hline Other-health related & $1,920.0$ & $\$ 38,000.00$ \\
\hline Other-not health related & 137.0 & $\$ 35,000.00$ \\
\hline Staff nurse & $13,265.0$ & $\$ 37,000.00$ \\
\hline
\end{tabular}

Note. Respondents who obtained initial U.S. licensure in 2015 were removed from analyses. Includes overtime and bonuses, but excludes sign-on bonuses.

LPN/VNs with the employment specialties of anesthesia $(\$ 56,556)$ and radiology $(\$ 50,000)$ made the highest median salaries, while those with specialties of orthopedic $(\$ 33,000)$ and school health $(\$ 25,000)$ made the lowest (Table 101). 


\section{TABLE 101}

\section{Average Salary in Primary Nursing Position, by Primary Employment Specialty}

\begin{tabular}{|c|c|c|}
\hline & $n$ & Median \\
\hline Acute care/critical care & 373.0 & $\$ 40,000.00$ \\
\hline Adult health/family health & 818.0 & $\$ 35,000.00$ \\
\hline Community & 206.0 & $\$ 35,000.00$ \\
\hline Emergency/trauma & 111.0 & $\$ 39,000.00$ \\
\hline Geriatric/gerontology & $5,068.0$ & $\$ 40,000.00$ \\
\hline Home health & $1,376.0$ & $\$ 37,000.00$ \\
\hline Informatics & 47.0 & $\$ 45,000.00$ \\
\hline Maternal-child health & 119.0 & $\$ 38,000.00$ \\
\hline Medical-surgical & 639.0 & $\$ 38,000.00$ \\
\hline Neurology/neurosurgical & 86.0 & $\$ 38,000.00$ \\
\hline Occupational health & 139.0 & $\$ 40,000.00$ \\
\hline Oncology & 98.0 & $\$ 42,000.00$ \\
\hline Orthopedic & 172.0 & $\$ 33,000.00$ \\
\hline Palliative care/hospice & 212.0 & $\$ 40,000.00$ \\
\hline Pediatrics & 921.0 & $\$ 35,000.00$ \\
\hline Perioperative & 78.0 & $\$ 45,000.00$ \\
\hline Primary care & $1,601.0$ & $\$ 36,379.00$ \\
\hline Psychiatric/mental health/substance abuse & 867.0 & $\$ 38,000.00$ \\
\hline Other & $2,714.0$ & $\$ 40,000.00$ \\
\hline
\end{tabular}

\section{Foreign-Educated Nurses}

Approximately $95.1 \%$ of respondents received their entry-level education in the United States; thus, in the current study $4.9 \%$ indicated being foreign-educated nurses.

\section{Age, Gender, and Education}

An analysis of foreign-educated LPN/VNs' status by age revealed lower percentages of foreign-educated nurses younger than age 40 and higher percentages of nurses between the ages of 40 and 50 when compared to U.S.-educated nurses (Table 102). 


\section{TABLE 102}

\section{Foreign-Educated Status, by Age}

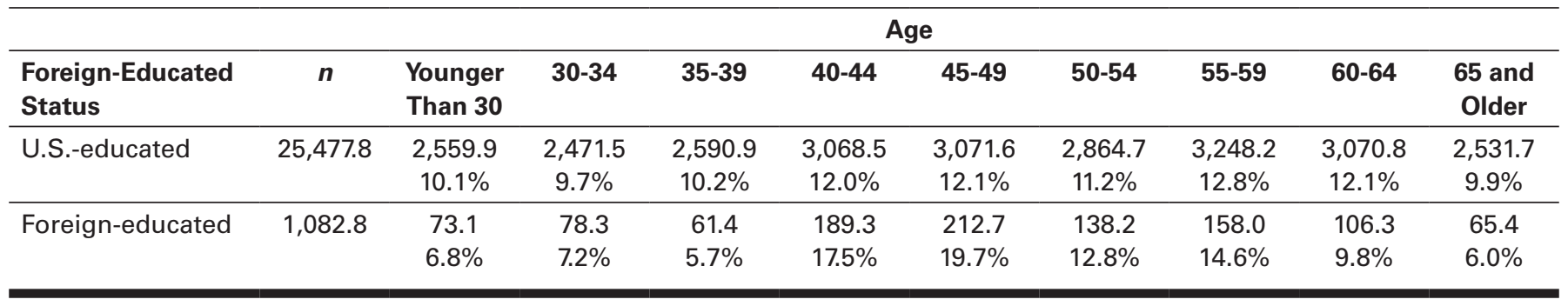

An analysis of gender by foreign-education status indicated a much larger percentage of foreign-educated LPN/VNs were male (22.7\%) compared to U.S.-educated LPN/VNs (6.7\%) (Table 103).

\section{TABLE 103}

\section{Foreign-Educated Status, by Gender}

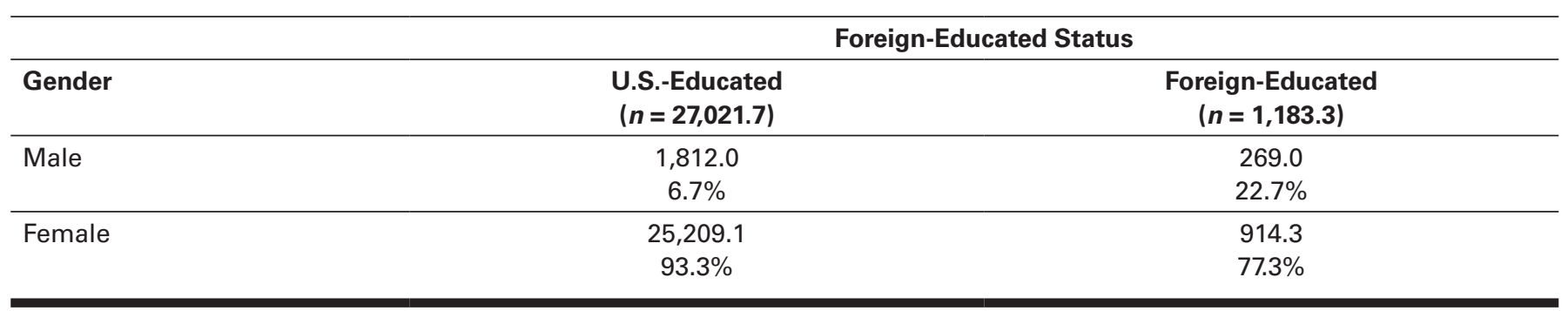

An analysis of highest level of education revealed that $17.6 \%$ of foreign-educated LPN/VNs held BSNs compared to $0.3 \%$ for U.S.-educated LPN/VNs (Table 104).

\section{TABLE 104}

\section{Foreign-Educated Status, by Highest Level of Education}

\begin{tabular}{|c|c|c|}
\hline \multirow[b]{2}{*}{ Highest Level of Education } & \multicolumn{2}{|c|}{ Foreign-educated status } \\
\hline & $\begin{array}{l}\text { U.S.-Educated } \\
(n=28,098.7)\end{array}$ & $\begin{array}{l}\text { Foreign-Educated } \\
\quad(n=1,214.5)\end{array}$ \\
\hline Vocational/practical certificate-nursing & $66.3 \%$ & $32.1 \%$ \\
\hline \multirow[t]{2}{*}{ Diploma } & $3,638.2$ & 148.8 \\
\hline & $12.9 \%$ & $12.3 \%$ \\
\hline ADN & $6.4 \%$ & $5.5 \%$ \\
\hline \multirow{2}{*}{ Associate's-other field } & $2,125.0$ & 85.3 \\
\hline & $7.6 \%$ & $7.0 \%$ \\
\hline \multirow[t]{2}{*}{ BSN } & 85.3 & 213.4 \\
\hline & $0.3 \%$ & $17.6 \%$ \\
\hline MSN & $0.0 \%$ & $0.0 \%$ \\
\hline \multirow[t]{2}{*}{ Master's-other field } & 268.8 & 61.6 \\
\hline & $1.0 \%$ & $5.1 \%$ \\
\hline
\end{tabular}


Foreign-educated status

\begin{tabular}{|c|c|c|}
\hline Highest Level of Education & $\begin{array}{l}\text { U.S.-Educated } \\
(n=28,098.7)\end{array}$ & $\begin{array}{l}\text { Foreign-Educated } \\
\quad(n=1,214.5)\end{array}$ \\
\hline \multirow[t]{2}{*}{ DNP } & 0.0 & 0.6 \\
\hline & $0.0 \%$ & $0.0 \%$ \\
\hline \multirow[t]{2}{*}{ PhD-nursing } & 0.0 & 0.0 \\
\hline & $0.0 \%$ & $0.0 \%$ \\
\hline Doctoral-nursing other & 1.0 & 0.0 \\
\hline \multirow[t]{2}{*}{ Doctoral-other field } & 30.3 & 18.4 \\
\hline & $0.1 \%$ & $1.5 \%$ \\
\hline
\end{tabular}

\section{Employment Setting and Licensure}

An analysis of primary employment setting indicated a similar breakdown between U.S.-educated nurses and foreign-educated nurses. However, a higher percentage of foreign-educated LPN/VNs (39.2\%) indicated working in a nursing home/extended care setting compared to $29.6 \%$ of U.S.-educated LPN/VNs. Primary position titles and primary employment specialty indicated similar distributions between U.S.-educated LPN/VNs and foreign-educated LPN/VNs.

An analysis of number of licenses held indicated foreign-educated nurses were more likely to hold multiple licenses (3.4\%) versus U.S.-educated nurses (1.9\%). On average, foreign-educated LPN/VNs worked slightly more hours during a typical week $(M=39.3, S D=16.6)$ versus U.S.-educated LPN/VNs $(M=37.8, S D=16.6)$. Additionally, foreign-educated LPN/VNs were more like to work two or more positions (21.8\%) compared to U.S-educated LPN/VNs (15.1\%)

\section{Discussion and Implications}

Approximately 121,000 LPNs/VNs were included in the sample; 32,263 responded (28.0\%). These data provide the most recent and detailed information on characteristics of licensed LPN/VNs, such as age, diversity, education, employment setting, position title, employment specialty, and salary. Data and research on the nursing workforce are often focused more on RNs and less so on LPN/VNs; therefore, the present study was a critical addition to nursing workforce data.

The average age of LPN/VNs was 47.8. Overall, 77.0\% of LPNs were employed in nursing. However, data indicated that LPN/VNs older than age 60 were less likely to be employed in nursing as compared to the younger-than-age-30 cohort. Thus, the evidence does not suggest a large number of LPN/VNs will be retiring and leaving a gap in supply. This finding supports an employment trend similar to what Coffman, Chan, and Bates (2015) reported using 2008 and 2013 American Community Survey data.

In terms of diversity, starting with racial/ethnic diversity, $31.9 \%$ of responding LPN/VNs identified themselves as a minority, while $68.1 \%$ of the respondents were White/Caucasian. This study's racial/ethnic diversity results are similar to HRSA's (2015) brief on gender and racial/ethnic diversity of U.S. health occupations for 2010-2012, which found a 68.2\% white (non-Hispanic) LPN/VN workforce, and to Coffman et al. (2015), who reported a 61\% white workforce. The largest reporting minority group was Black/African American, at 15\%; however, larger percentages of minorities were younger as compared to nearing retirement, suggesting the workforce will become more diverse as the younger-age cohorts advance. In terms of gender diversity, data revealed that $7.5 \%$ of the LPN/VN workforce was male, $0.8 \%$ to $1.5 \%$ lower than two other recent analyses of gender in the LPN/VN workforce (Coffman, Chan, \& Bates, 2015; HRSA, 2015). However, this study also found increasing proportions of males in more recently licensed cohorts, suggesting higher percentages of males in the LPN/VN workforce in the future.

Over two-thirds of LPN/VNs indicated their highest level of education was a vocational/practical certificate in nursing and the vast majority (95.1\%) were educated in the United States. The $4.9 \%$ of LPN/VNs who were educated outside the United States tended to have achieved higher levels of education: $17.6 \%$ of foreign-educated LPN/VNs held BSN degrees compared to $0.3 \%$ of U.S.-educated LPN/VNs. While it is unclear from the current study why foreign-educated LPN/VNs had a higher rate of BSN degrees, it is possible that educational, testing, and other licensure requirements may have prevented them from working as RNs in the United States.

The most common primary care setting of LPN/VNs respondents was in nursing home/extended care (30\%), followed by $15 \%$ in home health and approximately $11 \%$ in hospitals. Similarly, approximately $25 \%$ of LPN/VNs reported their primary practice specialty as geriatric/gerontology; this was the most common specialty of LPN/VNs in all licensure cohorts. These findings support a report by Coffman et al. (2015) that indicated long-term care employs more LPN/VNs than any other industry. In fact, the number of LPN/VNs working in long-term care increased from 258,670 in 2008 to 289,946 in 2013, an increase of 13\%, while the number of LPN/VNs working in hospitals, outpatient care, and other sectors decreased by $20 \%$. Position titles are likely 
similar in both types of settings; over two-thirds of LPN/VNs' primary title was "staff nurse." The current survey also found that almost $50 \%$ of LPN/VNs provided patient care services utilizing telehealth technologies; $17 \%$ did so across a state border, and $4 \%$ engaged in telehealth across a national border.

Median salaries of LPN/VNs differed by employment setting, position title, and other demographic characteristics. While the overall median earnings and the median earnings for female LPN/VNs was $\$ 38,000$, the median earnings for male LPN/VNs was $\$ 43,000$. Results showed that median salaries differed considerably based on geographic region: Washington, DC, and Alaska had the highest salaries and South Dakota and West Virginia, the lowest.

\section{Limitations}

Limitations of the current study include a response rate of $28.0 \%$, which was lower than the response rates for a similar sample of RNs (34.3\%). To supplement this statistic, a nonresponse bias analysis was conducted and indicated a slight overrepresentation of three distinct variables: white/Caucasian, female, 60 and older in the responding sample. As described earlier, gender and age were used to make nonresponse weighting adjustments, along with weighting adjustments for differing nursing population sizes across states. An additional limitation was missing or incomplete data. While the large sample size partially compensated for this, certain item nonresponse bias could have impacted the results, such as salary (39.0\% did not answer): Both upper and lower limits had been set on the salary figures; however, extreme values could still have skewed mean values upward; the medians were likely the more accurate statistic versus the mean for the measure of central tendency. Data used for comparison may have vastly different samples; for instance, the HRSA (2015) brief on gender and racial/ethnic diversity of U.S. health occupations used data on a U.S. working-age population age 16 or older who were currently employed or who were recently employed and were seeking employment (e.g., individuals who were recently laid off). Lastly, the data on telehealth may not be directly comparable to other statistics on this topic. Tracking trends in telehealth will require consistent use of common measures for telehealth use.

\section{Conclusion}

The current LPN/VN workforce is expected to change in terms of the ratios of racial/ethnic minority groups and of men to women; an impending shortage is not expected as a result of older LPN/VNs retiring. Changes in the health care environment are especially relevant for LPN/VNs because position setting demand may be changing as the health care environment calls for higher levels of nursing education. One potential piece of evidence showcasing this trend in higher levels of nursing education is discussed by Coffman et al. (2015), who reported that the LPN/VN workforce in the United States is declining in size, from 675,918 in 2008 to 635,975 in 2013 , a decrease of $6 \%$. The supply and demand of LPN/VNs will be affected by many other factors, including population growth, aging of the population, and economic conditions. This national survey of LPN/VNs represents one point in time; future workforce surveys on the supply of LPN/VNs may help illuminate additional workforce trends for this important segment of the nursing population.

\section{References}

AcademyHealth. (2007). U.S.-based international nurse recruitment: Structure and practices of a burgeoning industry. Retrieved from www.intlnursemigration.org/assets/pdfs/Report-on-Year-I.pdf

American Association of Colleges of Nursing. (2015). Nursing faculty shortage fact sheet. Retrieved from www.aacn.nche.edu/media-relations/FacultyShortageFS.pdf

American Association of Public Opinion Research. (2015). Standard definitions. Retrieved from http://www.aapor.org/Standards-Ethics/StandardDefinitions-(1).aspx

American Well. (2015). Telehealth index: 2015 consumer survey. Retrieved from http://info.americanwell.com/telehealth-index-2015-consumer-survey

Budden, J. S., Zhong, E. H., Moulton, P., \& Cimiotti, J. P. (2013). The National Council of State Boards of Nursing and The Forum of State Nursing Workforce Centers 2013 National Workforce Survey of Registered Nurses. Journal of Nursing Regulation, 4(supplement), S1-S72.

Buerhaus, P. I., Auerbach, D. I., \& Staiger, D. O. (2014). The rapid growth of graduates from associate, baccalaureate, and graduate programs in nursing. Nursing Economic\$, 32, 290-295, 311.

Coffman, J. M., Chan, K., \& Bates, T. (2015). Profile of the licensed practical nursellicensed vocational nurse workforce, 2008 and 2013. Retrieved from http://healthworkforce.ucsf.edu/sites/healthworkforce.ucsf.edu/files/Report-Profile_of_the_Licensed_Practical_Nurse_Licensed_Vocational_ Nurse_Workforce_2008_and_2013.pdf

Dillman, D. A., Smyth, J. D., \& Christian, L. M. (2009). Internet, mail, and mixed-mode surveys: The tailored design method (3rd ed.). Hoboken, NJ: Wiley.

Health Resources and Services Administration. (2010). The registered nurse population: Findings from the 2008 National Sample Survey of Registered Nurses. Retrieved from http://bhpr.hrsa.gov/healthworkforce/rnsurvey2008.html

Health Resources and Services Administration. (2012). Highlights from the 2012 National Sample Survey of Nurse Practitioners. Retrieved from http:// bhpr.hrsa.gov/healthworkforce/supplydemand/nursing/nursepractitionersurvey/npsurveyhighlights.pdf 
Health Resources and Services Administration. (2013). The U.S. nursing workforce: Trends in supply and education. Retrieved from http://bhpr.hrsa.gov/ healthworkforce/reports/nursingworkforce/

Health Resources and Services Administration. (2014). The future of the nursing workforce: National-and state-level projections, 2012-2025. Retrieved from http://bhpr.hrsa.gov/healthworkforce/supplydemand/nursing/workforceprojections/nursingprojections.pdf

Health Resources and Services Administration. (2015). Sex, race, and ethnic diversity of U.S. health occupations (2010-2012). Retrieved from http:// bhpr.hrsa.gov/healthworkforce/supplydemand/usworkforce/diversityushealthoccupations.pdf

HIMSS Analytics. (2015). Essentials brief: Telemedicine study. Retrieved from www.himssanalytics.org/research/essentials-brief-telemedicine-study

Institute of Medicine. (2010). The future of nursing: Focus on education. Retrieved from www.iom.edu/Reports/2010/The-Future-of-Nursing-LeadingChange-Advancing-Health/Report-Brief-Education.aspx

Institute of Medicine. (2015). Assessing progress on the Institute of Medicine report The Future of Nursing. Washington, DC: National Academies Press.

Moulton, P. L., Wiebusch, P. L., Cleary, B. L., Brunell, M. L., Napier, D. F., Bienemy, C., .. Cimiotti, J. P. (2013). Toward standardization (part 2): National nursing minimum data sets consensus building and implementation status. Policy, Politics and Nursing Practice, 13, $162-169$.

Muench, U., Sindelar, J., Busch, S., \& Buerhaus, P. I. (2015). Salary differences between male and female registered nurses in the United States. Journal of the American Medical Association, 313(12), 1265-1267.

National Council of State Boards of Nursing. (2013). APRNs in the U.S. Retrieved from www.ncsbn.org/aprn.htm .

Nooney, J., Cleary, B., Moulton, P., Wiebusch, P., Murray, J., Yore, M., \& Brunell, M. (2010). Towards standardization (part 1): Assessment of state and national nursing workforce data sources. Policy, Politics and Nursing Practice, 11, 173-183.

U.S. Bureau of Labor Statistics. (2014). Occupational outlook handbook. Retrieved from www.bls.gov/ooh/healthcare/registered-nurses.htm

U.S. Census Bureau. (2015). State $\mathcal{E}$ county quickfacts. Retrieved from http://quickfacts.census.gov 


\section{Appendix A - Registered Nurse Nonresponse Analyses and Sample Weighting}

A formal nonresponse bias analysis was conducted following the close of the survey. Although response rates are a valuable indicator of survey quality, they may not be a good measure of response bias. An analysis of basic demographic data (i.e., gender, age, race/ ethnicity, number of years since graduation, number of years since first licensed) for all registered nurse (RN) licensees sampled from the Nursys ${ }^{\circledast}$ database was used to compare the survey respondents, and nonrespondents, to determine the representativeness of the survey participants.

The complete data file, or sample, included 140,154 RNs. Variables in the data file came from either the Nursys database (i.e., the frame data) or responses to the survey (i.e., survey data). The variables used in the nonresponse analysis were from the frame and include state, date of birth, gender, ethnicity, original license date, and graduation date. The dependent variable in the analysis was whether or not the sampled RN completed the questionnaire.

\section{Preliminary Analysis}

Of the 140,154 RNs in the sample frame, 46,476 responded, for a response rate of $33.2 \%$. This response rate corresponds to the American Association of Public Opinion's Response Rate 1 (the minimum response rate), in which the numerator is the number of completed questionnaires and the denominator is the total sample size (American Association of Public Opinion Research, 2015) (Table A1).

Tables A2 and A3 show the frequencies for the categorical variables. Table A4 shows the descriptive statistics for the continuous variables, while Table A5 shows the number of respondents who had complete data on gender, race, age, years since graduation, and years since initial licensure. These 39,615 RNs were the basis of the nonresponse analysis.

\section{TABLE A1}

\section{Response Bias RNs: Response Rate}

\begin{tabular}{lcc}
\hline & $(\boldsymbol{n}=\mathbf{1 4 0 , 1 5 4 )}$ & Percentage \\
\hline No & 93,678 & $66.8 \%$ \\
\hline Yes & 46,476 & $33.2 \%$ \\
\hline
\end{tabular}

TABLE A2

\section{Response Bias RNs: Gender}

\begin{tabular}{|c|c|c|c|c|}
\hline & & $(n=140,154)$ & Percentage & Valid percent \\
\hline \multirow[t]{2}{*}{ Valid } & Female & 92,604 & $66.1 \%$ & $91.5 \%$ \\
\hline & Male & 8,645 & $6.2 \%$ & $8.5 \%$ \\
\hline \multirow[t]{2}{*}{ Missing } & Restricted/unknown & 6,234 & $4.4 \%$ & \\
\hline & Missing & 32,671 & $23.3 \%$ & \\
\hline
\end{tabular}

TABLE A3

Response Bias RNs: Race/Ethnicity

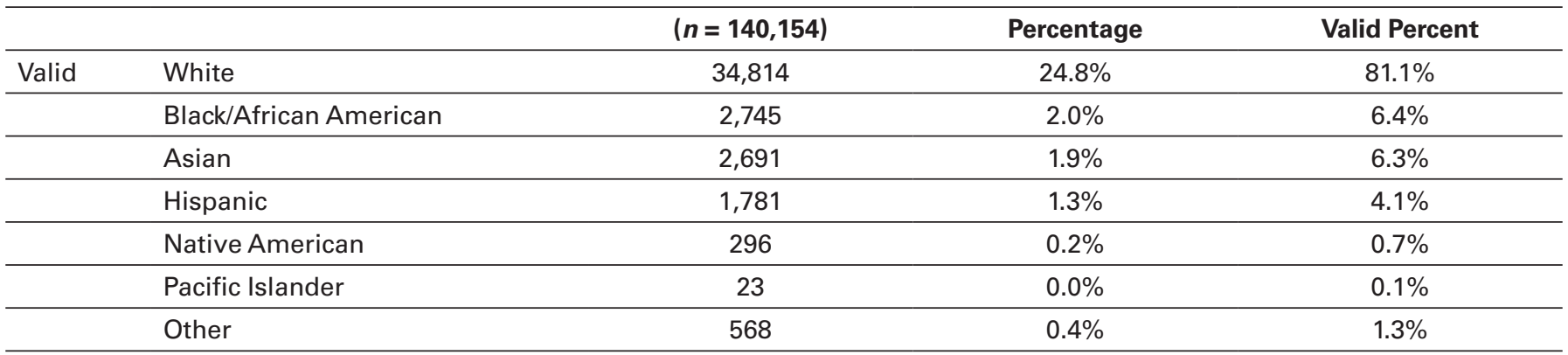




\begin{tabular}{clccc}
\hline & & $(\boldsymbol{n}=\mathbf{1 4 0 , 1 5 4 )}$ & Percentage & Valid Percent \\
\hline Total & 42,918 & $30.6 \%$ & $100.0 \%$ \\
\hline Restricted & 3,566 & $2.5 \%$ \\
\hline Unknown/blank & 69,580 & $49.6 \%$ \\
\hline Not supplied & 1,724 & $1.2 \%$ \\
\hline
\end{tabular}

TABLE A4

\section{Response Bias RNs: Descriptive Statistics for Continuous Measures}

\begin{tabular}{lccccc}
\hline & $\boldsymbol{n}$ & $\boldsymbol{M}$ & $\boldsymbol{S D}$ & Min & Max \\
\hline Age in years & 111,196 & 47.0 & 13.4 & 18 & 97 \\
\hline Number of years since graduation & 102,253 & 18.0 & 13.4 & 0 & 75 \\
\hline Number of years since original licensure & 117,274 & 15.4 & 12.6 & 0 & 74 \\
\hline
\end{tabular}

TABLE A5

\section{Response Bias RNs: Case Has Complete Data for Nonresponse Analysis}

\begin{tabular}{|c|c|c|}
\hline & $n$ & Percentage \\
\hline No & 100,539 & $71.7 \%$ \\
\hline Yes & 39,615 & $28.3 \%$ \\
\hline
\end{tabular}

\section{Bivariate Analysis}

Tables A6 and A7 show the bivariate relationships between the demographic variables from the sample frame and whether or not the respondent completed the survey. There were far fewer men in the database $(8,645$ compared to 92,604 women) and they were less likely to complete the survey (24.9\% compared to $33.9 \%$ among women).

\section{TABLE A6}

\section{Response Bias RNs: Survey Completion Rate by Gender}

\begin{tabular}{lccc}
\hline & \multicolumn{2}{c}{ Complete Survey? } & Yes \\
\hline Female & $\boldsymbol{n}$ & No & $33.9 \%$ \\
\hline Male & 8,604 & $66.1 \%$ & $24.9 \%$ \\
\hline Total & 101,249 & $75.1 \%$ & $33.2 \%$ \\
\hline Note. $\chi^{2}(1, n=101,249)=292.3, p<.001$. & $66.8 \%$ & & \\
\hline
\end{tabular}

From Table A7, nurses who identified as White were most likely to respond, with a response rate of 33.2\%. African American and Pacific Islander nurses were least likely to respond, with response rates of $21.8 \%$ and $21.7 \%$, respectively.

\section{TABLE A7}

\section{Response Bias RNs: Survey Completion Rate by Race/Ethnicity}

\begin{tabular}{lccc}
\hline & & & Complete Survey? \\
\hline Race/Ethnicity & $\boldsymbol{n}$ & No & Yes \\
\hline White & 34,814 & $66.8 \%$ & $33.2 \%$ \\
\hline
\end{tabular}




\begin{tabular}{lccc}
\hline & & & Complete Survey? \\
\hline Race/Ethnicity & $\boldsymbol{n}$ & No & Yes \\
\hline African American & 2,745 & $78.2 \%$ & $21.8 \%$ \\
\hline Asian & 2,691 & $73.5 \%$ & $26.5 \%$ \\
\hline Hispanic & 1,781 & $75.7 \%$ & $24.3 \%$ \\
\hline Native American & 296 & $73.0 \%$ & $27.0 \%$ \\
\hline Pacific Islander & 23 & $78.3 \%$ & $21.7 \%$ \\
\hline Other & 568 & $73.9 \%$ & $26.1 \%$ \\
\hline Total & 42,918 & $68.5 \%$ & $31.5 \%$ \\
\hline
\end{tabular}

Note. $\chi^{2}(6, n=42,918)=248.8, p<.001$.

Table A8 displays the mean age of RNs, mean number of years since graduation, and mean number of years since original licensure by completion status. On average, those who completed the survey were 5.2 years older than the nonrespondents; graduated 5.1 years earlier than the nonrespondents; and obtained their original license 4.6 years earlier than the nonrespondents. All relationships were statistically significant.

\section{TABLE A8}

\section{Response Bias RNs: Differences in Mean Age, Years Since Graduation, and Years Since Licensure, by Survey Completion}

\begin{tabular}{lcccc}
\hline Complete Survey? & Age in Years & $\begin{array}{c}\text { Number of Years Since } \\
\text { Graduation }\end{array}$ & $\begin{array}{c}\text { Number of Years Since } \\
\text { Original Licensure }\end{array}$ \\
\hline No & $n$ & 74,599 & 68,936 & 78,585 \\
\hline & $M$ & 45.3 & 16.3 & 13.9 \\
\hline Yes & $S D$ & 12.8 & 12.4 & 11.7 \\
\hline & $n$ & 36,597 & 33,317 & 38,689 \\
\hline & $M$ & 50.5 & 21.4 & 18.5 \\
\hline Total & \multicolumn{1}{c}{${ }^{2}$} & 13.8 & 14.6 & 13.9 \\
\hline & $M$ & 111,196 & 102,253 & 15.4 \\
\hline & $M$ & 17.0 & 18.0 & 12.6 \\
\hline
\end{tabular}

Note. In all three analyses, $t$-tests show that the relationships were significant at the $<.001$ level.

Table A9 shows that having complete data on all demographic variables was related to completing the survey. The Cramer's V statistic of -0.022 suggests this difference was of small effect. Therefore, while demographic characteristics themselves were related to response propensity, the lack of information about these characteristics was for the most part not.

Missing data on demographic characteristics were largely a function of the jurisdiction in which the respondent worked. Data on gender were completely missing in eight jurisdictions and largely missing (greater than 95\% of RNs) in four. Data on race/ethnicity were completely missing in six jurisdictions and largely missing (90\% of RNs or greater) in nine. Date of birth was completely missing in eight jurisdictions. In addition, response rates differed significantly by jurisdiction. The response rates ranged from a low of $18.1 \%$ in American Samoa to a high of $45.9 \%$ in Wisconsin $\left(\chi^{2}(54, n=140,154)=1581.8, p<.001\right)$.

\section{TABLE A9}

\section{Response Bias RNs: Survey Completion Rate by Status of Data}

\begin{tabular}{lccr}
\hline & & & \multicolumn{2}{c}{ Complete Survey? } \\
\hline Status of Data & $\boldsymbol{n}$ & No & Yes \\
\hline Incomplete & 100,539 & $66.2 \%$ & $33.8 \%$ \\
\hline Complete & 39,615 & $68.5 \%$ & $31.5 \%$ \\
\hline
\end{tabular}




\begin{tabular}{lccc}
\hline & & \multicolumn{2}{c}{ Complete Survey? } \\
\hline Status of Data & $\boldsymbol{n}$ & No & Yes \\
\hline Total & 140,154 & $66.8 \%$ & $33.2 \%$ \\
\hline
\end{tabular}

Note. $\chi^{2}(1, n=140,154)=66.6, p<.0001$.

\section{Weights}

In the 2013 National Workforce Survey of Registered Nurses study, nonresponse adjustments were not made because of the high degree of missing demographic data in the sample frame. However, for this survey, the gender $(27.8 \%$ missing) and age $(20.7 \%$ missing) categories were sufficiently populated to allow for a nonresponse adjustment. The large amount of missing race/ethnicity data $(69.4 \%$ missing) still made using that category impractical for nonresponse adjustment.

In order to create the combined age and gender (AgeGender) nonresponse weights (i.e., AgeGenderWgtC), the survey response rates for the age variable were compared at the 5-year age-group level and neighboring cells with similar response rates were collapsed. Upon completion of this process, nine age-groups were created (18-49, 50-54, 55-59, 60-64, 65-69, 70-74, 75-79, 80 or older, missing). These nine age-groups were combined with the gender variable response categories (male, female, missing) to produce 27 AgeGender categories. The survey response rate for each AgeGender category (\# responding/\# in sample frame) was calculated and used to create each category's weight as follows:

\section{AgeGender Category Weight = Overall Survey Response Rate/AgeGender Category Survey Response Rate}

As an example of how this was calculated, there were $201 \mathrm{RNs}$ in the sample frame whose gender was identified as male and whose age was missing. Out of these $201 \mathrm{RNs}, 41$ responded. The AgeGender response rate for this category was determined to be $41 / 201=.20398$. The overall survey response rate was $46476 / 140154=.331607$. So the AgeGender weight for the age missing-gender male category was $.331607 / .20398=1.626$.

When the AgeGender weights for each respondent are totaled up, the sum comes to 46,476- the same as the total number of respondents. Table A10 displays the weights for the 27 AgeGender categories.

TABLE A10

\section{Response Bias RNs: AgeGender Weights}

\begin{tabular}{lccc}
\hline Age-Group & Gender: Missing & Gender: Female & Gender: Male \\
\hline $18-49$ & 1.457 & 1.254 & 1.647 \\
\hline $50-54$ & 1.084 & 0.967 & 1.277 \\
\hline $55-59$ & 0.948 & 0.816 & 1.075 \\
\hline $60-64$ & 0.852 & 0.723 & 0.894 \\
\hline $65-69$ & 0.698 & 0.648 & 0.727 \\
\hline $70-74$ & 0.534 & 0.605 & 0.742 \\
\hline $75-79$ & 0.551 & 0.570 & 1.036 \\
\hline 80 or older & 0.516 & 0.558 & 0.531 \\
\hline Age missing & 0.959 & 1.144 & 1.626 \\
\hline
\end{tabular}

In a similar manner, post-stratification weights (i.e., Jurisdiction $\mathrm{WgtC}$ ) were constructed at the state level to adjust for differing sampling rates across states. However, these adjustments were made not by comparing the number of responses responses in a state in its sample frame count (i.e., the number of nurses sampled from a state), but rather by comparing the number of responses to the number of licensees in that state. Analysis of the raw data, without accounting for the sample design, would lead to the overall results being too heavily influenced by states with fewer licensees.

For example, there were 409,971 RNs in California, out of which 946 responded. The California response per license rate was $946 / 409,971=.002307$. The overall response per license rate was $46476 / 4378273=.010615$. So the post-stratification weight for California was $.010615 / .002307=4.600$.

Overall weights (pct_wgtC) that combined the AgeGender and post-stratification weights were created by multiplying the AgeGender and post-stratification weights for each individual to create an initial set of weights (labeled WgtCr), add- 
ing the initial weights together (sum $=46,561.19$ ), and slightly adjusting the weights so that they sum up to 46,476 (pct_ wgtC $=46476 * \mathrm{WgtCr} / 46561.19)$.

The overall weights simply adjust the distribution across states, age, and gender, but sum to the actual number of RNs in the subset of completed responses. They can be applied when analyzing relationships between variables without the effect of artificially increasing the degrees of freedom and thereby affecting significance tests. The AgeGender weights, post-stratification weights, and overall weights are summarized in Table A11.

TABLE A11

\section{Response Bias RNs: Descriptive Statistics of Weights, Complete Responses Only}

\begin{tabular}{lccccc}
\hline & $\boldsymbol{n}$ & Min & Max & Sum & Mean \\
\hline AgeGender (AgeGenderWgtC) & 46,476 & 0.516 & 1.647 & 46,476 & 1.000 \\
\hline Post-stratification (JurisdictionWgtC) & 46,476 & 0.065 & 4.600 & 46,476 & 1.000 \\
\hline Combined (pct_wgtC) & 46,476 & 0.036 & 7.562 & 46,476 & 1.000 \\
\hline
\end{tabular}

Note. Combined (pct_wgtC) was used in reporting results. 


\section{Appendix B - Licensed Practical/Vocational Nurse Nonresponse Analyses and Sample Weighting}

As with the registered nurses (RNs), a formal nonresponse bias analysis was conducted of the licensed practical/vocational nurse (LPN/VN) data following the close of the survey. The complete data file, or sample, included 120,793 LPN/VNs. Variables in the data file came from either the Nursys ${ }^{\circledast}$ database (i.e., the frame data) or responses to the survey (i.e., survey data). The variables used in the nonresponse analysis were from the frame and include state, date of birth, gender, ethnicity, original license date, and graduation date. The dependent variable in the analysis was whether or not the sampled LPN/VN completed the questionnaire.

\section{Preliminary Analysis}

Of the 120,793 LPN/VNs in the sample frame, 32,263 responded, for a response rate of 26.7\% (Table B1). Tables B2 and B3 show the frequencies for the categorical variables. Table B4 shows the descriptive statistics for the continuous variables, while Table B5 shows the number of respondents who had complete data on gender, race, age, years since graduation, and years since initial licensure. These 37,343 LPN/VNs were the basis of the nonresponse analysis.

\section{TABLE B1}

\section{Response Bias LPN/VN: Response Rate}

\begin{tabular}{lcc}
\hline & $(n=120,793)$ & Percentage \\
\hline No & 88,530 & $73.3 \%$ \\
\hline Yes & 32,263 & $26.7 \%$ \\
\hline
\end{tabular}

TABLE B2

\section{Response Bias LPN/VN: Gender}

\begin{tabular}{|c|c|c|c|c|}
\hline & & $(n=120,793)$ & Percentage & Valid Percent \\
\hline \multirow[t]{2}{*}{ Valid } & Female & 79,301 & $65.7 \%$ & $92.6 \%$ \\
\hline & Male & 6,360 & $5.3 \%$ & $7.4 \%$ \\
\hline \multirow[t]{2}{*}{ Missing } & Restricted/unknown & 2,827 & $2.3 \%$ & \\
\hline & Missing & 32,305 & $26.7 \%$ & \\
\hline
\end{tabular}

TABLE B3

\section{Response Bias LPN/VN: Race/Ethnicity}

\begin{tabular}{|c|c|c|c|c|}
\hline & & $(n=120,793)$ & Percentage & Valid Percent \\
\hline \multirow[t]{6}{*}{ Valid } & White & 28,699 & $23.8 \%$ & $73.6 \%$ \\
\hline & Black/African American & 6,510 & $5.4 \%$ & $16.7 \%$ \\
\hline & Hispanic & 2,332 & $1.9 \%$ & $6.0 \%$ \\
\hline & Native American & 383 & $0.3 \%$ & $1.0 \%$ \\
\hline & Pacific Islander & 7 & $0.0 \%$ & $0.0 \%$ \\
\hline & Total & 38,996 & $32.3 \%$ & $100.0 \%$ \\
\hline \multirow[t]{4}{*}{ Missing } & Restricted & 10 & $0.0 \%$ & \\
\hline & Unknown/blank & 56,154 & $46.5 \%$ & \\
\hline & Not supplied & 1,457 & $1.2 \%$ & \\
\hline & Missing & 24,176 & $20.0 \%$ & \\
\hline
\end{tabular}


TABLE B4

\section{Response Bias LPN/VN: Descriptive Statistics for Continuous Measures}

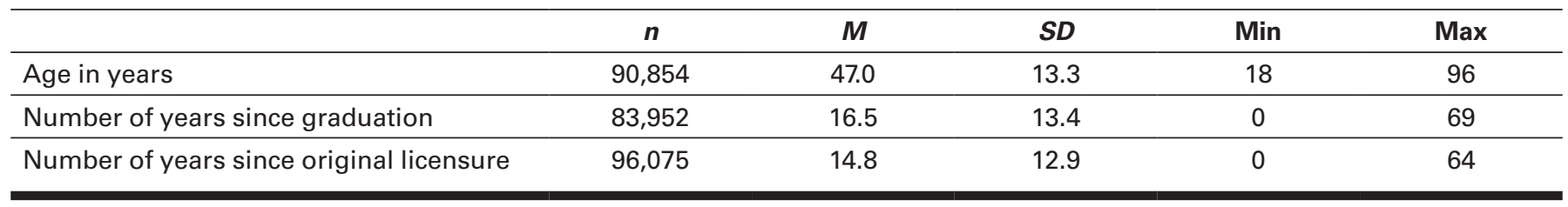

TABLE B5

\section{Response Bias LPN/VN: Case Has Complete Data for Nonresponse Analysis}

\begin{tabular}{lcc}
\hline & $\boldsymbol{n}$ & Percentage \\
\hline No & 83,450 & $69.1 \%$ \\
\hline Yes & 37,343 & $30.9 \%$ \\
\hline Total & 120,793 & $100.0 \%$ \\
\hline
\end{tabular}

Bivariate Analysis

Tables B6 and B7 show the bivariate relationships between the demographic variables from the sample frame and whether or not the respondent completed the survey. There were far fewer men in the database (6,360 compared to 79,301 women) and they were less likely to complete the survey ( $18.9 \%$ compared to $27.3 \%$ among women).

\section{TABLE B6}

Response Bias LPN/VN: Survey Completion Rate by Gender

\begin{tabular}{|c|c|c|c|}
\hline & \multicolumn{3}{|c|}{ Complete Survey? } \\
\hline & $n$ & No & Yes \\
\hline Female & 79,301 & $72.7 \%$ & $27.3 \%$ \\
\hline Total & 85,661 & $73.3 \%$ & $26.7 \%$ \\
\hline
\end{tabular}

From Table B7, nurses who identified as White were most likely to respond, with a response rate of $28.1 \%$. Other Race and Pacific Islander nurses were least likely to respond, with response rates of $16.8 \%$ and $0.0 \%$, respectively.

\section{TABLE B7}

\section{Response Bias LPN/VN: Survey Completion Rate by Race/Ethnicity}

\begin{tabular}{lccc}
\hline & & & Complete Survey? \\
\hline Race/Ethnicity & $\boldsymbol{n}$ & No & Yes \\
\hline White & 28,699 & $71.9 \%$ & $28.1 \%$ \\
\hline African American & 6,510 & $80.9 \%$ & $19.1 \%$ \\
\hline Asian & 480 & $74.8 \%$ & $25.2 \%$ \\
\hline Hispanic & 2,332 & $78.8 \%$ & $21.2 \%$ \\
\hline Native American & 383 & $76.0 \%$ & $24.0 \%$ \\
\hline Pacific Islander & 7 & $100.0 \%$ & $0.0 \%$ \\
\hline Other & 585 & $83.2 \%$ & $16.8 \%$ \\
\hline Total & 38,996 & $74.1 \%$ & $25.9 \%$ \\
\hline Note. $\chi^{2}(6, n=38,996)=282.6, p<.001$. & & \\
\hline
\end{tabular}


Table B8 displays the mean age of LPN/VNs, mean number of years since graduation, and mean number of years since original licensure by completion status. On average, those who completed the survey were 5.8 years older than the nonrespondents; graduated 5.2 years earlier than the nonrespondents; and obtained their original license 4.9 years earlier than the nonrespondents. All relationships were statistically significant.

\section{TABLE B8}

\section{Response Bias LPN/VN: Differences in Mean Age, Years Since Graduation, and Years Since Licensure, by Survey Completion}

\begin{tabular}{lcccr}
\hline Complete Survey? & Age in Years & $\begin{array}{c}\text { Number of Years Since } \\
\text { Graduation }\end{array}$ & $\begin{array}{c}\text { Number of Years Since } \\
\text { Original Licensure }\end{array}$ \\
\hline No & $n$ & 66,791 & 61,820 & 70,566 \\
\hline & $S D$ & 45.4 & 15.1 & 13.5 \\
\hline Yes & $n$ & 12.9 & 12.6 & 12.1 \\
\hline & $M$ & 24,063 & 22,132 & 125,509 \\
\hline Total & $S D$ & 51.2 & 20.3 & 18.4 \\
\hline & $n$ & 13.5 & 83,952 & 14.4 \\
\hline & $M$ & 90,854 & 16.5 & 96,075 \\
\hline
\end{tabular}

Note. In all three analyses, $t$-tests show that the relationships were significant at the $<.001$ level.

Table B9 shows that having complete data on all demographic variables was related to completing the survey. The Cramer's $\mathrm{V}$ statistic of -0.013 suggests this difference was of small effect. Therefore, while demographic characteristics themselves were related to response propensity, the lack of information about these characteristics was for the most part not.

Missing data on demographic characteristics were largely a function of the jurisdiction in which the respondent worked. Data on gender were completely missing in nine jurisdictions and mostly missing (greater than $95 \%$ of LPN/VNs) in three. Data on race/ethnicity were completely missing in 11 jurisdictions and largely missing (90\% of LPN/VNs or greater) in 24 . Data on date of birth were completely missing in nine jurisdictions and mostly missing (greater than 95\% of LPN/VNs) in two. In addition, response rates differed significantly by jurisdiction. The response rates ranged from a low of $9.3 \%$ in the Northern Mariana Islands to a high of $39.2 \%$ in Montana $\left(\chi^{2}(54, n=120,793)=1611.6, p<.001\right)$.

\section{TABLE B9}

\section{Response Bias LPN/VN: Survey Completion Rate by Status of Data}

\begin{tabular}{lccc}
\hline & & & Complete Survey? \\
\hline Status of Data & $\boldsymbol{n}$ & No & Yes \\
\hline Incomplete & 83,450 & $72.9 \%$ & $27.1 \%$ \\
\hline Complete & 37,343 & $74.2 \%$ & $25.8 \%$ \\
\hline Total & 120,793 & $73.3 \%$ & $26.7 \%$ \\
\hline
\end{tabular}

Note. $\chi^{2}(1, n=120,793)=22.4, p<.001$.

\section{Weights}

For the LPN/VN survey, the gender $(29.1 \%$ missing) and age $(24.8 \%$ missing) categories were not too poorly populated and it was determined that a nonresponse adjustment for gender and age could be made. The large amount of missing race/ethnicity data (67.7\% missing) made using that category impractical for nonresponse adjustment.

In order to create the combined age and gender (AgeGender) nonresponse weights (i.e., AgeGenderWgtC), the survey response rates for the age variable were compared at the 5-year age-group level and neighboring cells with similar response rates were collapsed. Upon completion of this process, six age-groups were created (18-49, 50-54, 55-59, 60-64, 65 or older, missing). These six age-groups were combined with the gender variable response categories (male, female, missing) to produce 18 AgeGender categories. The survey response rate for each age-gender category (\# responding/\# in sample frame) was calculated and used to create each category's weight as follows: 
An example of how this was calculated can be found in the RN nonresponse sample weighting section. When the AgeGender weights for each respondent are totaled up, the sum comes to 32,263, which was the same as the total number of respondents. Table B10 displays the weights for the 18 AgeGender categories.

\section{TABLE B10}

\section{Response Bias LPN/VN: AgeGender Weights}

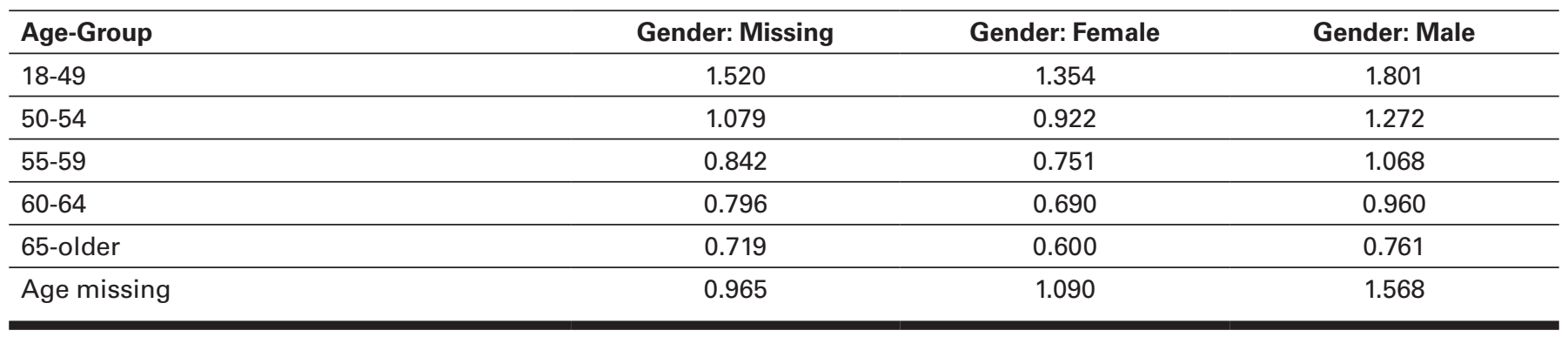

In a similar manner, post-stratification weights (i.e., Jurisdiction WgtC) were constructed at the state level to adjust for differing sampling rates across states. However, these adjustments were made not by comparing the number of responses in a states' sample count, but rather by comparing the number of responses to the number of licensees in that state. An example of how these weights were calculated can be found in the RN nonresponse sample weighting section.

Overall weights (pct_wgtC) that combined the age-gender and post-stratification weights were created by multiplying the AgeGender and post-stratification weights for each individual to create an initial set of weights (labeled WgtCr), adding the initial weights together (sum $=33,097.18$ ), and slightly adjusting the weights so that they sum up to 32,263 (pct_ wgtC $=32263 * \mathrm{WgtCr} / 33097.18)$.

The overall weights simply adjust the distribution across states, age, and gender, but sum to the actual number of LPN/VNs in the subset of completed responses. They can be applied when analyzing relationships between variables without the effect of artificially increasing the degrees of freedom and thereby affecting significance tests. The AgeGender weights, post-stratification weights, and overall weights are summarized in Table B11.

TABLE B11

Response Bias LPN/VN: Descriptive Statistics of Weights, Complete Responses Only

\begin{tabular}{lccccc}
\hline & $\boldsymbol{n}$ & Min & Max & Sum & Mean \\
\hline AgeGender (AgeGenderWgtC) & 32,263 & 0.600 & 1.807 & 32,263 & 1.000 \\
\hline Post-stratification (JurisdictionWgtC) & 32,263 & 0.097 & 4.583 & 32,263 & 1.000 \\
\hline Combined (pct_wgtC) & 32,263 & 0.057 & 7.558 & 32,263 & 1.000 \\
\hline
\end{tabular}

Note. pct_wgtC was used in reporting results. 


\section{Appendix C - Listing of Tables}

Table 1

Table 2

Table 3

Table 4

Table 5

Table 6

Table 7

Table 8

Table 9

Table 10

Table 11

Table 12

Table 13

Table 14

Table 15

Table 16

Table 17

Table 18

Table 19

Table 20

Table 21

Table 22

Table 23

Table 24

Table 25

Table 26

Table 27

Table 28

Table 29

Table 30

Table 31

Table 32

Table 33

Table 34

Table 35

Table 36

Table 37

Table 38

Table 39

Table 40

Table 41

Table 42

Table 43

Table 44

Table 45

Table 46

Table 47

Table 48

Table 49

Table 50

Table 51
RN Sampling: Number of Active RN Licenses . . . . . . . . . . . . . . . . . . . . . . . . S9

LPN/VN Sampling: Number of Active LPN/VN Licenses $\ldots \ldots \ldots \ldots \ldots \ldots \ldots \ldots \ldots \ldots \ldots$

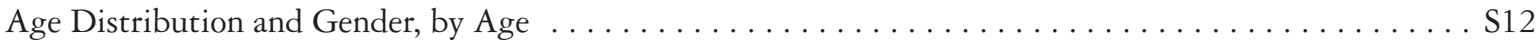

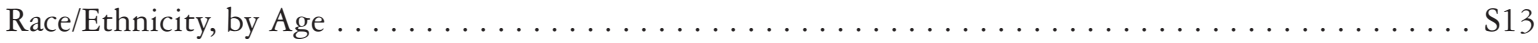

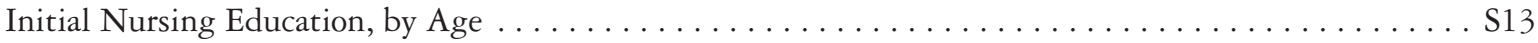

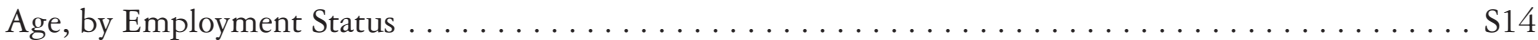

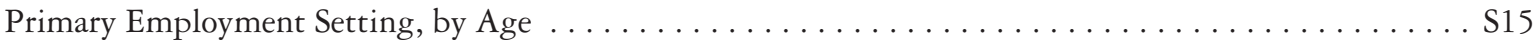

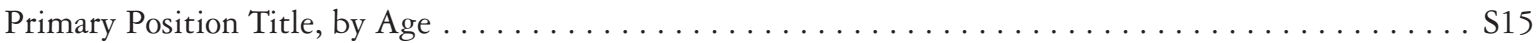

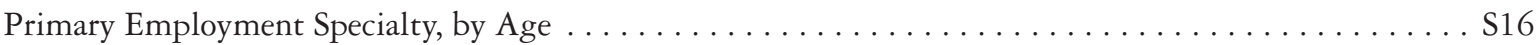

Initial Nursing Education of RNs Employed in Nursing, by Gender $\ldots \ldots \ldots \ldots \ldots \ldots \ldots \ldots . . \ldots$

Highest Level of Education of RNs Employed in Nursing, by Gender . . . . . . . . . . . . . . . S18

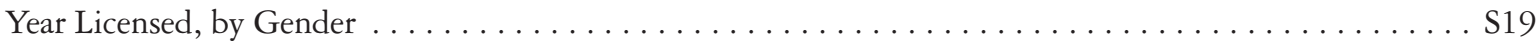

Primary Employment Setting, by Gender . . . . . . . . . . . . . . . . . . . . . . . . . . . . S19

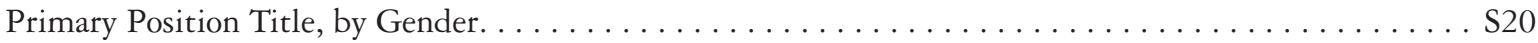

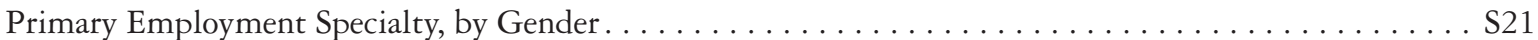

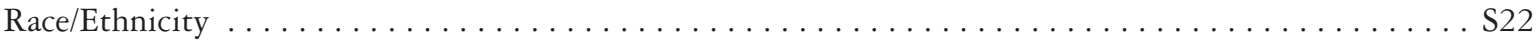

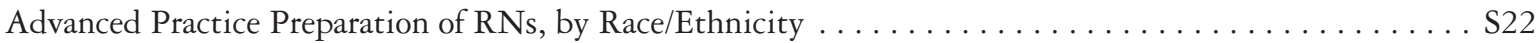

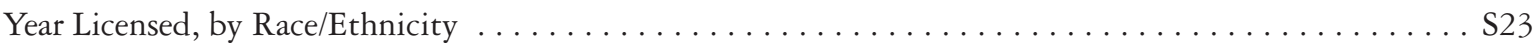

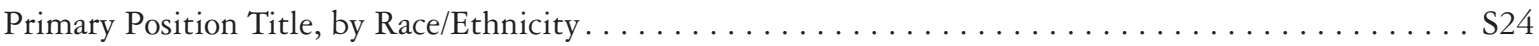

Type of Nursing Degree/Credential That Qualified Respondents for First U.S. Nursing License . . . . . . S24

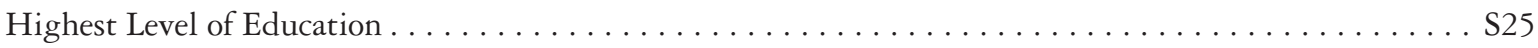

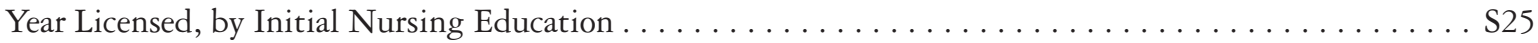

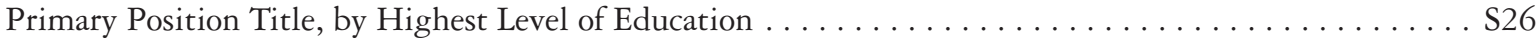

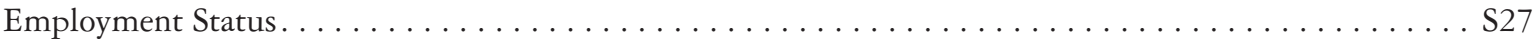

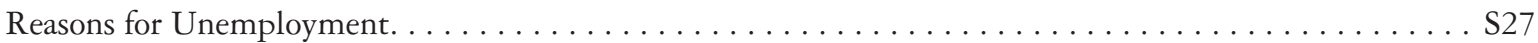

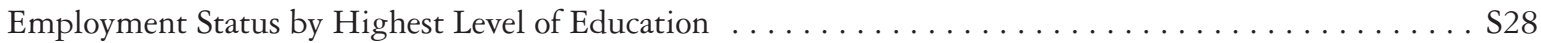

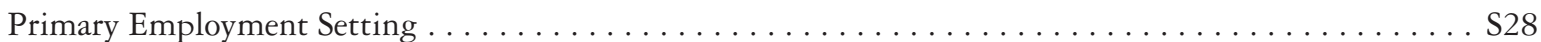

Primary Position Title . . . . . . . . . . . . . . . . . . . . . . . . . . . . . . . . . S29

Primary Employment Specialty . . . . . . . . . . . . . . . . . . . . . . . . . . . . . . . S29

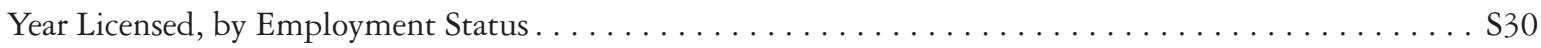

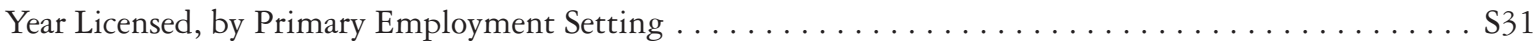

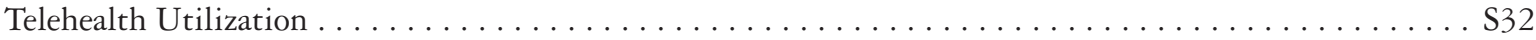

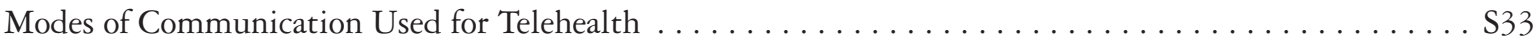

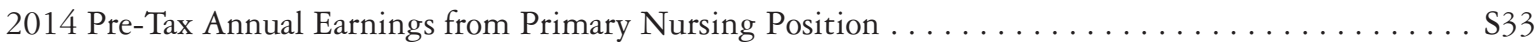

Annual Earnings in Primary Nursing Position, by State(s) Where Currently Practicing . . . . . . . . . S33

Annual Earnings in Primary Nursing Position, by Age . . . . . . . . . . . . . . . . S34

Annual Earnings in Primary Nursing Position, by Year Licensed $\ldots \ldots \ldots \ldots \ldots \ldots \ldots \ldots \ldots \ldots \ldots \ldots \ldots \ldots$

Annual Earnings in Primary Nursing Position, by Gender $\ldots \ldots \ldots \ldots \ldots \ldots \ldots \ldots \ldots \ldots \ldots \ldots \ldots \ldots \ldots$

Annual Earnings in Primary Nursing Position, by Race/Ethnicity . . . . . . . . . . . . . S35

Average Salary in Primary Nursing Position, by Highest Level of Education . . . . . . . . . . . . S36

Annual Earnings in Primary Nursing Position, by APRN Certification/Licensure . . . . . . . . . . S36

Annual Earnings in Primary Nursing Position, by Primary Employment Setting . . . . . . . . . . . S36

Annual Earnings in Primary Nursing Position, by Primary Position Title . . . . . . . . . . . . . S37

Annual Earnings in Primary Nursing Position, by Primary Employment Specialty . . . . . . . . . S37

Age Distribution of RNs with "Nurse Faculty" as Primary or Secondary Position Title . . . . . . . . S38

RNs Employed as Faculty in a Secondary Position Title, by Primary Position Title . . . . . . . . . . S39

Hours Worked per Week, by RNs With "Nurse Faculty" as Primary or Secondary Position Title . . . . . . S39

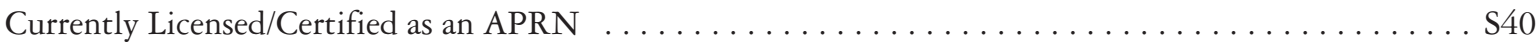

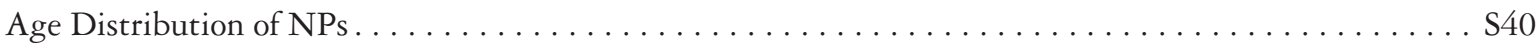

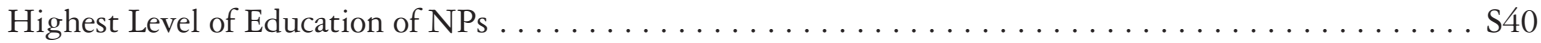

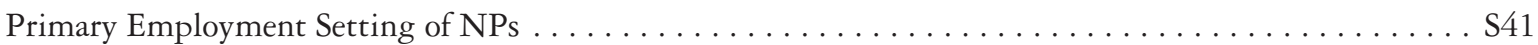




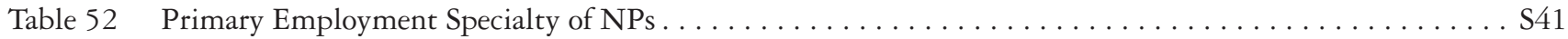

Table 53 NPs Whose Primary Employment Specialty is Primary Care, by Primary Employment Setting . . . . . . . S42

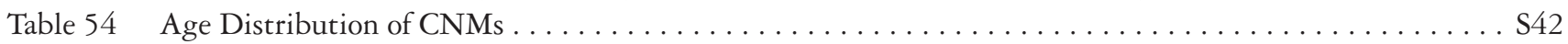

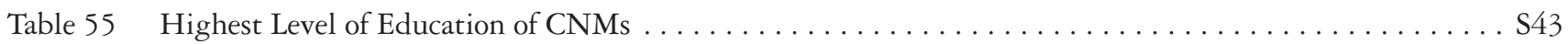

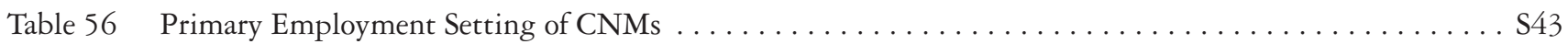

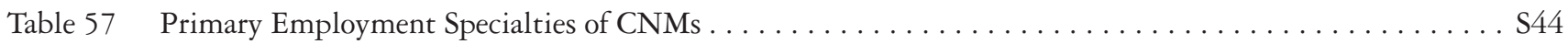

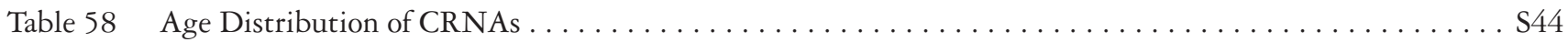

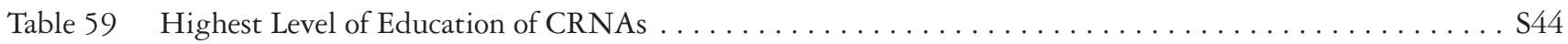

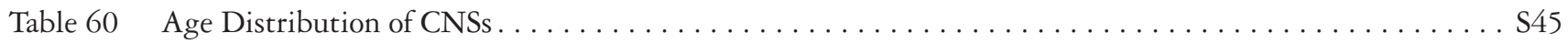

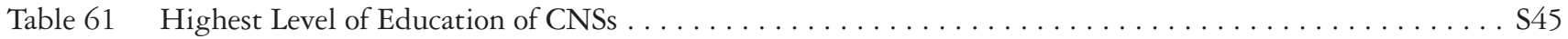

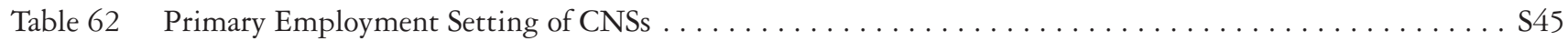

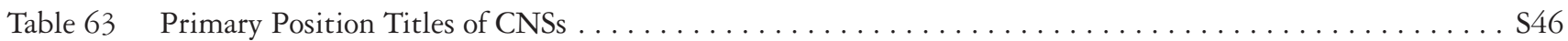

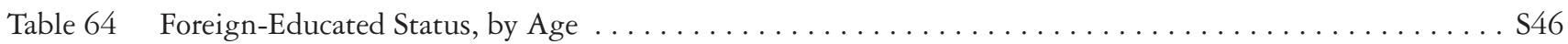

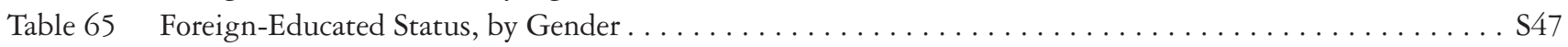

Table 66 Year Licensed and Foreign-Educated Status, by Initial Nursing Education $\ldots \ldots \ldots \ldots \ldots \ldots \ldots \ldots$ S47

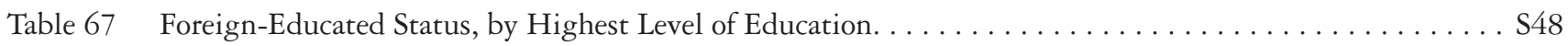

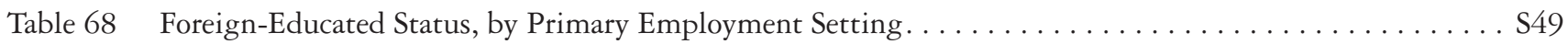

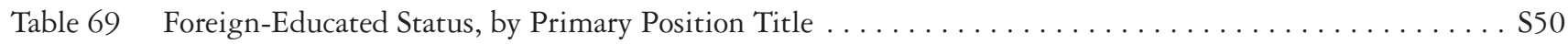

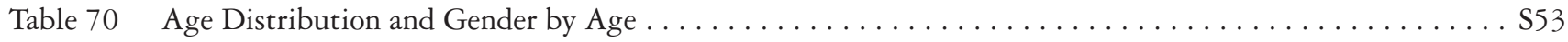

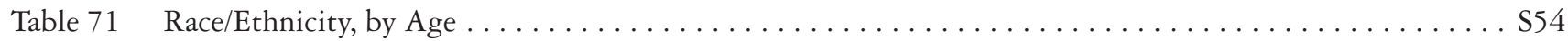

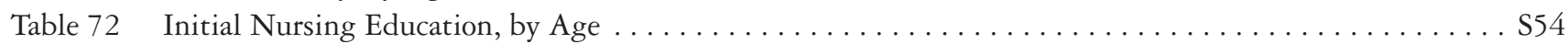

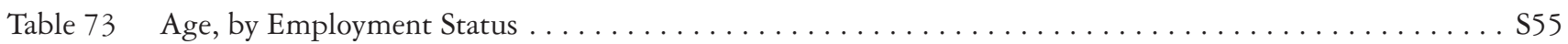

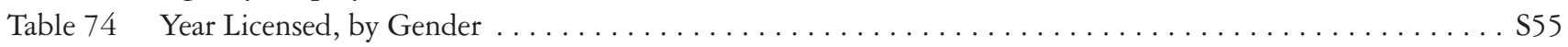

Table 75 Highest Level of Education of LPN/VNs Employed in Nursing, by Gender . . . . . . . . . . . S56

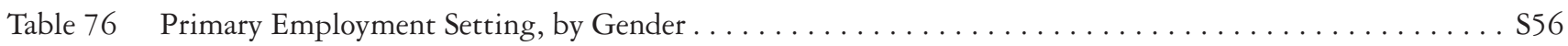

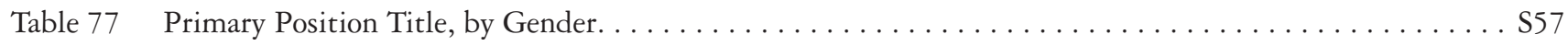

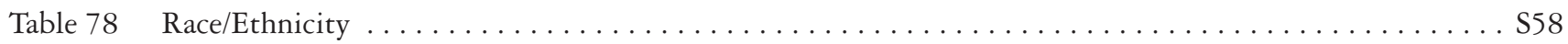

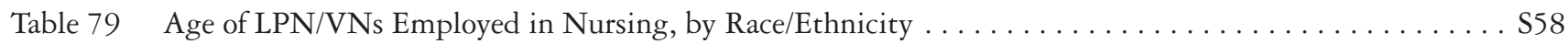

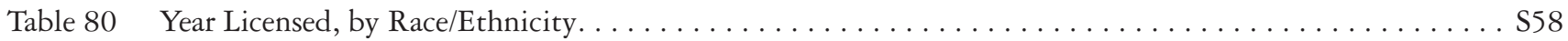

Table 81 Highest Level of Education of LPN/VNs Employed in Nursing, by Race/Ethnicity . . . . . . . . . . . . S59

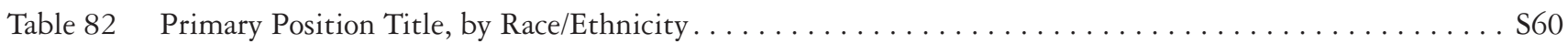

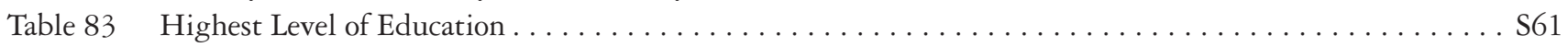

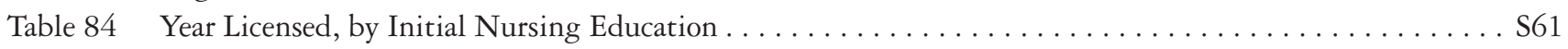

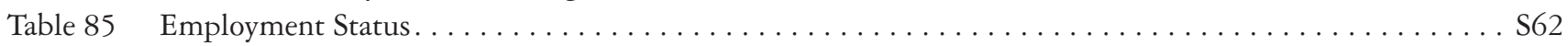

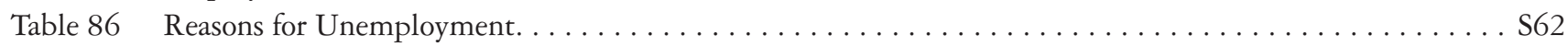

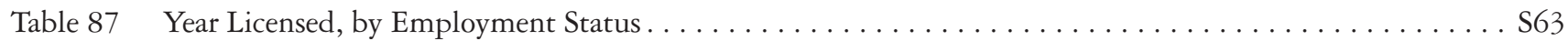

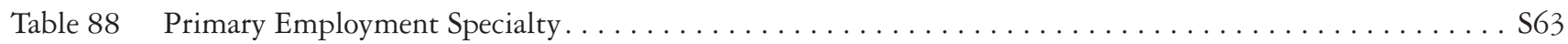

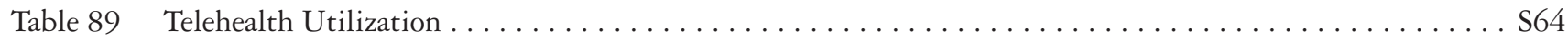

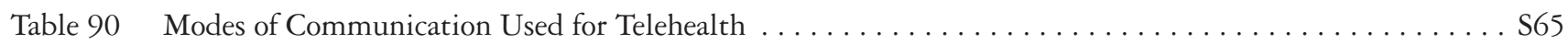

Table 912014 Pre-Tax Annual Earnings from Primary Nursing Position . . . . . . . . . . . . . . . . . . S65

Table 92 Annual Earnings in Primary Nursing Position, by Age . . . . . . . . . . . . . . . . . . . S66

Table 93 Annual Earnings in Primary Nursing Position, by Year Licensed . . . . . . . . . . . . . . . S66

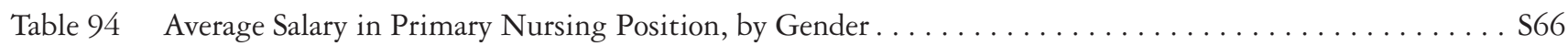

Table 95 Average Salary in Primary Nursing Position, by Race/Ethnicity . . . . . . . . . . . . . . . . S67

Table 96 Average Salary in Primary Nursing Position, by Highest Level of Education . . . . . . . . . . . . S67

Table 97 Average Salary in Primary Nursing Position, by State(s) Where Currently Practicing . . . . . . . . . . . . S67

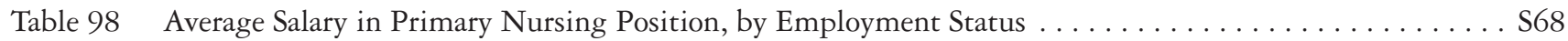

Table 99 Average Salary in Primary Nursing Position, by Primary Employment Setting. . . . . . . . . . . . . . . . . . S69

Table 100 Average Salary in Primary Nursing Position, by Primary Position Title . . . . . . . . . . . . . . . . S69

Table 101 Average Salary in Primary Nursing Position, by Primary Employment Specialty . . . . . . . . . . . . S70

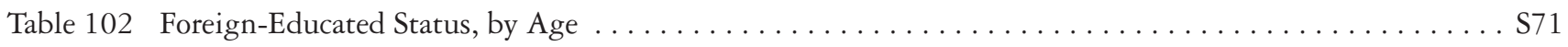

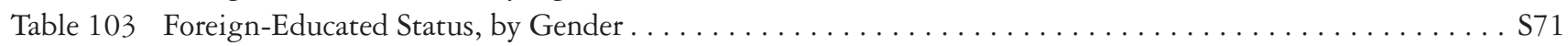


Table 104 Foreign-Educated Status, by Highest Level of Education. . . . . . . . . . . . . . . . . . . . S71

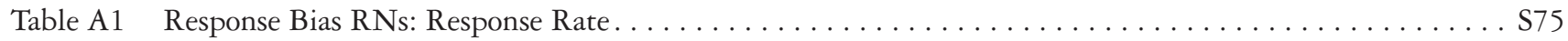

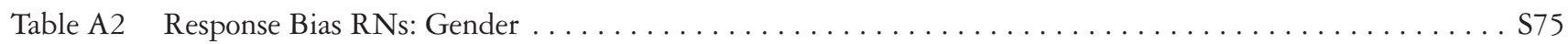

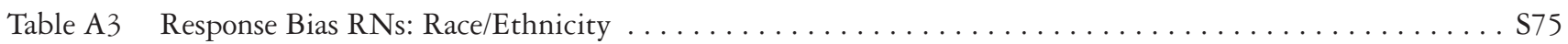

Table A4 Response Bias RNs: Descriptive Statistics for Continuous Measures . . . . . . . . . . . . . . . . . S76

Table A5 Response Bias RNs: Case Has Complete Data for Nonresponse Analysis. . . . . . . . . . . . . . . . . . S76

Table A6 Response Bias RNs: Survey Completion Rate by Gender . . . . . . . . . . . . . . . . . . S76

Table A7 Response Bias RNs: Survey Completion Rate by Race/Ethnicity. . . . . . . . . . . . . . . . . . . . S76

Table A8 Response Bias RNs: Differences in Mean Age, Years Since Graduation, and Years Since Licensure,

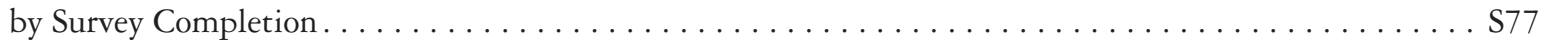

Table A9 Response Bias RNs: Survey Completion Rate by Status of Data . . . . . . . . . . . . . . . . . . . S77

Table A10 Response Bias RNs: AgeGender Weights . . . . . . . . . . . . . . . . . . . . . S78

Table A11 Response Bias RNs: Descriptive Statistics of Weights, Complete Responses Only . . . . . . . . . . . . . S79

Table B1 Response Bias LPN/VN: Response Rate . . . . . . . . . . . . . . . . . . . . . . . . S80

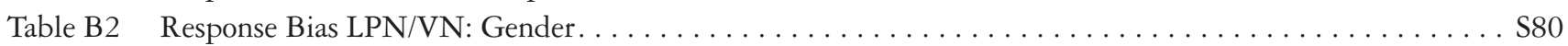

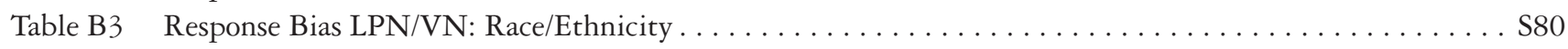

Table B4 Response Bias LPN/VN: Descriptive Statistics for Continuous Measures . . . . . . . . . . . . . . . S81

Table B5 Response Bias LPN/VN: Case Has Complete Data for Nonresponse Analysis . . . . . . . . . . . . . . . S81

Table B6 Response Bias LPN/VN: Survey Completion Rate by Gender . . . . . . . . . . . . . . . . . . . . . . S81

Table B7 Response Bias LPN/VN: Survey Completion Rate by Race/Ethnicity . . . . . . . . . . . . . . . . . S81

Table B8 Response Bias LPN/VN: Differences in Mean Age, Years Since Graduation, and Years Since Licensure, by Survey Completion. . . . . . . . . . . . . . . . . . . . . . . . . . . . S82

Table B9 Response Bias LPN/VN: Survey Completion Rate by Status of Data . . . . . . . . . . . . . . . . . . S82

Table B10 Response Bias LPN/VN: AgeGender Weights . . . . . . . . . . . . . . . . . . . . S83

Table B11 Response Bias LPN/VN: Descriptive Statistics of Weights, Complete Responses Only . . . . . . . . . . . . S83 
$\because=\mathrm{NCSSBN}$ Notionel Gouncel of Stetet Baerdi of Nurring
THE NATIONAL FOR

OF STATE NURSING WORKFORCE CENTERS

\section{(S) \\ NAT \\ A

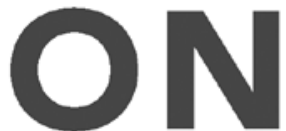 \\ $\mathrm{AL}$ \\ NURSING WORKFORCE SURVEY}

\section{Marking Instructions}

Use a No. 2 pencil or blue or black ink pen only.

Make no stray marks on this form Do not use pens with ink that soaks through the paper. Do not tear or mutilate this form. Make solid marks that fill the oval completely.

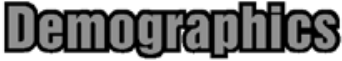

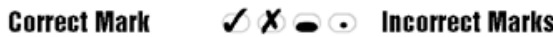

1. What is your gender?

$\bigcirc$ Male $\bigcirc$ Female

2. What is your race/ethnicity? (Mark all that apply)

American Indian or Alaska Native

3. In what year

were you born?

$\bigcirc$ Asian

Black/African American

Native Hawaiian or Other Pacific Islander

White/Caucasian

$\checkmark$ Hispanic/Latino

$\bigcirc$ Other

4. What type of nursing degree/credential qualified you for your first US nursing license?
Vocational/practical certificate-nursing
Master's degree-nursing
$\bigcirc$ Diploma-nursing
$\bigcirc$ Doctoral degree-nursing (DNP)
Associate degree-nursing
Doctoral degree-nursing ( $\mathrm{PhD}$ )
Baccalaureate degree-nursing
$\bigcirc$ Doctoral degree-nursing other

5. What is your highest level of education?
$\checkmark$ Vocational/practical certificate-nursing
$\bigcirc$ Diploma-nursing
Associate degree-nursing
Associate degree-other field
Baccalaureate degree-nursing
$\checkmark$ Baccalaureate degree-other field

Master's degree-nursing
Master's degree-other field
Doctoral degree-nursing practice (DNP)
Doctoral degree-nursing (PhD)
Doctoral degree-nursing other
Doctoral degree-other field




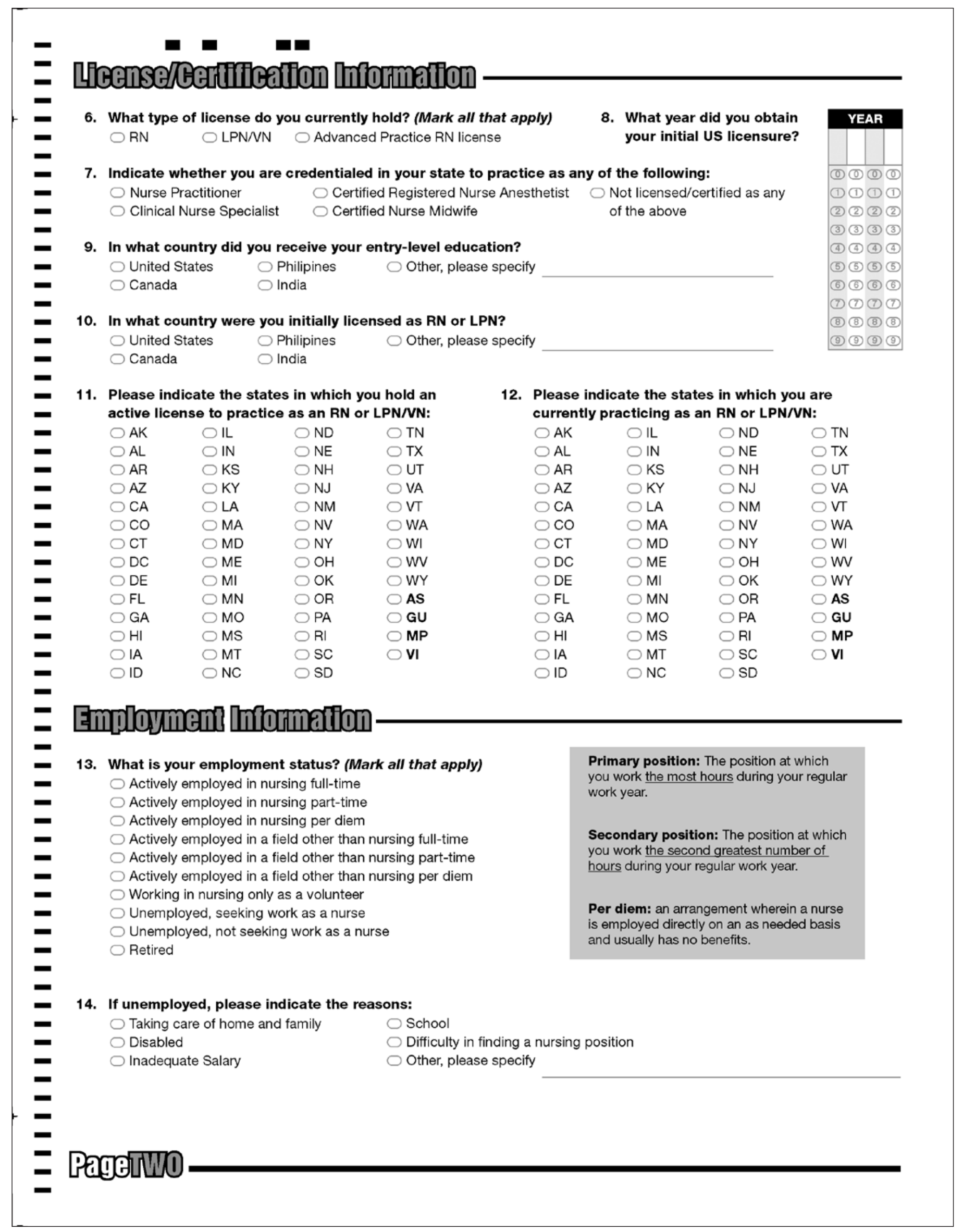

S88 Journal of Nursing Regulation 
Please answer questions 15 - 31 only if you are actively employed in nursing, if you are not actively employed in nursing you have completed the survey.

15. In how many positions are you currently employed as a nurse? $\bigcirc 1 \quad \bigcirc 2 \quad \bigcirc 3$ or more

16. How many hours do you work during a typical week in all your nursing positions?

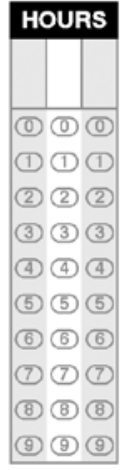

18. Please indicate the state and zip code of your primary employer:

\begin{tabular}{|c|c|c|c|c|}
\hline$\bigcirc \mathrm{AK}$ & $\bigcirc \mathrm{IL}$ & $\bigcirc \mathrm{ND}$ & $\bigcirc \mathrm{TN}$ & ZIP CODE \\
\hline$\bigcirc \mathrm{AL}$ & $\bigcirc \mathbb{I N}$ & $\bigcirc \mathrm{NE}$ & $\bigcirc \mathrm{TX}$ & \\
\hline AR & $\bigcirc \mathrm{KS}$ & $\bigcirc \mathrm{NH}$ & $\bigcirc$ UT & \\
\hline$A Z$ & $\bigcirc \mathrm{KY}$ & $\bigcirc \mathrm{NJ}$ & $\bigcirc \mathrm{VA}$ & (1) (1) (1) (1) (1) \\
\hline $\mathrm{CA}$ & $\bigcirc \mathrm{LA}$ & $\bigcirc \mathrm{NM}$ & $\bigcirc \mathrm{VT}$ & (1) (1) \\
\hline $\mathrm{CO}$ & $\bigcirc \mathrm{MA}$ & $\bigcirc \mathrm{NV}$ & $\bigcirc W A$ & (2) \\
\hline $\mathrm{CT}$ & $\bigcirc \mathrm{MD}$ & $\bigcirc \mathrm{NY}$ & $\bigcirc \mathrm{WI}$ & (3) \\
\hline$D C$ & $\bigcirc \mathrm{ME}$ & $\bigcirc \mathrm{OH}$ & $\bigcirc \mathrm{WV}$ & (4) (4) (4) (4) (4) \\
\hline$D E$ & $\bigcirc \mathrm{MI}$ & $\bigcirc \mathrm{OK}$ & $\bigcirc W Y$ & (5) (5) (5) (5) (5) \\
\hline $\mathrm{FL}$ & $\mathrm{MN}$ & $\bigcirc \mathrm{OR}$ & $\bigcirc \mathbf{A S}$ & (6) (6) (6) (6) (6) \\
\hline $\mathrm{GA}$ & $\bigcirc \mathrm{MO}$ & $\bigcirc \mathrm{PA}$ & $\bigcirc \mathbf{G U}$ & (7) (7) (7) (7) (7) \\
\hline $\mathrm{HI}$ & MS & $\bigcirc \mathrm{Rl}$ & $\bigcirc \mathrm{MP}$ & (8) (8) (8) (8) \\
\hline IA & MT & $\bigcirc \mathrm{SC}$ & $\bigcirc \mathbf{V I}$ & (9) (9) (9) (9) \\
\hline
\end{tabular}

17. Please indicate if you work in any of these areas or specialty settings:
a. Camp Nurse
b. Correctional
c. Developmental Disability
$\checkmark$ Yes $\bigcirc$ No
$\checkmark$ Yes $\bigcirc$ No
d. Faith-based (ex: Parish Nurse)
e. Forensic
f. Holistic
g. Military/uniform Services
h. Telehealth
i. Travel Nurse
$\checkmark$ Yes $\bigcirc$ No
$\bigcirc$ Yes $\bigcirc$ No
$\checkmark$ Yes $\bigcirc$ No
$\checkmark$ Yes $\bigcirc$ No
$\checkmark$ Yes $\bigcirc$ No
Yes $\bigcirc$ No

19. Please estimate your 2014 pre-tax annual earnings from your primary nursing position. Include overtime and bonuses, but exclude sign-on bonuses.

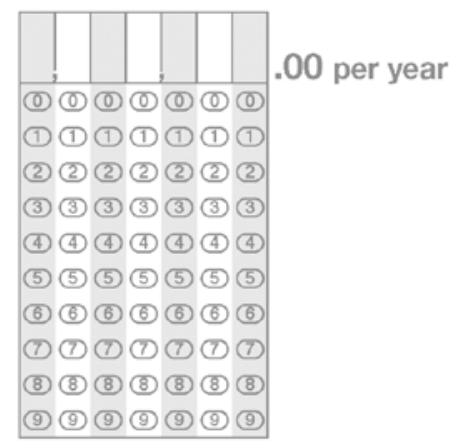

$\bigcirc I D \bigcirc N C \bigcirc S D$

20. Please identify the type of setting that most closely corresponds to your primary nursing practice position:
$\bigcirc$ Academic Setting
Home Health
Ambulatory Care Setting
Hospital
Insurance Claims/Benefits
Nursing Home/Extended Care
$\checkmark$ Policy/Planning/ic Health
Assisted Living Facility
Community Health
$\bigcirc$ Occupational Health
School Health Service
$\bigcirc$ Other
$\checkmark$ Correctional Facility

21. Please identify the position title that most closely corresponds to your primary nursing practice position:

$\begin{array}{llll}\bigcirc \text { Advanced Practice Nurse } & \bigcirc \text { Consultant } & \bigcirc \text { Nurse Manager } & \bigcirc \text { Other-Not Health Related } \\ \bigcirc \text { Case Manager } & \bigcirc \text { Nurse Executive } & \bigcirc \text { Nurse Researcher } & \bigcirc \text { Staff Nurse } \\ \bigcirc \text { Clinical Nurse Leader } & \bigcirc \text { Nurse Faculty } & \bigcirc \text { Other-Health Related } & \end{array}$

22. Please identify the employment specialty that most closely corresponds to your primary nursing practice position:

$\bigcirc$ Acute Care/Critical Care
Adult Health/Family Health
Anesthesia
Community
Emergency/Trauma
Genetics
Geriatric/Gerontology
Home Health
Informatics
Maternal-Child Health

Medical Surgical

Neonatal

Nephrology

Neurology/Neurosurgical

$\bigcirc$ Occupational Health

$\bigcirc$ Oncology

Orthopedic

Palliative Care/Hospice

$\bigcirc$ Pediatrics

$\bigcirc$ Perioperative
Primary Care

$\checkmark$ Psychiatric/Mental Health/Substance Abuse

Public Health

$\bigcirc$ Radiology

Rehabilitation

$\checkmark$ School Health

$\bigcirc$ Urologic

$\checkmark$ Women's Health

Other 


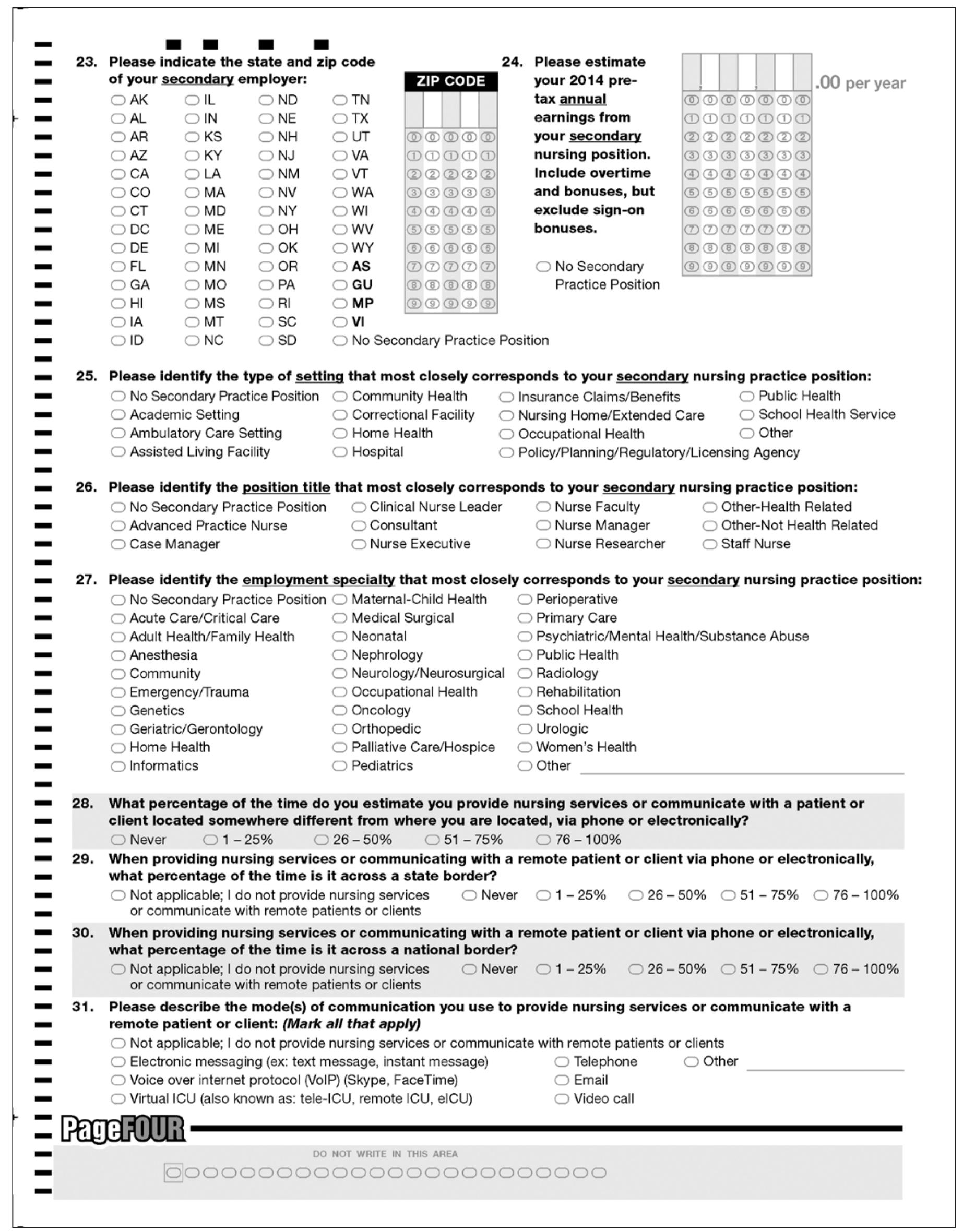

S90 Journal of Nursing Regulation 